DANUSA DE SOUZA RAMOS

\title{
Elastografia hepatoesplênica para predizer varizes esofágicas em pacientes com hipertensão portal não cirrótica: estudo de acurácia diagnóstica
}

Dissertação apresentada à Faculdade de Medicina da Universidade de São Paulo para obtenção do título de Mestre em Ciências

Programa de Ciências em Gastroenterologia Orientador: Prof. Dr. Alberto Queiroz Farias

São Paulo 
DANUSA DE SOUZA RAMOS

Elastografia hepatoesplênica para predizer varizes esofágicas em pacientes com hipertensão portal não cirrótica: estudo de acurácia diagnóstica

Dissertação apresentada à Faculdade de
Medicina da Universidade de São Paulo para
obtenção do título de Mestre em Ciências

Programa de Ciências em Gastroenterologia

Orientador: Prof. Dr. Alberto Queiroz Farias

São Paulo 
Dados Internacionais de Catalogação na Publicação (CIP)

Preparada pela Biblioteca da

Faculdade de Medicina da Universidade de São Paulo

Creprodução autorizada pelo autor

Ramos, Danusa de Souza

Elastografia hepatoesplênica para predizer

varizes esofágicas em pacientes com hipertensão

portal não cirrótica : estudo de acurácia diagnóstica

/ Danusa de Souza Ramos. -- São Paulo, 2018.

Dissertação(mestrado) --Faculdade de Medicina da

Universidade de São Paulo.

Programa de Ciências em Gastroenterologia.

Orientador: Alberto Queiroz Farias.

Descritores: 1.Hipertensão portal 2. Técnicas de imagem por elasticidade 3.Varizes esofágicas e gástricas 4.Endoscopia 5.Diagnóstico 6.Baço

$\mathrm{USP} / \mathrm{FM} / \mathrm{DBD}-223 / 18$

Responsável: Kátia Maria Bruno Ferreira - CRB-8/6008 


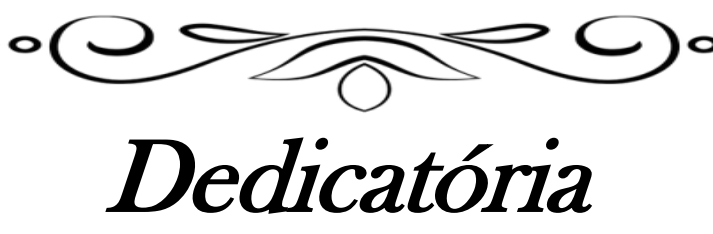

020 
Aos meus pais, Maria Neri de Souza Ramos e José Domingues de Ramos Filho, que são meu porto seguro e que me educaram em sua forma mais natural e sensível, são meus exemplos, meus valores, minha razão de ser

Ao meu irmão Rafael de Souza Ramos, que com tantos desafios compartilhados, dividimos um aprendizado eterno

E ao Manuel Florian Winterfeld pelo infindável apoio na construção desse trabalho. Por todo carinho, amor e paciência concedidos como meu companheiro, que mesmo com a distância foi capaz de me dar o acalento tão necessário 


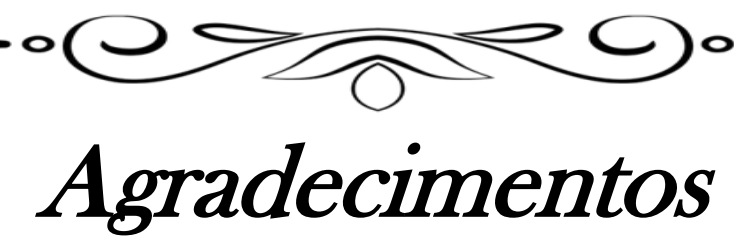

O 20 


\section{AGRADECIMENTOS}

O trabalho do pesquisador pode ser equiparado com o ofício do artesão; a arte do uso das mãos; mediante a interação entre a idéia, habilidade técnica e o componente intelectual, requeridos para criar, produzir e divulgar são componentes necessários para a construção do trabalho. Muitas pessoas me ladearam e incentivaram durante esse percurso. Dedico esses agradecimentos aqueles que acompanharam diretamente essa trajetória.

Ao meu orientador Prof. Dr. Alberto Queiroz Farias, a aceitação de orientação; ao desmedido incentivo na construção desse trabalho, toda atenção, entusiasmo e conhecimento na fase de amadurecimento da pesquisa e o cuidadoso auxilio e disponibilidade na finalização dessa dissertação. Certamente é o responsável pelo meu amadurecimento intelectual e uma grande influência acadêmica.

Á Prof. Dra. Guadalupe Garcia-Tsao, do departamento de doenças digestivas da Universidade de Yale, pela sua valiosa colaboração, que me permitiu aquilatar uma série de ideias durante o processo de desenvolvimento desse estudo.

Ao Prof. Dr. Flair José Carrilho, Prof. Dr. Mario Guimarães Pessoa e Prof. Dra. Irene Kazue Miura, que fizeram parte da minha banca de qualificação, agradeço os comentários e indicações valiosas com compartilhamento de amplo conhecimento.

À Prof. Dra. Denise Cerqueira Paranaguá Vezozzo, com a contribuição técnica competente, associada ao zelo e leniência no trato dessa pesquisa. $\grave{A}$ Enf. Juliana de Medeiros Batista, pela infindável dedicação a esse trabalho, o clima de mútua compreensão, principalmente nas adversidades, foi de extrema importância e a Conceição que estava sempre disponível com uma leveza no trato com o outro imensurável e tão necessária. Agradeço toda dedicação, generosidade e atenção depositada durante todo processo desse estudo. 
À Enf. Patricia Momoyo Yoshimura Zitelli, por ter trilhado comigo esse caminho da pesquisa clínica, pelas conversas e cumplicidade, por todas sugestões e idéias, apontamentos tão cruciais. Saber que você estava na sala ao lado era um tanto quanto acalentador.

Agradeço aos membros de um grupo de que tive o prazer de trabalhar: Psicóloga Mary Ellen, Dr. Odilson, Enf. Beatriz, Bióloga Caroline, Dr. Daniel, Dr. Evandro, Dr. Roque, Dr. Rafael, Dra. Renée, Dra. Betania, Dr. Miyake, Dra. Marina, e tantos outros, cujo o anseio pelo conhecimento em seu mais amplo sentido, me influenciaram não apenas academicamente.

À diretora de Divisão de Enfermagem, Enf. Carmen Mohamad Saleh Rida, pelo apoio para a realização deste trabalho.

Agradeço toda equipe multiprofissional da Enfermaria de Gastroenterologia Clinica, principalmente a equipe de enfermagem, aqui representada pela Enf. Sylvia Fernandes Assumpção e Enf. Liliam de Moura, que foram os principais apoiadores e incentivadores para a realização desse trabalho.

Aos estatísticos Márcio Diniz, Leandro Ferreira e o epidemiologista Alex Cassenote, que analisaram os dados de forma criteriosa, integrando a interface analítica com a clínica.

Agradeço a equipe administrativa da secretaria do Departamento de Gastroenterologia e Hepatologia clínica, todos sempre dispostos a oferecer estutura adequada ou soluções apropriadas para execução desse trabalho. À Comissão de Pós-graduação pela atenção e orientação.

Ao Departamento de Gastroenterologia e Hepatologia clínica do Hospital das Clinicas da Faculdade de Medicina da Universidade de São Paulo, a oportunidade de realizar esse trabalho. Aos Profs. Flair José Carrilho e Luiz Augusto Carneiro D'Albuquerque por ajudarem a viabilizar e incentivar a pesquisa multidisciplinar. 


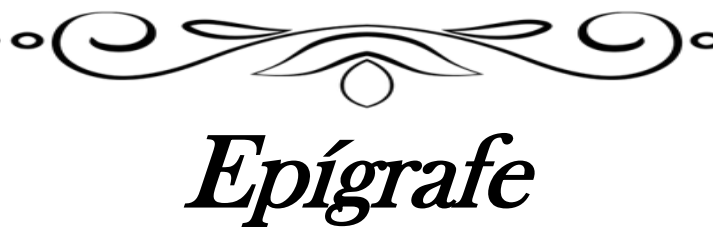

0

O Co 
"Vivendo, se aprende; mas o que se aprende, mais, é só a fazer outras maiores perguntas"

João Guimarães Rosa 
-

Normalização adotada

020 
Esta dissertação está de acordo com as seguintes normas, em vigor no momento desta publicação:

Referências: adaptado de International Committee of Medical Journals Editors (Vancouver).

Universidade de São Paulo. Faculdade de Medicina. Divisão de Biblioteca e Documentação. Guia de apresentação de dissertações, teses e monografias. Elaborado por Anneliese Carneiro da Cunha, Maria Julia de A. L. Freddi, Maria F. Crestana, et al. Universidade de São Paulo. Faculdade de Medicina. Divisão de Biblioteca e Documentação. 3a ed. São Paulo: Divisão de Biblioteca e Documentação; 2011.

Abreviaturas dos títulos dos periódicos de acordo com List of Journals Indexed in Index Medicus. 
$\circ$

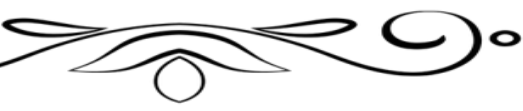

Sumário

0 


\section{SUMÁRIO}

LISTA DE FIGURAS

LISTA DE TABELAS

LISTA DE ABREVIATURAS, SÍMBOLOS E SIGLAS

RESUMO

\section{ABSTRACT}

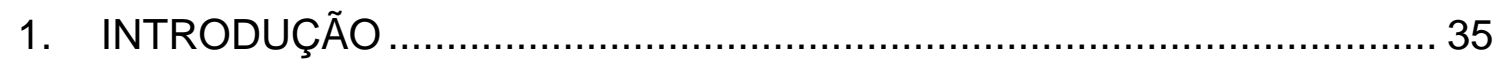

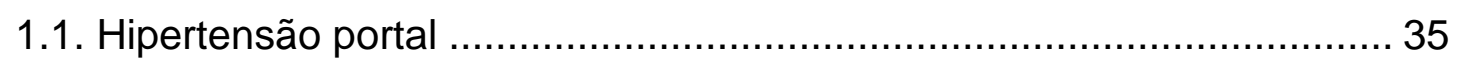

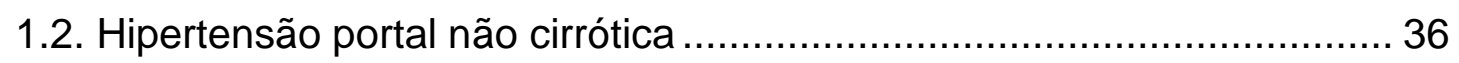

1.3. Risco de sangramento por ruptura de varizes ..................................... 39

1.4. Avaliação da hipertensão portal e rastreamento de varizes ................... 39

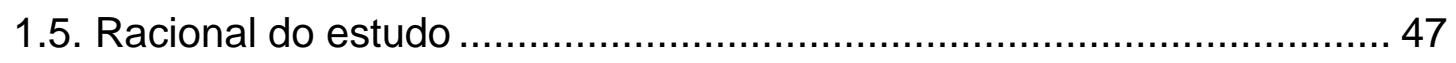

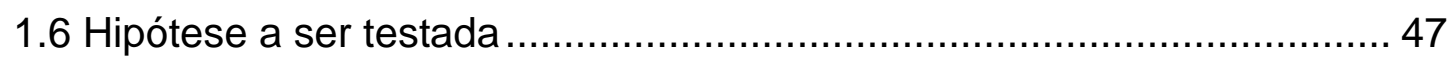

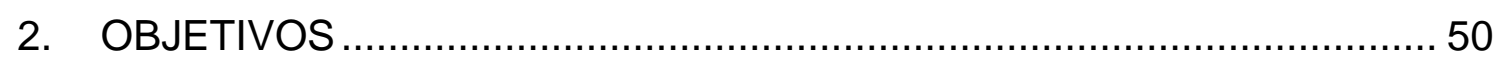

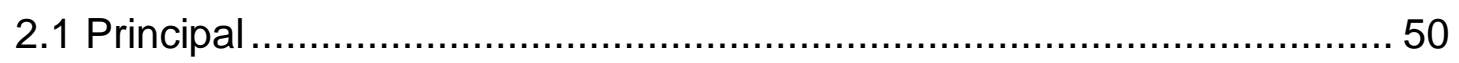

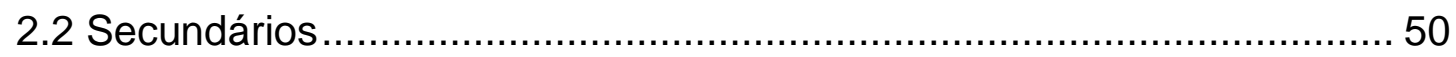

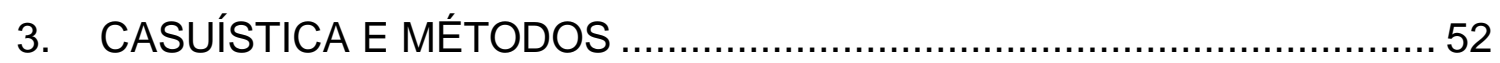

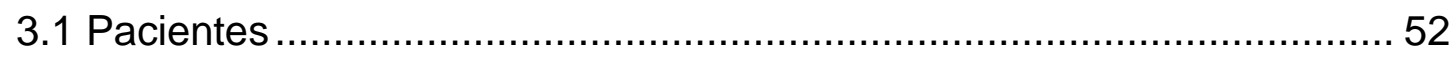

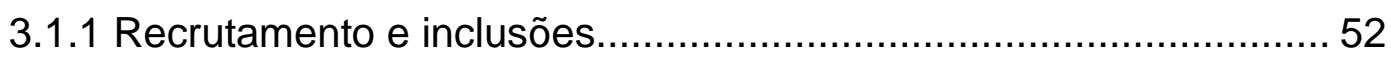

3.1.2 Critérios diagnósticos das causas de hipertensão portal não cirrótica 53

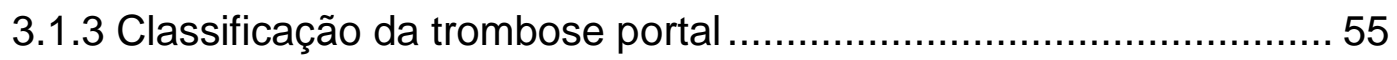

3.1.4 Critério diagnóstico de hipertensão portal ..................................... 56

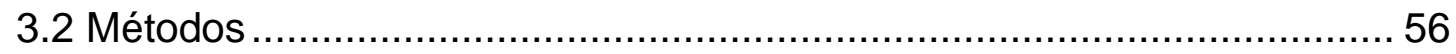

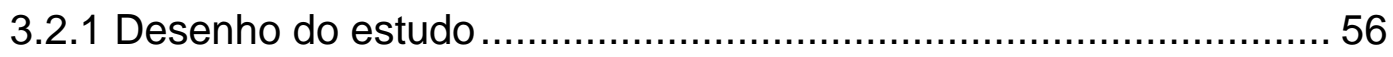

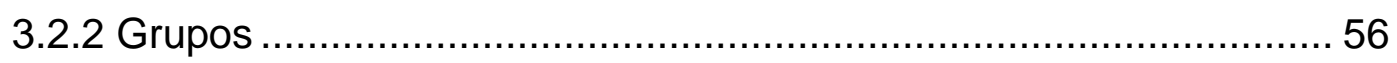

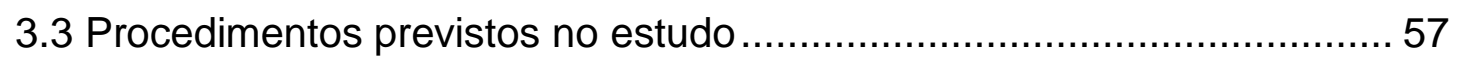

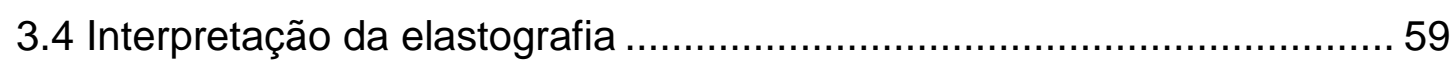


3.5 Interpretação dos índices APRI, FIB-4 e razão plaqueta/baço 61

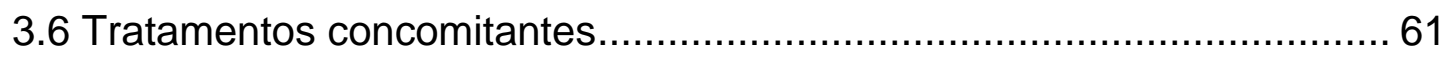

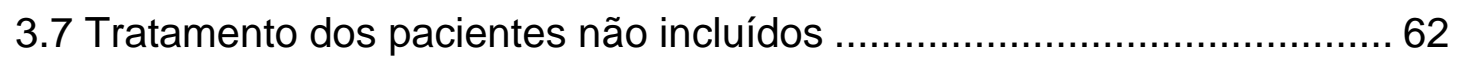

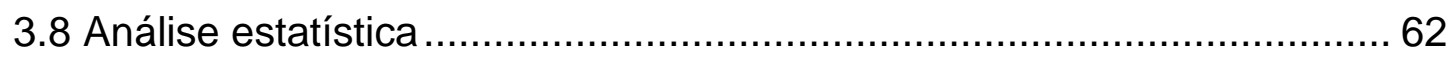

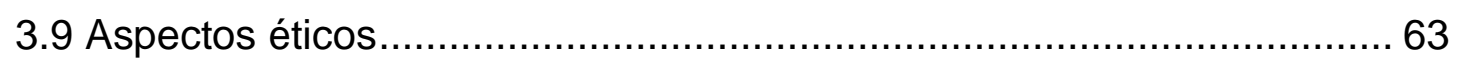

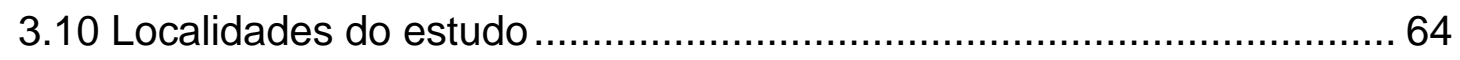

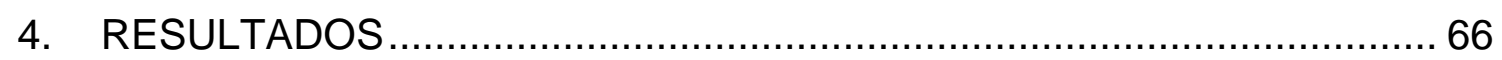

4.1 Características gerais da população do estudo .................................... 67

4.2 Características da população quanto aos parâmetros laboratoriais ....... 69

4.3 Resultados globais da elastografia transitória por FibroScan ................. 71

4.4 Resultados globais da elastografia por ARFI ....................................... 71

4.5 Resultados globais dos índices APRI, FIB-4 e razão plaqueta/baço ...... 71

4.6 Resultados da elastografia transitória por FibroScan e ARFI e dos índices APRI, FIB-4 e razão plaqueta/baço segundo a etiologia subjacente da

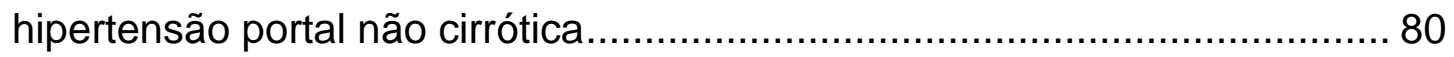

4.7 Comparação entre a população do estudo, segundo a presença de

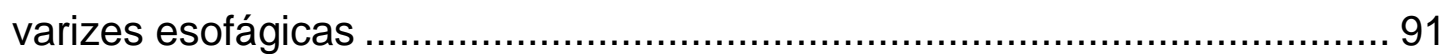

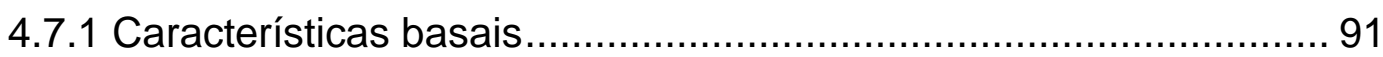

4.7.2 Características dos parâmetros de imagem dos pacientes em relação a presença ou não de varizes esofágicas .................................. 92

4.7.3 Características dos parâmetros laboratoriais dos pacientes em relação à presença ou não de varizes esofágicas .................................. 95

4.7.4 Características dos métodos não invasivos dos pacientes em relação à presença ou não de varizes esofágicas .................................. 97

4.8 Comparação da população do estudo, segundo a presença de varizes

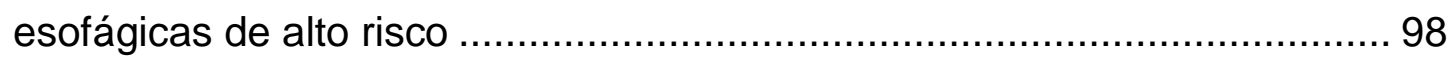

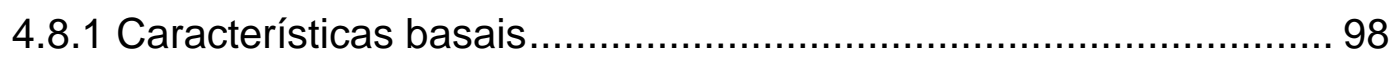

4.8.2 Características dos parâmetros de imagem dos pacientes em relação a presença de varizes esofágicas de alto risco ........................... 99 4.8.3 Características dos parâmetros laboratoriais dos pacientes em relação à presença de varizes esofágicas de alto risco ........................... 99 4.8.4 Valores dos métodos não invasivos dos pacientes em relação à presença de varizes de alto risco. 
4.9 Acurácia diagnóstica da elastografia e dos índices APRI, FIB-4 e razão plaqueta/baço para predizer varizes esofágicas ....................................... 102

4.10 Acurácia diagnóstica da elastografia e dos índices APRI, FIB-4 e razão plaqueta/baço para predizer varizes esofágicas de alto risco de sangramento 103

4.11 Combinação de métodos não invasivos ……….............................. 104

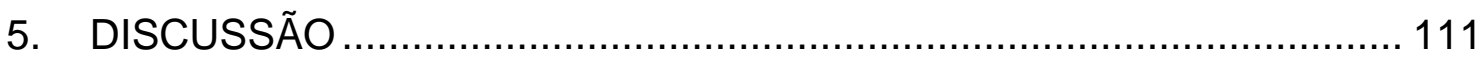

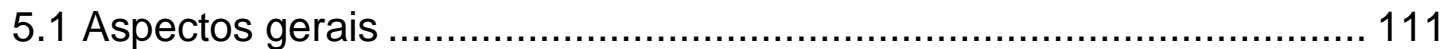

5.2 Métodos não invasivos para predizer presença de varizes esofágicas 115

5.3 Métodos não invasivos para predizer presença de varizes esofágicas de

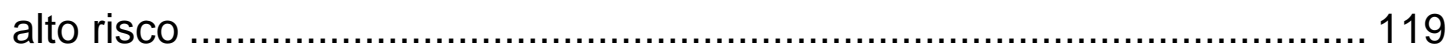

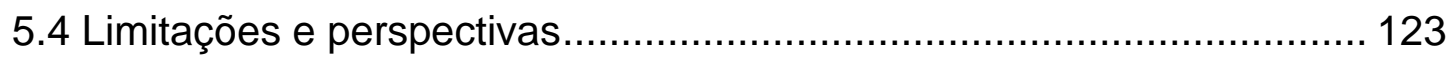

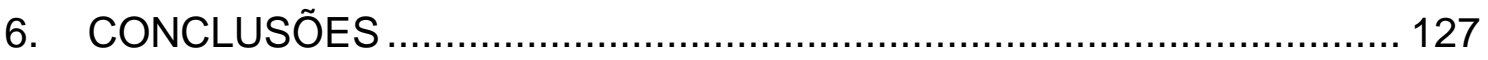

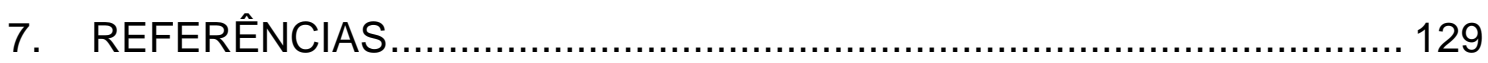


- $20 C_{0}^{\circ}$

Lista de figuras

020 


\section{LISTA DE FIGURAS}

Figura 1 - Distribuição dos valores da elastografia esplênica e hepática em pacientes com HVPG $<12$ ou $\geq 12 \mathrm{mmHg}$ ( $\mathrm{A}$ e $\mathrm{B}$, respectivamente), HVPG $<10$ ou $\geq 10 \mathrm{mmHg}$ ( $C$ e $D$, respectivamente) e com ou sem varizes esofágicas ( $E$ e

$\mathrm{F}$, respectivamente) 46

Figura 2 - Classificação da trombose portal segundo o Consenso de Baveno V 55

Figura 3 - Equipamentos para a realização da elastografia. 59

Figura 4 - Posicionamento do transdutor no espaço intercostal para a realização das medidas de elastografia.

Figura 5 - Concordância entre medidas de elastografia em unidades $\mathrm{kPa}$ e graus de fibrose hepática. 60

Figura 7 - Resultados globais da elastografia transitória hepática por FibroScan, nos pacientes com hipertensão portal não cirrótica 73

Figura 8 - Resultados globais do método ARFI hepático, nos pacientes com hipertensão portal não cirrótica 74

Figura 9 - Resultados globais da elastografia transitória esplênica por FibroScan, nos pacientes com hipertensão portal não cirrótica 75 Figura 10 - Resultados globais do método ARFI esplênico, nos pacientes com hipertensão portal não cirrótica 76 
Figura 11 - Resultados globais do índice APRI, nos pacientes com hipertensão portal não cirrótica

Figura 12 - Resultados globais do índice FIB-4, nos pacientes com hipertensão portal não cirrótica

Figura 13 - Resultados globais da razão plaqueta/baço, nos pacientes com hipertensão portal não cirrótica 79

Figura 14 - Resultados por etiologia da elastografia hepática transitória por FibroScan, nos pacientes com hipertensão portal não cirrótica 82

Figura 15 - Resultados por etiologia do método ARFI hepático, nos pacientes com hipertensão portal não cirrótica 83

Figura 16 - Resultados por etiologia da elastografia esplênica transitória por FibroScan, nos pacientes com hipertensão portal não cirrótica 84 Figura 17 - Resultados por etiologia do método ARFI esplênico, nos pacientes com hipertensão portal não cirrótica 85

Figura 18 - Resultados por etiologia do índice APRI, nos pacientes com hipertensão portal não cirrótica 86

Figura 19 - Resultados por etiologia do índice FIB-4, nos pacientes com hipertensão portal não cirrótica 87

Figura 20 - Resultados por etiologia da razão plaqueta/baço, nos pacientes com hipertensão portal não cirrótica 88

Figura 21 - Comparação entre os pacientes com a presença ou não de varizes esofágicas, de acordo com o diâmetro do baço. 94

Figura 22 - Comparação entre os pacientes com a presença ou não de varizes esofágicas, de acordo com a área do baço. 95 
Figura 23 - Resultados por etiologia da elastografia transitória esplênica por FibroScan $\mathrm{x}$ razão plaqueta/baço, nos pacientes com hipertensão portal não cirrótica. 105

Figura 24 - Resultados por etiologia do ARFI esplênico por FibroScan x razão plaqueta/baço, nos pacientes com hipertensão portal não cirrótica 105 Figura 25 - Comparação entre os pacientes com a presença de varizes de baixo risco e de alto risco, de acordo com os valores obtidos pela equação 1 


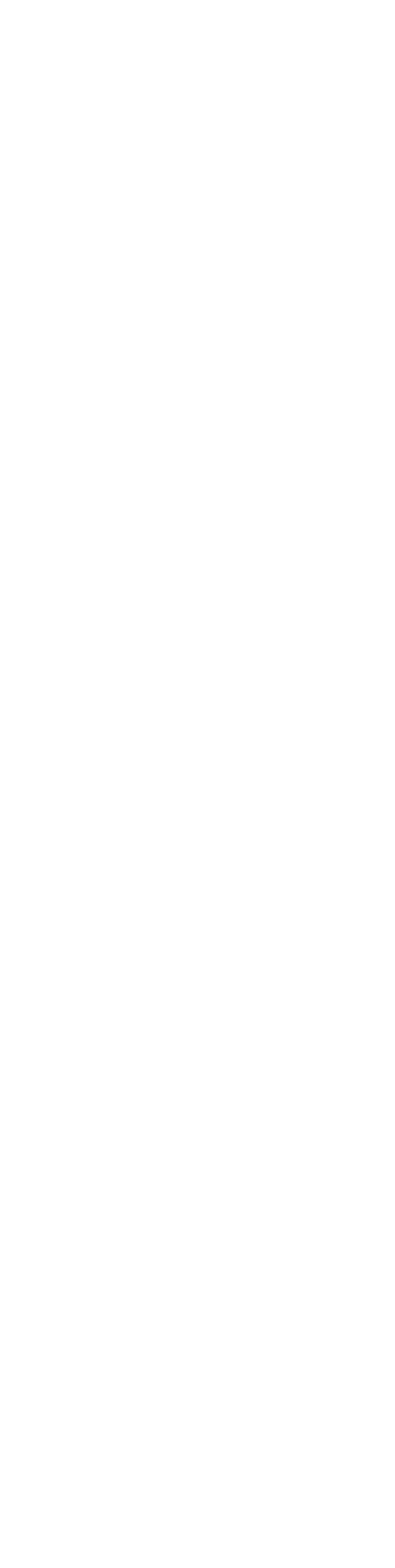

(बक्र

Lista de tabelas

020 


\section{LISTA DE TABELAS}

Tabela 1 - Critérios de Aoki et al. para hipertensão portal não cirrótica idiopática 38

Tabela 2 - Critérios de Schouten et al. para hipertensão portal não cirrótica idiopática 38

Tabela 3 - Criterios da APASL para hipertensão portal não cirrótica 38

Tabela 4 - Características gerais dos pacientes. 67

Tabela 5 - Características dos parâmetros de imagem e endoscópicos dos pacientes 68

Tabela 6 - Classificação do tipo da trombose de veia porta por etiologia ........ 69

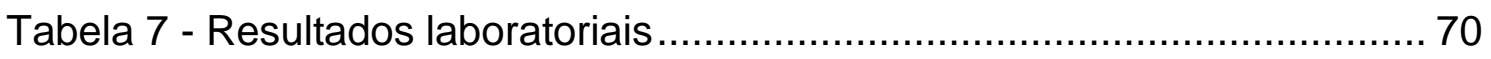

Tabela 8 - Resultados globais dos métodos não invasivos para detecção de

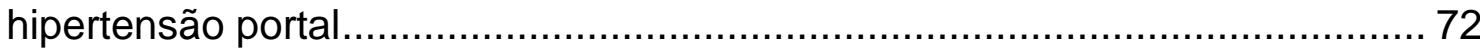

Tabela 9 - Métodos não invasivos para detecção de hipertensão portal por etiologia subjacente 81

Tabela 10 - Características basais dos pacientes com valor de elastografia hepática transitória por FibroScan $\geq 12 \mathrm{kPa}(\mathrm{n}=10)$ 89

Tabela 11 - Características dos pacientes com valor de elastografia hepática transitória por FibroScan $\geq 12 \mathrm{kPa}$, segundo os achados por imagem e relatório anatomopatológico $(n=10)$ 90 
Tabela 12 - Comparação entre os pacientes de acordo com a presença ou não de varizes esofágicas, segundo as características gerais $(=120)$ 91 Tabela 13 - Comparação entre os pacientes de acordo com a presença ou não de varizes esofágicas, segundo os parâmetros radiológicos $(n=120)$. 93 Tabela 14 - Comparação entre os pacientes do estudo de acordo com a presença ou não de varizes esofágicas, segundo os parâmetros laboratoriais $(n=120)$. 96

Resultados entre colchetes representam intervalo interquartil 96

Tabela 15 - Comparação entre os pacientes do estudo de acordo com a presença ou não de varizes esofágicas, segundo os métodos não invasivos para detecção de hipertensão portal $(n=120)$. 97 Tabela 16 - Comparação entre os pacientes de acordo com a presença de varizes esofágicas de alto risco, segundo as características gerais $(n=120) \ldots 98$ Tabela 17 - Comparação entre os pacientes de acordo com a presença de varizes esofágicas de alto risco, segundo os parâmetros radiológicos $(n=120) 99$ Tabela 18 - Comparação entre os pacientes do estudo de acordo com a presença ou não de varizes esofágicas, segundo os parâmetros laboratoriais $(n=120)$. 100

Tabela 19 - Comparação entre os pacientes do estudo de acordo com a presença varizes esofágicas de alto risco, segundo os métodos não invasivos para detecção de hipertensão portal $(n=120)$ 101

Tabela 20 - Desempenho global dos testes, de acordo com a presença de varizes esofágicas 102

Tabela 21 - Desempenho global dos testes, de acordo com a presença de varizes esofágicas de alto risco. 103 
Tabela 22 - Comparação entre os pacientes do estudo de acordo com a presença de varizes esofágicas, segundo as equações 1 e 2 para detecção de hipertensão portal $(n=120)$ 105

Tabela 23 - Comparação entre os pacientes do estudo de acordo com a presença varizes esofágicas de alto risco, segundo as equações 1 e 2 para detecção de hipertensão portal $(n=120)$ 106

Tabela 24 - Desempenho global das equações, de acordo com a presença de varizes esofágicas 108

Tabela 25 - Desempenho global das equações, de acordo com a presença de varizes esofágicas de alto risco 109 
Lista de abreviaturas, símbolos e siglas $0 \curvearrowright 0$ 


\section{LISTA DE ABREVIATURAS, SÍMBOLOS E SIGLAS}

\begin{tabular}{ll}
\hline & Percentagem \\
$>$ & Menor \\
\pm & Maior \\
$\leq$ & Mais ou Menos \\
$\geq$ & Menor ou Igual \\
ALT & Maior ou Igual \\
APASL & Alanina Aminotransferase \\
APRI & Sociedade Ásia-Pacífico para Estudo do Fígado \\
APRICOT & Ast to Platelet Ratio Índex \\
ARFI & Aids Pegasys Ribavirin International Coinfection Trial \\
AST & Acoustic Radiation Force Impulse \\
CAPPESQ & Aspartato Aminotransferase \\
cm ${ }^{2}$ & Comissão de Ética para Análise de Projetos de Pesquisa \\
DP & Centímetro quadrado \\
FIB-4 & Desvio Padrão \\
g/dL & Fibrosis-4 \\
HCFMUSP & Grama por decilitro \\
HIV & Hospital das Clínicas da Faculdade de Medicina da \\
HVPG & Universidade de São Paulo \\
IC & Human Immunodeficiency Virus \\
IMC & Hepatic Venous Pressure Gradient \\
INR & Intervalo de Confiança \\
Kg/m ${ }^{2}$ & Kilogramational Normalized Ratio \\
&
\end{tabular}




$\begin{array}{ll}\mathrm{kPa} & \text { Kilopascal } \\ \mathrm{m} / \mathrm{s} & \text { Metros por Segundo } \\ \mathrm{mg} / \mathrm{dL} & \text { Miligrama por Decilitro } \\ \mathrm{Mm} & \text { Milimetro } \\ \mathrm{mmHg} & \text { Milímetros de Mercúrio } \\ \mathrm{n} & \text { Tamanho da Amostra } \\ \mathrm{N} / \mathrm{mm}^{3} & \text { Número por Milímetro ao Cubo } \\ \mathrm{NASH} & \text { Esteato-Hepatite Não-Alcoólica } \\ \text { OMS } & \text { Organização Mundial da Saúde } \\ \mathrm{p} & \text { Valor-p } \\ \mathrm{ROC} & \text { Receiver-Operating-Characteristic } \\ \mathrm{RV}- & \text { Razão de Verossimilhança Negativa } \\ \mathrm{RV}+ & \text { Razão de Verossimilhança Positiva } \\ \mathrm{STARD} & \text { Statement for Reporting Studies of Diagnostic Accuracy: } \\ \text { UI/L } & \text { Explanation and Elaboration } \\ \text { VHC } & \text { Unidades Internacionais por Litro } \\ \text { VPN } & \text { Hepatite por Virus C } \\ \text { VPP } & \text { Valor Preditivo Negativo } \\ \text { VS } & \text { Valor Preditivo Positivo } \\ & \text { Versus }\end{array}$




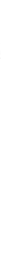

$\circ 20$ 


\section{RESUMO}

Ramos DS. Elastografia hepatoesplênica para predizer varizes esofágicas em pacientes com hipertensão portal não cirrótica: estudo de acurácia diagnóstica [dissertação]. São Paulo: Faculdade de Medicina, Universidade de São Paulo; 2018.

Introdução: elastografia ultrassônica é um método não invasivo validado e rotineiro para a determinação indireta do grau de fibrose hepática e em investigação para predizer a presença de varizes esofágicas. Entretanto, a elastografia foi validada somente em doenças que evoluem para cirrose. $\mathrm{Na}$ revisão de literatura que realizamos, observamos que há escassez de estudos de acurácia diagnóstica em pacientes com hipertensão portal não cirrótica. Objetivos: avaliar a acurácia diagnóstica das técnicas de elastografia hepatoesplênica (transitória por FibroScan e ARFI) para predizer a presença de varizes esofágicas e se as varizes são de risco de sangramento em pacientes com hipertensão portal não cirrótica. Avaliar a concordâncias das duas técnicas e correlacioná-las com outros índices (plaquetas/baço, APRI e FIB-4). Métodos: Foram incluídos pacientes com diagnóstico confirmado das seguintes condições: oclusão da veia porta extra-hepática, esquistossomose mansônica, hipertensão portal não cirrótica idiopática e fibrose hepática congênita. A endoscopia digestiva alta foi considerada como marcador da presença de hipertensão portal clinicamente significante. Critérios de inclusão: idade acima de um ano; diagnóstico etiológico definido; concordância do paciente ou responsável legal em participar do estudo. Critérios de exclusão: cirrose, confirmada pela combinação de critérios diagnósticos clínicos, de imagem e laboratoriais ou pela biópsia hepática quando o resultado estivesse disponível; hipertensão portal pós sinusoidal; condições que impeçam tecnicamente a realização da elastografia (ascite volumosa e insuficiência cardíaca); esplenectomia; gestação; carcinoma hepatocelular avançado. O desenho do estudo foi prospectivo, transversal, de acordo com a metodologia STARD, avaliando a acurácia, sensibilidade, especificidade, valores preditivos positivos e negativos e razões de verossimilhança positiva e negativa. Procedimentos no estudo: consulta aos dados de prontuário; ultrassonografia abdominal e elastografia hepatoesplênica com os equipamentos/métodos FibroScan e ARFI. Os pontos de corte foram determinados por curva ROC. Resultados: os valores de elastografia transitória hepática por FibroScan foram de 5,91 $\pm 1,87 \mathrm{kPa}$ na oclusão da veia porta extra-hepática, 8,89 $\pm 3,96$ $\mathrm{kPa}$ na esquistossomose, $10,60 \pm 3,89 \mathrm{kPa}$ na hipertensão portal não cirrótica idiopática e 10,30 $\pm 4,14 \mathrm{kPa}$ na fibrose hepática congênita, enquanto os 
valores de ARFI foram de $1,27 \pm 0,23 \mathrm{~m} / \mathrm{s} ; 1,35 \pm 0,45 \mathrm{~m} / \mathrm{s} ; 1,43 \pm 0,40 \mathrm{~m} / \mathrm{s}$; $1,55 \pm 0,39 \mathrm{~m} / \mathrm{s}$; respectivamente. Os valores de elastografia transitória esplênica por FibroScan foram de $60,82 \pm 20,56 \mathrm{kPa}$ na oclusão da veia porta extra-hepática, $54,16 \pm 22,94 \mathrm{kPa}$ na esquistossomose, $52,64 \mathrm{kPa} \pm 21,97 \mathrm{kPa}$ na hipertensão portal não cirrótica idiopática e 48,50 $\pm 24,86 \mathrm{kPa}$ na fibrose hepática congênita, enquanto os valores de ARFI foram de $3,22 \pm 0,62 \mathrm{~m} / \mathrm{s}$; $3,01 \pm 0,74 \mathrm{~m} / \mathrm{s} ; 2,86 \pm 0,53 \mathrm{~m} / \mathrm{s} ; 2,80 \pm 0,55 \mathrm{~m} / \mathrm{s}$; respectivamente. A elastografia esplênica por FibroScan com ponto de corte $65,1 \mathrm{kPa}$ apresentou acurácia de 0,62 (intervalo de confiança 95\% 0,46-0,78; $\mathrm{p}=0,121$ ) para presença de varizes. Para predizer varizes de alto risco de sangramento, 0 melhor ponto de corte foi $40,05 \mathrm{kPa}$, que apresentou acurácia de 0,63 (intervalo de confiança 95\% 0,52-0,76; $p=0,016$ ). A elastografia esplênica ARFI com ponto de corte de $2,67 \mathrm{~m} / \mathrm{s}$ apresentou acurácia de 0,64 (intervalo de confiança $95 \%, 0,50-0,78 ; p=0,065)$ para presença de varizes. O melhor ponto de corte para predizer varizes de alto risco de sangramento com esse método foi de $3,17 \mathrm{~m} / \mathrm{s}$, que apresentou acurácia de 0,61 (intervalo de confiança 95\%, 0,51$0,71 ; p=0,033)$. Conclusões: métodos de elastografia esplênica apresentaram uma acurácia moderada e valor preditivo positivo elevado para diagnosticar presença de varizes. A elastografia transitória esplênica por FibroScan quando associada à razão plaqueta/baço apresentou acurácia moderada com especificidade alta para predizer varizes de alto risco de sangramento. Entretanto, considerável superposição de valores foi observada entre pacientes com e sem varizes esofagianas, o que limita a aplicação a utilidade clínica do método.

Descritores: hipertensão portal; técnicas de imagem por elasticidade; varizes esofágicas e gástricas; endoscopia; diagnóstico; baço. 
$\circ$

$\mathrm{O}^{\circ}$

Abstract

020 


\section{ABSTRACT}

Ramos DS. Liver and spleen transient elastography to predict esophageal varices in patients with non-cirrhotic portal hypertension: a diagnostic accuracy study [dissertation]. São Paulo: "Faculdade de Medicina, Universidade de São Paulo"; 2018.

Background and rationale: transient elastography is a noninvasive, validated, method allowing evaluation of liver fibrosis by measurement of liver stiffness and under investigation to predict the presence of esophageal varices. However, elastography has been validated only in diseases that progress to cirrhosis. In a literature review we found few studies on diagnostic accuracy in patients with non-cirrhotic portal hypertension. Aims: to evaluate the accuracy of hepatosplenic elastography (FibroScan and ARFI) to predict the presence of esophageal varices and whether varices are at risk of bleeding in patients with non-cirrhotic portal hypertension. To evaluate the concordances of the two techniques and correlate them with other indexes such as the platelet/spleen diameter ratio, APRI and FIB-4. Methods: patients with confirmed diagnosis of the following conditions were included: extrahepatic portal vein occlusion, schistosomiasis, idiopathic non-cirrhotic portal hypertension and congenital hepatic fibrosis. Upper digestive endoscopy was considered as a marker of the presence of clinically significant portal hypertension. Inclusion criteria: age above one year; defined etiological diagnosis; agreement of the patient or legal guardian to participate in the study. Exclusion criteria: cirrhosis confirmed by combination of clinical, imaging and laboratory diagnostic criteria or by liver biopsy when the result was available; post sinusoidal portal hypertension; conditions that technically preclude the performance of elastography (massive ascites and heart failure); splenectomy; pregnancy; advanced hepatocellular carcinoma. The study design was prospective, transversal, according to the STARD methodology, evaluating the accuracy, sensitivity, specificity, positive and negative predictive values and positive and negative likelihood ratios. The procedures of the study were: review of medical records data, abdominal ultrasonography and hepatosplenic elastography with FibroScan and ARFI equipment / methods. Cut-off points for elastography were determined by ROC curves. Results: liver stiffness measurement by FibroScan were $5.91 \pm 1.87$ $\mathrm{kPa}$ in extrahepatic portal vein occlusion, $8.89 \pm 3.96 \mathrm{kPa}$ in schistosomiasis, $10.60 \pm 3.89 \mathrm{kPa}$ in portal hypertension non-cirrhotic idiopathic and $10.30 \pm$ $4.14 \mathrm{kPa}$ in congenital hepatic fibrosis, whereas by ARFI were $1.27 \pm 0.23 \mathrm{~m} / \mathrm{s}$; $1.35 \pm 0.45 \mathrm{~m} / \mathrm{s} ; 1.43 \pm 0.40 \mathrm{~m} / \mathrm{s} ; 1.55 \pm 0.39 \mathrm{~m} / \mathrm{s}$; respectively. Spleen stiffness measurement by FibroScan were $60.82 \pm 20.56 \mathrm{kPa}$ in extrahepatic portal vein occlusion, $54.16 \pm 22.94 \mathrm{kPa}$ in schistosomiasis, $52.64 \pm 21.97 \mathrm{kPa}$ in idiopathic 
non-cirrhotic portal hypertension, and $48.50 \pm 24.86 \mathrm{kPa}$ in congenital hepatic fibrosis, while by ARFI were $3.22 \pm 0.62 \mathrm{~m} / \mathrm{s} ; 3.01 \pm 0.74 \mathrm{~m} / \mathrm{s} ; 2.86 \pm 0.53 \mathrm{~m} / \mathrm{s}$; $2.80 \pm 0.55 \mathrm{~m} / \mathrm{s}$; respectively. Liver stiffness measurement by FibroScan with a cut-off of $65.1 \mathrm{kPa}$ had an accuracy of 0.62 (95\%confidence interval, 0.46-0.78, $\mathrm{p}=0.121$ ) for the presence of esophageal varices. The best cut-off point for predicting the presence of varices at high risk of bleeding was $40.05 \mathrm{kPa}$ (accuracy, 0.63, 95\% confidence interval, 0.52-0.76, $p=0.016$ ). The spleen stiffness measurement by ARFI with a cut-off of $2.67 \mathrm{~m} / \mathrm{s}$ showed (accuracy, $0.64,95 \%$ confidence interval, $0.50-0.78, p=0.065$ ) for the presence of esophageal varices. The best cut-off point for predicting the presence of varices at high risk of bleeding was $3.17 \mathrm{~m} / \mathrm{s}$ (accuracy, $0.61,95 \%$ confidence interval, 0.51-0.71, $\mathrm{p}=0.033$ ) for varices at high risk of bleeding. Conclusions: spleen stiffness measurement by transient elastography (FibroScan and ARFI) presented a moderate accuracy and a high positive predictive value to diagnose the presence of esophageal varices. Spleen stifness by FibroScan when associated with platelet/spleen diameter ratio, there is a moderate accuracy with a high specificity to predict varices at high risk of bleeding. However, overlapping values between patients with or without varices was high and this precludes the clinical applicability of these methods.

Descriptors: hypertension, portal; elasticity imaging techniques; esophageal and gastric varices; endoscopy; diagnosis; spleen. 
(2)

\section{Introdução}

020 


\section{INTRODUÇÃO}

\subsection{Hipertensão portal}

A hipertensão portal é uma síndrome clínica definida por valores do gradiente de pressão venosa portal superior a cinco mmHg. São reconhecidas duas formas: a hipertensão portal cirrótica e a hipertensão portal não cirrótica, tema do presente estudo. Em pacientes com cirrose, a hipertensão portal está associada à elevação do gradiente de pressão venosa hepática (HVPG, da sigla em língua inglesa Hepatic Venous Pressure Gradient) em decorrência do aumento da resistência sinusoidal e do hiperfluxo portal. Na hipertensão portal não cirrótica, o HVPG é normal ou apenas levemente elevado, uma vez que as suas principais etiologias não acometem significativamente o parênquima hepático e por isso não determinam aumento da resistência ao fluxo pelos sinusóides. ${ }^{1}$

Pela perspectiva clínica, a hipertensão portal é o mecanismo subjacente à maioria das complicações de doença hepática crônica. As apresentações mais comuns são as varizes esôfago-gástricas, que podem se romper e ocasionar episódios de hemorragia digestiva, a anemia e a esplenomegalia, causando desconforto abdominal e hiperesplenismo. Embora menos comum que as apresentações anteriores, as denominadas complicações vasculares, que incluem a síndrome hepatopulmonar e a síndrome porto pulmonares ou hipertensão arterial pulmonar, podem surgir como complicação da hipertensão portal..$^{2,3}$ 


\subsection{Hipertensão portal não cirrótica}

A expressão hipertensão portal não cirrótica designa um grupo heterogêneo de doenças hepáticas caracterizadas por acometimento pré-sinusoidal ou póssinusoidal, pressão sinusoidal normal, preservação da função hepática até as fases terminais da doença e ausência de evolução para cirrose.

O número de casos de hipertensão portal não cirrótica parece estar aumentando, provavelmente em decorrência da maior atenção que essa condição vem recebendo na literatura, levando à revisão do diagnóstico de pacientes que há anos foram erroneamente diagnosticados com cirrose criptogênica. ${ }^{4}$

A hipertensão portal não cirrótica geralmente acomete jovens, pois uma das suas principais causas, a oclusão da veia porta extra-hepática, é principalmente uma doença da infância, mas pode se apresentar em qualquer idade a partir de seis semanas até a vida adulta. ${ }^{5}$

Dentro da hipertensão portal não cirrótica encontram-se transtornos vasculares hepáticos que englobam uma série de condições raras, tendo uma prevalência inferior a 5/10.000 habitantes. Entre esses, destacam-se a síndrome de Budd-Chiari, a oclusão da veia porta extra-hepática e a esclerose hepatoportal sem ou com hiperplasia nodular regenerativa associada. ${ }^{4}$

Em nosso meio, a esquistossomose mansônica hepatoesplênica responde por elevada frequência de casos, estando presente em 19 dos 27 estados do Brasil, principalmente nos estados da região nordeste e sudeste do país.6,7 Outras entidades, como a fibrose hepática congênita, apresentam uma prevalêcia ainda menor. ${ }^{4}$ 
As doenças que levam à hipertensão portal não cirrótica são fundamentalmente de natureza vascular e anatomicamente classificadas com base no local da resistência ao fluxo sanguíneo. Em algumas vezes é uma manifestação tardia de doença primária não hepática. ${ }^{1} \mathrm{~A}$ hipertensão portal não cirrótica é uma condição distinta e não deve ser considerada um evento na história natural nem uma associação de doença hepática primária. É importante ressaltar que a nomenclatura obstrução da veia porta extra-hepática, com ou sem transformação cavernomatosa ou biliopatia portal, exclui a trombose de veia porta secundária à cirrose e/ou por invasão por carcinoma. Da mesma forma, não se considera a oclusão isolada da veia esplênica ou mesentérica superior, uma vez que a etiologia é diferente. ${ }^{8}$

Os critérios diagnósticos da hipertensão portal vêm sendo debatidos e padronizados na literatura. Os principais critérios foram propostos por Aoki et al. ${ }^{9}$, Shouten et $a l .{ }^{10}$ e pela Sociedade Ásia-Pacífico para Estudo do Fígado APASL. ${ }^{11}$ As tabelas de 1 a 3 apresentam detalhadamente esses critérios. A biópsia do fígado não é essencial para o diagnóstico de hipertensão portal não cirrótica a menos que haja suspeita de doença hepática crônica subjacente. ${ }^{12}$ De qualquer modo, quatro achados patológicos seriam comumente vistos e necessários para caracterizar hipertensão portal não cirrótica: esclerose hepatoportal, fibrose periportal, fibrose perissinusoidal e hiperplasia nodular regenerativa. ${ }^{13}$ 
Tabela 1 - Critérios de Aoki et al. ${ }^{9}$ para hipertensão portal não cirrótica idiopática

\section{Critérios}

Doença clínica sem etiologia definida com:

Esplenomegalia, anemia e hipertensão portal, sendo:

Não cirrótico, não hematológico, sem parasitos hepatobiliares e oclusão das veias hepática e porta

Tabela 2 - Critérios de Schouten et al. ${ }^{10}$ para hipertensão portal não cirrótica idiopática

\section{Critérios}

Sinais clínicos de hipertensão portal: esplenomegalia; varizes esofágicas; ascite (não neoplasica);

Exclusão de cirrose por biópsia

Exclusão de causas de doença hepática crônica que levam à cirrose

Paciente com veias hepáticas e porta pérvias por meio de métodos de imagem

Tabela 3 - Criterios da APASL ${ }^{11}$ para hipertensão portal não cirrótica

\section{Critérios}

Presença de esplenomegalia moderada a importante

Evidência de hipertensão portal, varizes e/ou colaterais

Veias porta, esplênica e hepáticas pérvias ao ultrassom com Doppler

Resultados de exames demostrando função hepática normal ou próximo à normalidade

Gradiente de pressão venosa hepática normal ou próximo ao valor normal

Histologia hepática sem evidência de cirrose 


\subsection{Risco de sangramento por ruptura de varizes}

A hemorragia digestiva varicosa continua sendo uma das principais causas de mortalidade em pacientes com hipertensão portal. ${ }^{14}$ Cerca de $60 \%$ dos pacientes com cirrose descompensada e 30\% daqueles com cirrose compensada apresentam varizes no momento do diagnóstico. Na hipertensão portal não cirrótica as varizes esofágicas são vistas em $80-90 \%$ casos. ${ }^{15}$

$\mathrm{Na}$ hipertensão portal não cirrótica os dados são escassos, geralmente de estudos retrospectivos, com casuística pequena e com foco na análise da prevalência hospitalar. Portanto, podem não representar a real magnitude da hipertensão portal não cirrótica. Dados mais confiáveis referem-se à cirrose, onde se descrevem taxas de primeiro sangramento varicoso em torno de $30 \%$, com período de maior risco de ressangramento nas primeiras seis semanas após o episódio de hemorragia, que se reduz gradativamente ao longo de um ano. ${ }^{12} \mathrm{~A}$ mortalidade relacionada ao ressangramento atualmente situa-se ao redor de 15 a $20 \% .{ }^{16}$

Na população pediátrica, estima-se que $50 \%$ das crianças com hepatopatia apresentem pelo menos um episódio de hemorragia digestiva ${ }^{17}$. Nas crianças com diagnóstico de obstrução da veia porta extra-hepática, essa prevalência apresenta uma variabilidade de 70,9 a $90 \%$ dos $\operatorname{casos}^{18}$. No estudo de Ferri et al. ${ }^{19}$, a prevalência de sangramento nas crianças brasileiras com hipertensão portal não cirrótica foi de $71 \%$.

\subsection{Avaliação da hipertensão portal e rastreamento de varizes}

A história natural das varizes esofágicas em pacientes com hipertensão portal não cirrótica não é conhecida, mas em pacientes cirróticos a progressão 
do tamanho das varizes ocorre a uma taxa de $10-15 \%$ por ano, em sua maioria em decorrência da disfunção hepática. Tal progressão das varizes em pacientes com hipertensão portal não cirrótica é menos provável de ocorrer, pois a função hepática geralmente permanece preservada até fases finais da doença. ${ }^{20}$

Diferentes diretrizes ${ }^{21-23}$ recomendam que todos os pacientes com hipertensão portal devam ser submetidos à endoscopia para rastreamento de varizes esôfago-gástricas, no momento em que a doença hepática for diagnosticada. Após a triagem, os pacientes seguem em acompanhamento endoscópico. Os intervalos recomendados são de 2 a 3 anos para os pacientes com doença hepática compensada e sem varizes, e de 1 a 2 anos para aqueles com varizes de fino calibre e 1 ano para aqueles com doença descompensada, com ou sem varizes. ${ }^{24,25}$

Estas recomendações geram uma carga considerável de endoscopias e custos relacionados. Nos últimos anos, foram realizados estudos que avaliaram o potencial de utilizar outros métodos, além da endoscopia digestiva alta, para o diagnóstico de varizes esofágicas. Têm sido avaliados parâmetros bioquímicos, clínicos, marcadores sanguíneos de fibrose, elastografia, ultrassonografia, tomografia computadorizada, vídeocápsula endoscópica, entre outros. ${ }^{26}$ Estes métodos podem ser divididos em dois grupos: invasivos e não invasivos.

\section{a) Métodos invasivos}

A endoscopia digestiva alta tem sido tradicionalmente considerada o padrão-ouro para avaliação de varizes esofágicas. Apesar de pouco invasivo, é 
um procedimento propenso a gerar desconfortos e até mesmo, em raros casos, causar alguma complicação mais grave ao paciente. ${ }^{27} \mathrm{~A}$ endoscopia digestiva alta deve ser realizada em todos os pacientes com suspeita de hipertensão portal. ${ }^{20,28,29}$ Além de apresentar alta acurácia diagnóstica para a presença de varizes, é capaz de estratificar pacientes em alto e baixo risco de sangramento. A presença de varizes maiores que cinco $\mathrm{mm}$ e com sinais da cor vermelha em sua superfície são os principais sinais endoscópicos indicativos de risco elevado de ruptura. ${ }^{30}$

A do HVPG apresenta excelente correlação com o desenvolvimento de varizes e risco de ruptura em pacientes com cirrose. ${ }^{31}$ Para o surgimento de varizes esofágicas o HVPG deve ser superior a $10 \mathrm{mmHg}$, enquanto que gradiente um maior que $12 \mathrm{mmHg}$ é necessário para que haja ruptura e sangramento. ${ }^{32,} 33$ Todavia, o HVPG costuma apresentar valores normais ou pouco alterados na hipertensão portal não cirrótica, o que constitui uma limitação do método para esse subgrupo de pacientes. Em virtude do seu caráter invasivo e alto custo, a medida do HVPG não é realizada de forma rotineira na prática clínica.

\section{b) Métodos minimamente invasivos ou não invasivos}

A ultrassonografia com Doppler é o exame de primeira linha para investigação por métodos de imagem na hipertensão portal não cirrótica. Achados como fígado de tamanho normal, espessamento de ramos portais, esplenomegalia, dilatação da veia porta e colaterais portosistêmicas são comuns, porém não permitem diferenciar hipertensão portal cirrótica da não cirrótica. $^{12}$ 
$\mathrm{Na}$ tomografia computadorizada é possível observar anormalidades do sistema venoso portal intra-hepático: não visualização, redução do calibre, tromboses de ramos venosos; sinais de hiperplasia nodular focal e a alteração da perfusão venosa. A ressonância magnética e espectroscopia por ressonância magnética são técnicas não invasivas, mas apesar dos resultados promissores, ainda precisam ser validadas e padronizados para avaliar fibrose. ${ }^{34}$ Além disso, essas modalidades de imagem são caras e não são prontamente disponíveis. ${ }^{12}$

A razão plaqueta/baço como proposto por Giannini et al. ${ }^{35}$ é um método não invasivo, que utiliza a razão entre a contagem de plaquetas e o diâmetro do baço como avaliação não invasiva de varizes esofágicas. Esse índice foi validado entre pacientes que não tinham varizes esofágicas em endoscopia de triagem e que foram acompanhados prospectivamente. ${ }^{36}$ Os resultados obtidos por outros autores demonstraram que a acurácia diagnóstica da relação entre a contagem de plaquetas e o diâmetro do baço é mantida em subconjuntos de pacientes de diferentes etiologias de doença hepática. ${ }^{37,38}$

A combinação de biomarcadores para o desenvolvimento de preditores para a detecção de fibrose hepática é uma alternativa interessante. Em 2003, o índice AST to platelet ratio índex (APRI) foi proposto em pacientes com hepatite C. Nesse método utiliza-se o valor de aspartato aminotransferase dividido pela contagem de plaquetas, multiplicado por 100 para caracterizar fibrose hepática avançada e com isso, indiretamente, inferir a presença de varizes esofágicas. ${ }^{39}$

Em 2006, o grupo de estudos AIDS Pegasys Ribavirin International Coinfection Trial (APRICOT), desenvolveu um índice para detecção de fibrose 
hepática em uma população com co-infecção VHC/HIV. De modo análogo ao APRI, permite inferir se há risco de haver varizes esofágicas, dado que se propõe a diagnosticar graus de fibrose hepática. Denominado FIB-4, utiliza os seguintes parâmetros: idade, aspartato aminotransferase (AST), alanina aminotransferase (ALT) e contagem de plaquetas..$^{40}$

Esses índices apresentam importante limitação, pois utilizam valores de aminotransferases e, portanto, estão sujeitos a resultado falso positivo em decorrência da inflamação hepática, tendendo a superestimar a presença de fibrose hepática. Por esse motivo, em que pese o APRI e o FIB-4 serem índices de importante uso clínico, eles devem ser utilizados como meros métodos adjuntos de diagnóstico. ${ }^{41}$

O sistema de endoscopia por vídeocápsula fornece uma abordagem menos invasiva para identificar varizes de esôfago. As vantagens incluem a eliminação da necessidade de sedação consciente, a natureza minimamente invasiva do exame e a capacidade do paciente realizar as atividades diárias normalmente após o procedimento. Além disso, a cápsula endoscópica é susceptível de ser mais facilmente aceita pelos pacientes que a endoscopia digestiva alta. ${ }^{42}$ Alguns estudos demonstraram que em pacientes com cirrose, a cápsula pode ser útil na detecção e avaliação do tamanho das varizes esofágicas. Porém, é um método de alto custo e não pode ser utilizado em crianças. ${ }^{26}$

Em decorrência dessas pecualiaridades, várias abordagens não-invasivas têm sido desenvolvidas. As técnicas de elastografia tecidual vêm ganhando espaço na literatura como promissoras. Podem ser realizadas por métodos acústicos (elastografia transitória ou Acoustic Radiation Force Impulse - ARFI) ou por ressonância magnética. 
As técnicas e equipamentos mais empregados e com maior experiência publicada na literatura são aqueles baseados em métodos acústicos. Ambos têm como princípio físico a utilização de ondas sonoras cuja velocidade de propagação pelo tecido analisado é proporcional ao grau de fibrose. A grande vantagem é o seu caráter não invasivo, sem requerer sedação ou punções. Não apresentam riscos à saúde, podendo ser realizadas em pacientes de qualquer idade, por não utilizar radiação eletromagnética. ${ }^{43}$

A elastografia transitória é feita por equipamento denominado FibroScan, que utiliza um sistema em que a excitação mecânica externa é canalizada para o fígado e as velocidades das ondas de cisalhamento são medidas utilizando a ultra-sonografia. A elasticidade do órgão é reduzida pelo acúmulo de fibrose, de modo que a medida da elasticidade correlaciona-se com esse grau de fibrose. A tecnologia ARFI baseia-se no princípio da excitação mecânica de tecido por pulsos acústicos de curta duração. Essa tecnologia foi inicialmente utilizada para geração de imagens de diferentes materiais em tecidos moles, produzindo ondas de cisalhamento. ${ }^{43}$

A utilidade clínica da elastografia transitória por FibroScan tem sido amplamente replicada, após o primeiro relato da técnica por Sandrin et al. ${ }^{44} \mathrm{O}$ primeiro relato clínico da aplicabilidade da elastografia foi em pacientes japoneses com hepatite C crônica, a fim de detectar a rigidez hepática..$^{45} \mathrm{Em}$ relação à elastografia por $\mathrm{ARFI}$, Fahey et al. ${ }^{46}$ relataram pela primeira vez a eficácia desse método na detecção e monitorização da progressão do carcinoma hepatocelular e câncer renal.

A elastografia esplênica associada com a hepática foi recentemente avaliada na literatura para determinar a sua acurácia no diagnóstico da 
hipertensão portal. Talwalkar et $a l .{ }^{47}$ encontraram que a rigidez esplênica média, medida por ressonância magnética, foi significantemente inferior em voluntários saudáveis do que nos doentes com fibrose hepática $(3,6 \pm 0,3 \mathrm{kPa}$ vs $5,6 \pm 5,0 \mathrm{kPa})$. Uma rigidez esplênica de $10,5 \mathrm{kPa}$ ou superior foi característica de pacientes com varizes esofágicas.

A elastografia por ARFI do fígado e do baço foi avaliada em um estudo recente e se verificou que uma onda de cisalhamento do baço com velocidade de corte de $2,73 \mathrm{~m} / \mathrm{s}$ pode ser utilizada para diferenciar pacientes com cirrose daqueles com pacientes saudáveis. ${ }^{48,}, 49$

Estudos publicados em periódicos de alto impacto favorecem a elastografia do baço para predizer a ocorrência de varizes esofágicas em pacientes com cirrose, como pode ser observado na figura $1 .{ }^{50}$ No estudo de Kim et al. ${ }^{51}$, houve correlação entre a rigidez hepática e o diâmetro do baço, a contagem de plaquetas e o risco maior do paciente apresentar varizes esofágicas. 

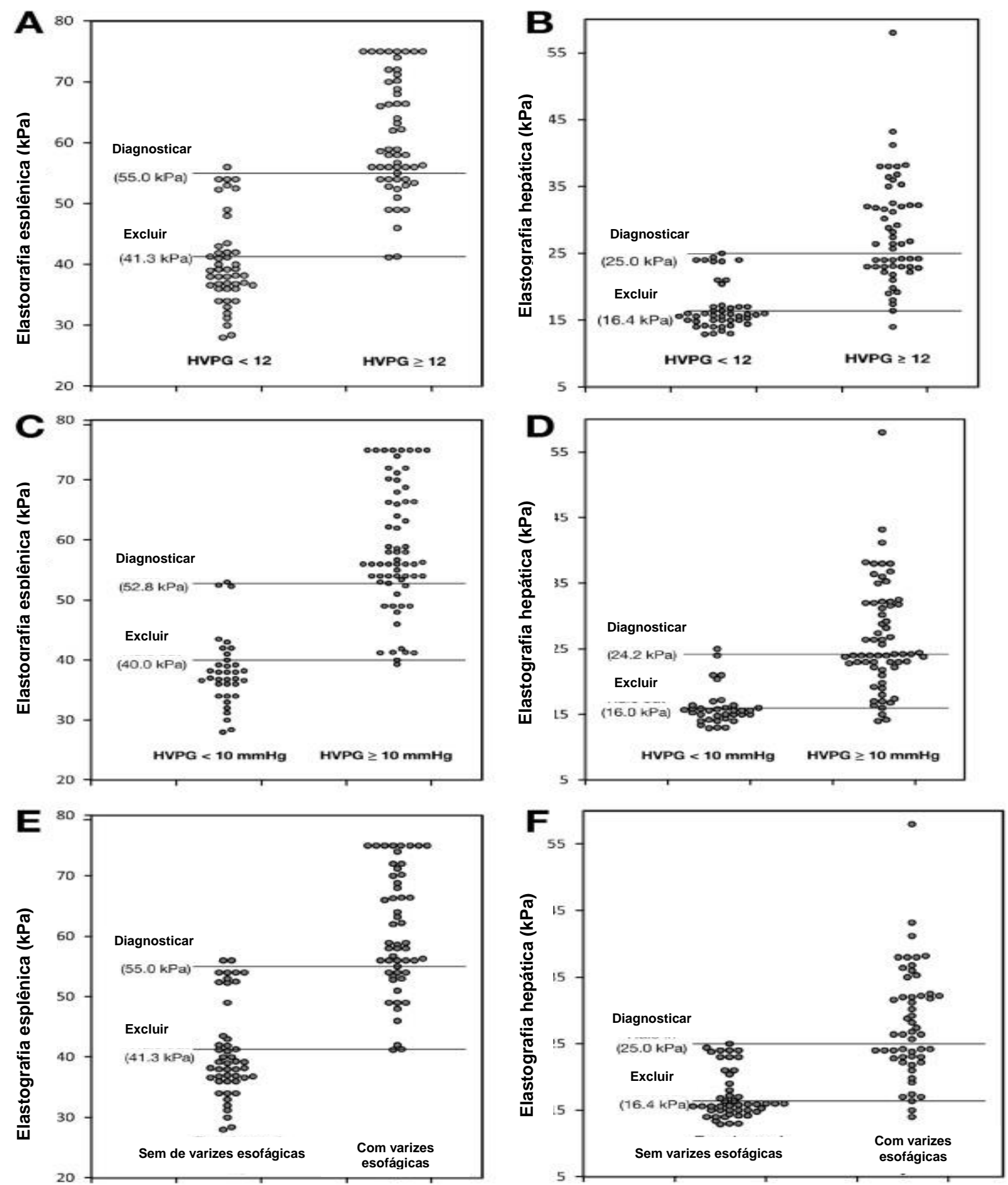

Fonte: Colecchia et al. ${ }^{50}$

Figura 1 - Distribuição dos valores da elastografia esplênica e hepática em pacientes com HVPG $<12$ ou $\geq 12 \mathrm{mmHg}$ (A e B, respectivamente), HVPG $<10$ ou $\geq 10 \mathrm{mmHg}$ ( $C$ e $D$, respectivamente) e com ou sem varizes esofágicas ( $E$ e $\mathrm{F}$, respectivamente) 
Entretanto, a elastografia do fígado somente foi validada em doenças que evoluem para cirrose, enquanto a elastografia do baço foi avaliada somente em pacientes com cirrose de etiologia viral. Em uma revisão realizada na base de dados Pubmed observamos a escassez de estudos de acurácia da elastografia em pacientes com hipertensão portal não cirrótica. Por essa razão, estudos sobre a acurácia diagnóstica da elastografia hepatoesplênica em pacientes com hipertensão portal não cirrótica, para predizer varizes esofágicas são necessários.

\subsection{Racional do estudo}

Considerando que a hipertensão portal não cirrótica acomete comumente indivíduos jovens e crianças e que habitualmente é necessário realizar endoscopia digestiva sob sedação para o rastreamento de varizes esofágicas, há espaço na literatura para avaliar o papel de métodos não invasivos como a elastografia hepatoesplênica para predizer varizes. As vantagens intrínsecas desses métodos, tais como o caráter não invasivo, sem necessidade de sedação, rapidez, sem interferir nas atividades diárias do pacientes após 0 exame, tornam a elastografia particularmente interessante para os pacientes com hipertensão portal não cirrótica.

\subsection{Hipótese a ser testada}

Formulamos a hipótese que a elastografia hepatoesplênica poderia predizer a presença de varizes esofágicas e, se as varizes são de risco de sangramento em pacientes com hipertensão portal não cirrótica de diferentes etiologias. Com 
isso, ajudaria a selecionar os candidatos à endoscopia digestiva para realização de procedimentos visando à prevenção do sangramento varicoso. 
-

Objetivos 


\section{OBJETIVOS}

\subsection{Principal}

Avaliar a acurácia diagnóstica das técnicas de elastografia hepatoesplênica (transitória por FibroScan e ARFI) para predizer a presença de varizes esofágicas e se as varizes são de risco de sangramento em pacientes com hipertensão portal não cirrótica.

\subsection{Secundários}

a) Avaliar a concordância das duas técnicas de elastografia hepatoesplênica.

b) Correlacionar os resultados da elastografia com a razão plaqueta/baço, índice APRI e índice FIB-4. 


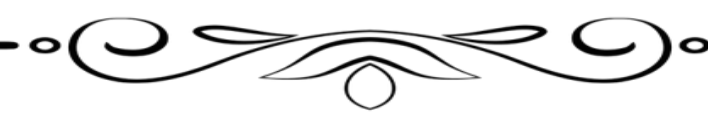

Casuística e métodos

020 


\section{CASUÍSTICA E MÉTODOS}

\subsection{Pacientes}

\subsubsection{Recrutamento e inclusões}

\section{Critérios de inclusão}

a) Idade acima de um ano.

b) Diagnóstico definido de doença que causa hipertensão portal não cirrótica.

c) Concordância do paciente e/ou representante legal em participar do estudo.

\section{Critérios de exclusão}

a) Cirrose confirmada pela combinação de critérios diagnósticos clínicos, de imagem e laboratoriais ou pela biópsia hepática quando o resultado estivesse disponível.

b) Hipertensão portal pós-sinusoidal.

c) Condições que impeçam tecnicamente a realização da elastografia (ascite volumosa e insuficiência cardíaca).

d) Esplenectomia.

e) Gestação.

f) Carcinoma hepatocelular avançado. 


\subsubsection{Critérios diagnósticos das causas de hipertensão portal não cirrótica}

a) Oclusão da veia porta extra-hepática - nesse trabalho utilizamos essa nomenclatura, para referirmos à trombose portal não cirrótica e não tumoral que ocorre sem hepatopatia de base, para evitar confusão com a trombose portal secundária à esquistossomose e a outras condições subjacentes. O seu diagnóstico foi feito pela identificação de trombo parcial ou total, agudo ou crônico na veia porta, por método de imagem (ultrassonografia com Doppler ou angiotomografia ou ressonância magnética) em paciente com ou sem trombofilia conhecida ou demonstrável. ${ }^{22}$

b) Esquistossomose mansônica hepatoesplênica - diagnosticada pela presença atual ou pregressa de ovos de $S$. mansoni nas fezes e pelos achados ultrassonográficos, de acordo com o protocolo da Organização Mundial de Saúde (OMS) ${ }^{52}$

c) Hipertensão portal não cirrótica idiopática (esclerose hepatoportal e hiperplasia nodular regenerativa) - o diagnóstico foi estabelecido pela combinação dos seguintes parâmetros:

- Sinais clínicos inequívocos de hipertensão portal (varizes gastroesofágicas, varizes ectópicas, esplenomegalia, ascite, presença de colaterais).

- Exclusão de cirrose e de outras causas específicas de doença hepática que podem levar à hipertensão portal. A exclusão foi 
realizada pelos critérios diagnósticos padrão, incluindo a realização de biópsia hepática.

- Biópsia hepática com fragmento de tamanho representativo, demonstrando alterações da arquitetura hepática, variando de mínimas a mais relevantes, como a esclerose portal, com espessamento da camada íntima e hipertrofia da muscular, causando um estreitamento e obliteração do lúmen das vênulas portais, dilatação sinusoidal, presença de vasos portais aberrantes, microtrombose ou a presença de hiperplasia nodular regenerativa.

- Perviedade das veias hepáticas e do eixo esplenoportal aos métodos de imagem. ${ }^{53}$

d) Fibrose hepática congênita - diagnóstico estabelecido por biópsia hepática. Caracteristicamente, observa-se extensa fibrose nos espaços porta, associada a aumento do número de estruturas biliares que exibem distribuição anômala dentro das traves fibrosas e que podem apresentar dilatação e secreção biliar ou proteica em seu interior. Nos espaços porta, identificam-se estruturas arteriolares hepáticas, porém os ramos venosos portais são hipoplásicos ou completamente ausentes, atribuíveis à hipertensão portal. Os ramos venosos portais principais geralmente são pérvios e de tamanho normal. 
Raramente são identificadas alterações inflamatórias nas formas puras. O parênquima hepático presente entre as traves fibrosas é estritamente normal. ${ }^{54}$

\subsubsection{Classificação da trombose portal}

A trombose portal independente da sua etiologia foi classificada conforme recomendação do Consenso de Baveno $\mathrm{V}^{1}$ nos seguintes tipos, ilustrados na figura 2.
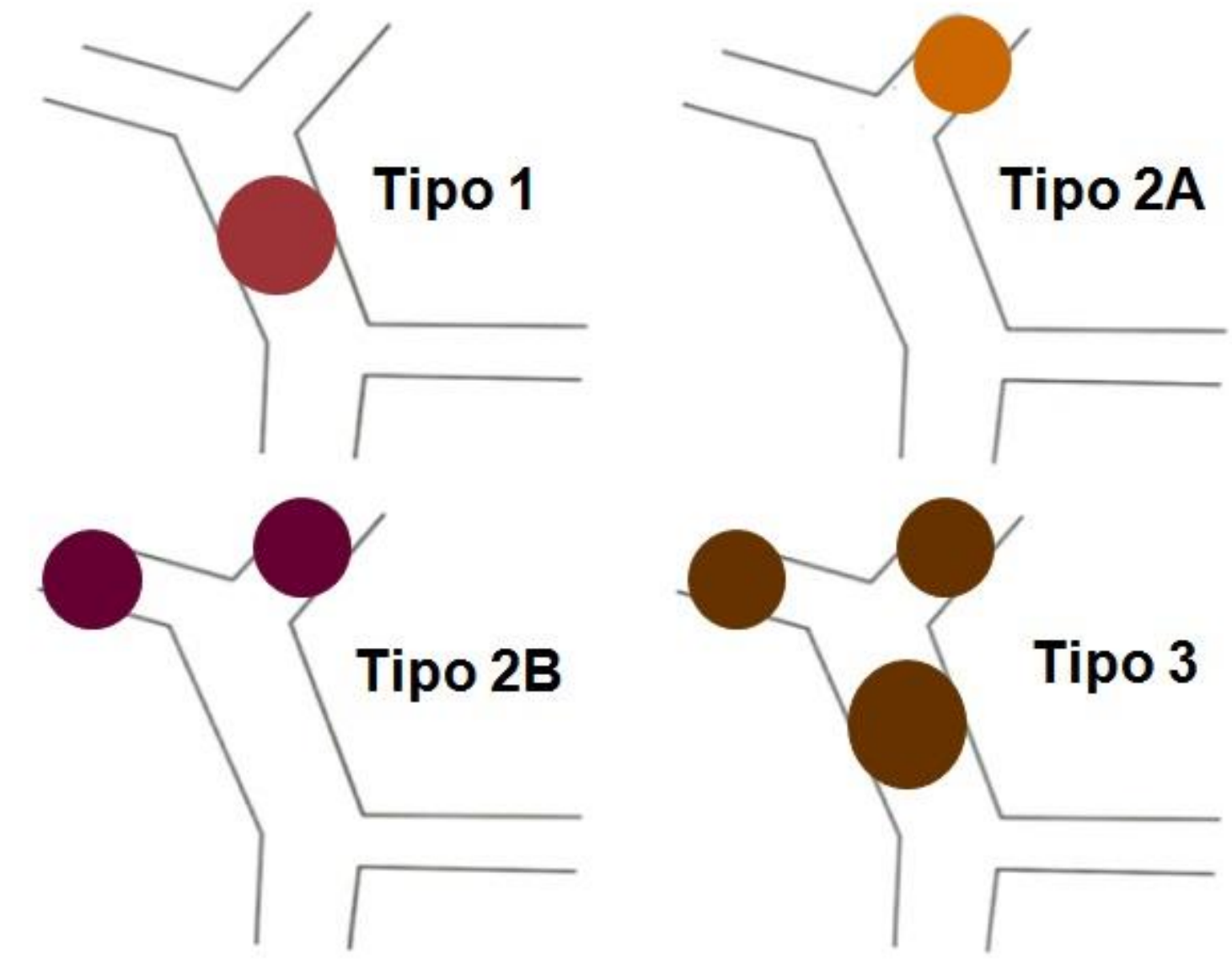

Tipo 1 - trombose de tronco da veia; tipo $2 \mathrm{a}$ - trombose de um ramo; tipo $2 \mathrm{~b}$ - trombose de dois ramos; tipo 3 - trombose de tronco e ramos.

Figura 2 - Classificação da trombose portal segundo o Consenso de Baveno V 


\subsubsection{Critério diagnóstico de hipertensão portal}

a) Endoscopia digestiva alta - de acordo com os consensos e diretrizes internacionais e nacionais ${ }^{1,11,23}$, todos os pacientes diagnosticados com uma das doenças que causam hipertensão portal devem obrigatoriamente ser submetidos à endoscopia digestiva para rastreamento de varizes como parte da investigação diagnóstica, com o objetivo de adotar medidas profiláticas do sangramento varicoso.

b) HVPG - não foi considerado critério diagnóstico de hipertensão portal no presente estudo porque avaliamos um grupo de doenças que cursam com hipertensão presinusoidal, situação em que caracteristicamente os valores são normais ou discretamente alterados.

\subsection{Métodos}

\subsubsection{Desenho do estudo}

Estudo prospectivo, transversal, unicêntrico, desenhado de acordo com as recomendações STARD (Statement for Reporting Studies of Diagnostic Accuracy: Explanation and Elaboration).$^{55}$

\subsubsection{Grupos}

Os pacientes incluídos foram alocados em quatro diferentes subgrupos: a) Oclusão da veia porta extra-hepática; b) Esquistossomose mansônica 
hepatoesplênica; c) Hipertensão portal não cirrótica idiopática; d) Fibrose hepática congênita.

\subsection{Procedimentos previstos no estudo}

a) Convite para o paciente participar do estudo, exposição do protocolo e assinatura do termo de consentimento pelo paciente ou seu responsável legal.

b) Entrevista do paciente e/ou responsável legal para obtenção de dados demográficos e clínicos.

c) Consulta aos dados de prontuário do paciente - os dados clínicos necessários à estimativa da gravidade da doença hepática (presença de ascite e histórico de encefalopatia hepática) foram pesquisados no prontuário, assim como foram avaliados e registrados todos os exames destinados à definição etiológica da doença de base. Esses exames foram solicitados pelo médico do paciente como parte da investigação clínica e não foram específicos do presente estudo. A sua realização ocorreu de forma independente da inclusão ou não do paciente no protocolo. Foram pesquisados sistematicamente os resultados dos exames listados a seguir:

- Parâmetros laboratoriais no sangue: hemoglobina, leucócitos, plaquetas, AST, ALT, fosfatase alcalina, gama glutamil transferase, bilirrubina total, international normalized ratio (INR), proteínas totais, albumina e creatinina.

- Endoscopia digestiva alta - foi registrado o último resultado disponível da endoscopia de rotina, delimitando em até um ano como período máximo do tempo entre a realização da endoscopia e da elastografia. Foram registrados o número e as características das varizes esofágicas. 
- $\quad$ Tomografia de abdome ou ressonância de abdome - quando disponíveis estes resultados foram avaliados para caracterizar a veia porta e avaliar os sinais indiretos de hipertensão portal.

- Biópsias hepáticas - quando disponíveis, os resultados foram consultados para confirmar o diagnóstico etiológico da hipertensão portal.

d) Ultrassonografia de abdome superior e razão plaqueta/baço - a ultrassonografia no momento do ARFI foi procedimento de rotina para localizar a posição exata do fígado e do baço e evitar erros de medida, podendo ser considerada parte do procedimento. A razão plaqueta/baço ${ }^{35}$ foi expresso pela razão entre a contagem de plaquetas em $\mathrm{n} / \mathrm{mm}^{3}$ e o diâmetro bipolar do baço em milímetros. A medida dos diâmetros do baço e dos diâmetros e fluxos dos vasos portais, foram realizadas utilizando o mesmo equipamento empregado para o ARFI esplênico.

e) Elastografia hepática e esplênica - foi realizada preferencialmente de forma ambulatorial, com período de jejum de seis horas e antes da dose matinal de betabloqueador. $\mathrm{O}$ exame foi realizado com o paciente em decúbito dorsal e teve uma duração estimada de 5 a 10 minutos. A técnica habitual consistiu em apoiar o transdutor sobre a pele entre as costelas do paciente e realizar 10 medições válidas no mesmo local, utilizando as técnicas padronizadas. ${ }^{56} \mathrm{O}$ examinador que realizou as elastografias tem larga experiência nessa área. Foram utilizados os seguintes equipamentos:

- Elastografia transitória por FibroScan, fabricado pela companhia Echosens, França

- $\quad \mathrm{ARFI}$, fabricado pela companhia Siemens, Alemanha. 
A figura 3 mostra os equipamentos de elastografia e a figura 4 ilustra a técnica de exame.
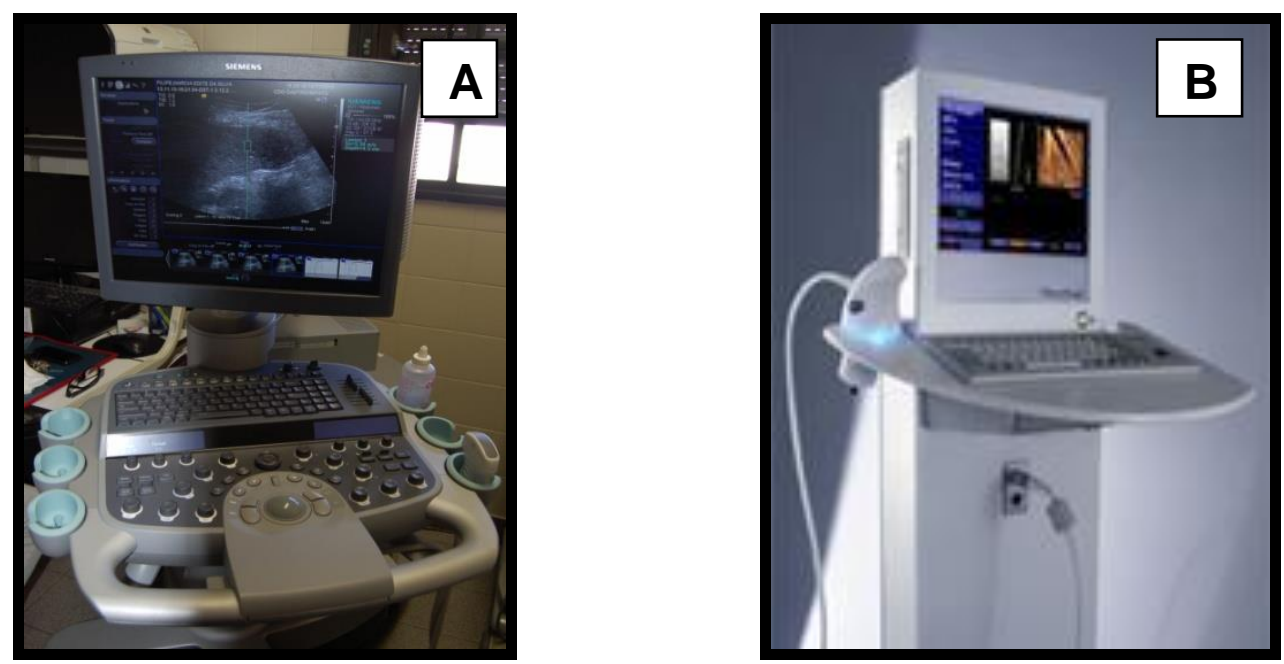

Figura 3 - Equipamentos para a realização da elastografia. A) Equipamento FibroScan; B) Equipamento ARFI
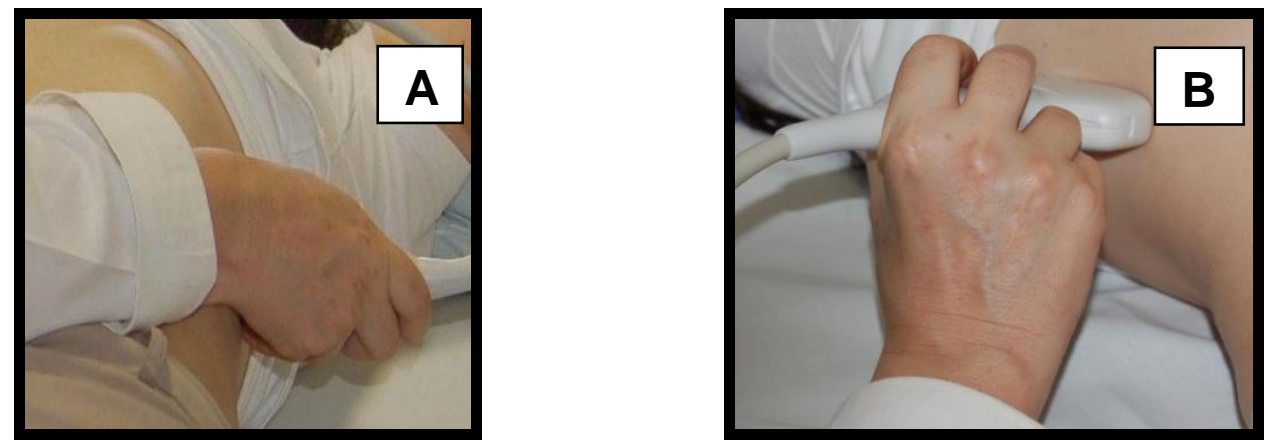

Figura 4 - Posicionamento do transdutor no espaço intercostal para a realização das medidas de elastografia. A) Baço; B) Fígado 
Para a interpretação dos valores da elastografia transitória hepática por FibroScan utilizamos os parâmetros da figura 5, segundo a qual cinco faixas de valores, expressos em unidades KiloPascais (KPa), caracterizam o grau de fibrose hepática, correlacionando-se com o estadiamento histológico de fibrose, segundo a definição Metavir. ${ }^{56,57}$

No método de elastografia hepática por ARFI nos pacientes com cirrose, considera-se, fibrose grau 0 ou 1 , valores em até $1,34 \mathrm{~m} / \mathrm{s}$; fibrose grau 2 quando os valores estão iguais ou maiores que 1,34 m/s; fibrose grau 3 quando os valores estão iguais ou maiores que $1,55 \mathrm{~m} / \mathrm{s}$; e fibrose grau 4 quando valores estão acima de 1,8 m/s; no ARFI esplênico considera-se um corte de $2,73 \mathrm{~m} / \mathrm{s}$ para detectar varizes esofágicas. ${ }^{48,58}$

Para a elastografia transitória esplênica os valores de corte foram definidos pela análise estatística a partir das curvas Receiver-operating-characteristic (ROC) e das razões de verossimilhança positiva e negativa para predizer ou excluir a presença de varizes e as varizes de alto risco.

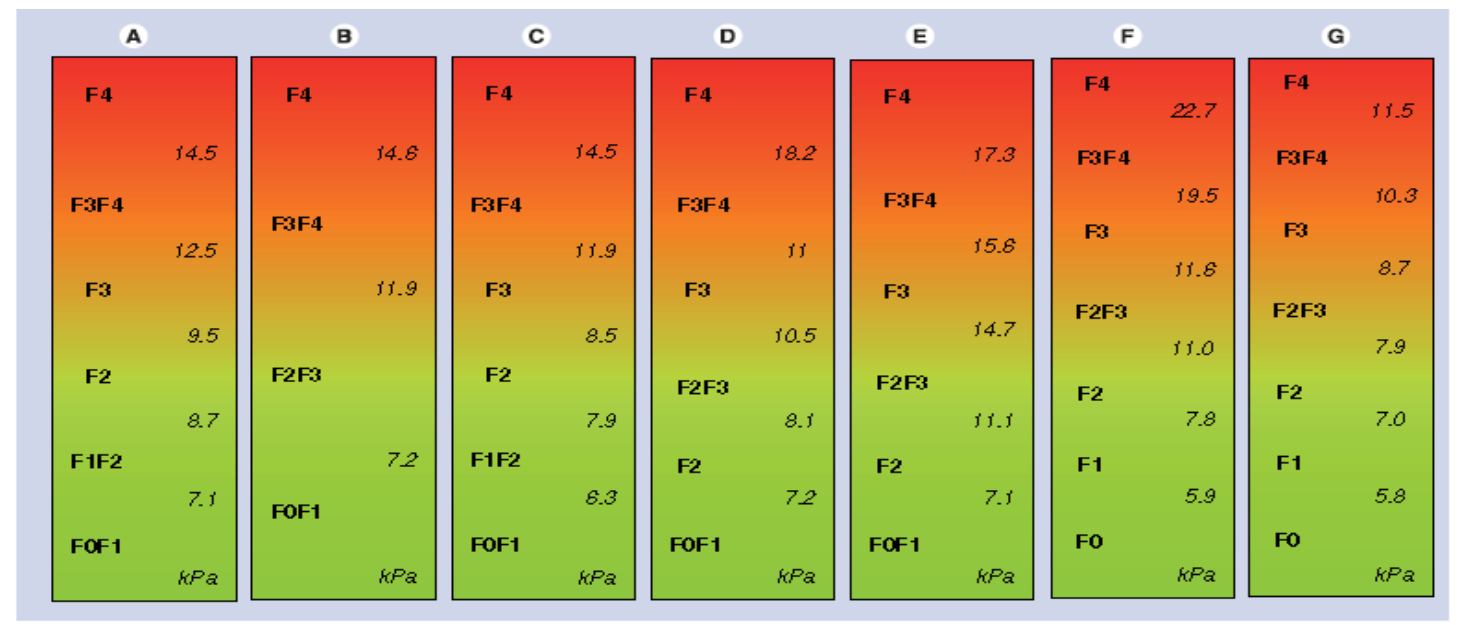

Figura 5 - Concordância entre medidas de elastografia em unidades kPa e graus de fibrose hepática. (A) Vírus $C$; (B) Co-infecção virus $C$ e HIV; (C) Vírus $C$ pós transplante; (D) virus B; $(E)$ Doença hepática colestática; $(F)$ Doença alcoólica; $(G)$ Doença gordurosa não alcoólica. 


\subsection{Interpretação dos índices APRI, FIB-4 e razão plaqueta/baço}

No índice APRI considera-se fibrose 0 ou 1 quando apresenta um valor $<0,5$ e quando o valor está $>1,5$ o indivíduo apresenta fibrose grau 3 ou 4; em um resultado entre 0,5 e 1,5 o índice não consegue identificar se existe grau de fibrose ou cirrose. ${ }^{39}$ Para o cálculo do índice APRI, foi utilizada a seguinte fórmula:

$A P R I=[(A S T \div$ limite superior da normalidade $A S T(U I / L)) \times 100)] \div$ Número de plaquetas $\left(\mathrm{N} / \mathrm{mm}^{3}\right)$

No índice FIB-4 para pacientes que apresentam esteato-hepatite não alcoólica (NASH), o valor para fibrose graus 0 e 1 é $<1,30$; e para fibrose graus 3 e 4 é >2,67; em paciente com hepatite por vírus $\mathrm{C}$ o valor para fibrose graus 0 e 1 é $<1,45$; e para fibrose graus 3 e 4 é $>3,25 .{ }^{40}$ Para o cálculo do índice FIB-4, foi utilizada a seguinte fórmula:

FIB-4 $=($ idade (anos) $\times$ AST $(U I / L)) \div$ Número de plaquetas $\left(N / \mathrm{mm}^{3}\right) \times \sqrt{ } A L T(U I / L)$

A razão plaqueta/baço tem como ponto de corte 909, com uma acurácia de $86 \%$, com sensibilidade de $91,5 \%$ e especificidade de $67 \%$, no estudo proposto por Giannini et al. ${ }^{35}$ Para o cálculo da razão plaqueta/baço, foi utilizada a seguinte fórmula:

Razão plaqueta/baço $=$ Número de plaquetas $\left(\mathrm{N} / \mathrm{mm}^{3}\right) \div$ Diâmetro do baço $(\mathrm{mm})$

\subsection{Tratamentos concomitantes}


Todos os tratamentos necessários do ponto de vista clínico foram permitidos, segundo o julgamento do médico assistente responsável pelo paciente. Não houve vedação a nenhum tratamento concomitante.

\subsection{Tratamento dos pacientes não incluídos}

Os pacientes que não preencheram os critérios de inclusão foram registrados indicando a causa pela qual não puderam participar do ensaio, conforme as recomendações STARD.

\subsection{Análise estatística}

a) Cálculo do tamanho amostral - um tamanho de amostra de pelo menos 23 pacientes foi calculado, assumindo uma sensibilidade de $90 \%$ e um intervalo de confiança 95\% (IC 95\%) com largura de $\pm 10 \%$ e uma prevalência de varizes esofágicas de $80 \%$ na hipertensão portal não cirrótica, segundo dados de prevalência relatados na literatura. ${ }^{12,59}$

b) Análise de resultados - $O$ processo de análise de dados do presente estudo iniciou-se com uma exploração descritiva resultando em tabelas de frequência para variáveis qualitativas, com inclusão do intervalo de confiança para a proporção (IC95\%). As estatísticas de tendência central e de dispersão foram calculadas para as variáveis quantitativas. O teste de qui-quadrado ou teste exato de Fisher foram utilizados para comparação de dois grupos no caso de variáveis qualitativas ordinais ou nominais. O teste de Mann-Whitney foi usado para a comparação de dois grupos independentes no caso das variáveis quantitativas discretas ou contínuas. O pressuposto exigido para a aplicação do teste Mann- 
Whitney foi que as duas amostras fossem independentes e aleatórias, e que as variáveis fossem numéricas ou ordinais.

A curva $\mathrm{ROC}$ foi aplicada para se avaliar a acurácia diagnóstica dos fatores que se mostraram significativamente associados à presença de varizes e de alto risco; a curva $\mathrm{ROC}$ é uma representação gráfica que ilustra o desempenho de um sistema classificador binário por meio da análise da área sob a curva. O ponto de corte discriminatório foi determinado pela melhor relação entre sensibilidade e especificidade pelo índice $\mathrm{J}$.

Para a análise do desempenho diagnóstico foram calculados os valores preditivo positivo (VPP) e negativo (VPN) e a razão de verossimilhança positiva $\left(R V_{+}\right)$e negativa $(R V-)$ para esses pontos de corte.

Todos os testes realizados levaram em consideração um $\alpha$ bidirecional de 0.05 e intervalo de confiança (IC) de $95 \%$ e foram realizados com apoio computacional dos softwares IBM SPSS 23 (Statistical Package for Social Sciences) e Excel 2010® (Microsoft Office). Os resultados foram descritos através de tabelas de freqüência simples e relativa, expressos em média e desvio padrão, mediana e intervalo interquartil e por representações gráficas de dispersão.

\subsection{Aspectos éticos}

O presente estudo foi realizado após aprovação pela Comissão ÉticoCientífica do Departamento de Gastroenterologia e Comissão de Ética para 
Análise de Projetos de Pesquisa (CAPPesq) do Hospital das Clínicas da Faculdade de Medicina da Universidade de São Paulo (HCFMUSP), em sessão de 06/08/2014, sob o número 742.321. Foram respeitados os princípios éticos estabelecidos pela Declaração de Helsinque. Todos os pacientes e/ou seus responsáveis legais receberam informações claras, em linguagem acessível, acerca dos objetivos do estudo, procedimentos necessários, riscos e benefícios esperados, assinando o termo de consentimento pós-informado. Os autores do projeto declaram que não possuem qualquer vinculação com os fabricantes dos equipamentos, não havendo qualquer relacionamento que possa ser considerado conflito de interesses.

\subsection{Localidades do estudo}

O estudo foi realizado na Divisão de Gastroenterologia e Hepatologia clínica do HCFMUSP, onde foram realizados todos os atendimentos, tanto dos pacientes da própria divisão como daqueles encaminhados do Instituto da Criança. O exame de elastografia hepática e esplênica foi realizado no setor de ultrassonografia e elastografia da citada divisão, localizado no $9^{\circ}$ andar do Instituto Central do HCFMUSP. 
- 290

\section{Resultados}




\section{RESULTADOS}

Entre agosto de 2014 a julho de 2017, foram avaliados para inclusão no estudo 892 pacientes em acompanhamento na divisão de Gastroenterologia e Hepatologia Clínica do HCFMUSP. Desses, 151 preencheram os critérios de inclusão, e 31 foram excluídos, sendo os motivos: hipertensão portal póssinusoidal $(n=21)$; avaliações incompletas $(n=7)$; esplenectomia $(n=2)$; recusa em participar do estudo $(n=1)$. A etiologia dos 120 pacientes restantes foi: oclusão da veia porta extra-hepática $(n=63)$; esquistossomose mansônica hepatoesplênica ( $n=42$ ); hipertensão portal não cirrótica idiopática (esclerose hepatoportal e hiperplasia nodular regenerativa; $n=10)$; e fibrose hepática congênita $(n=5)$, conforme mostrado na figura 6 .

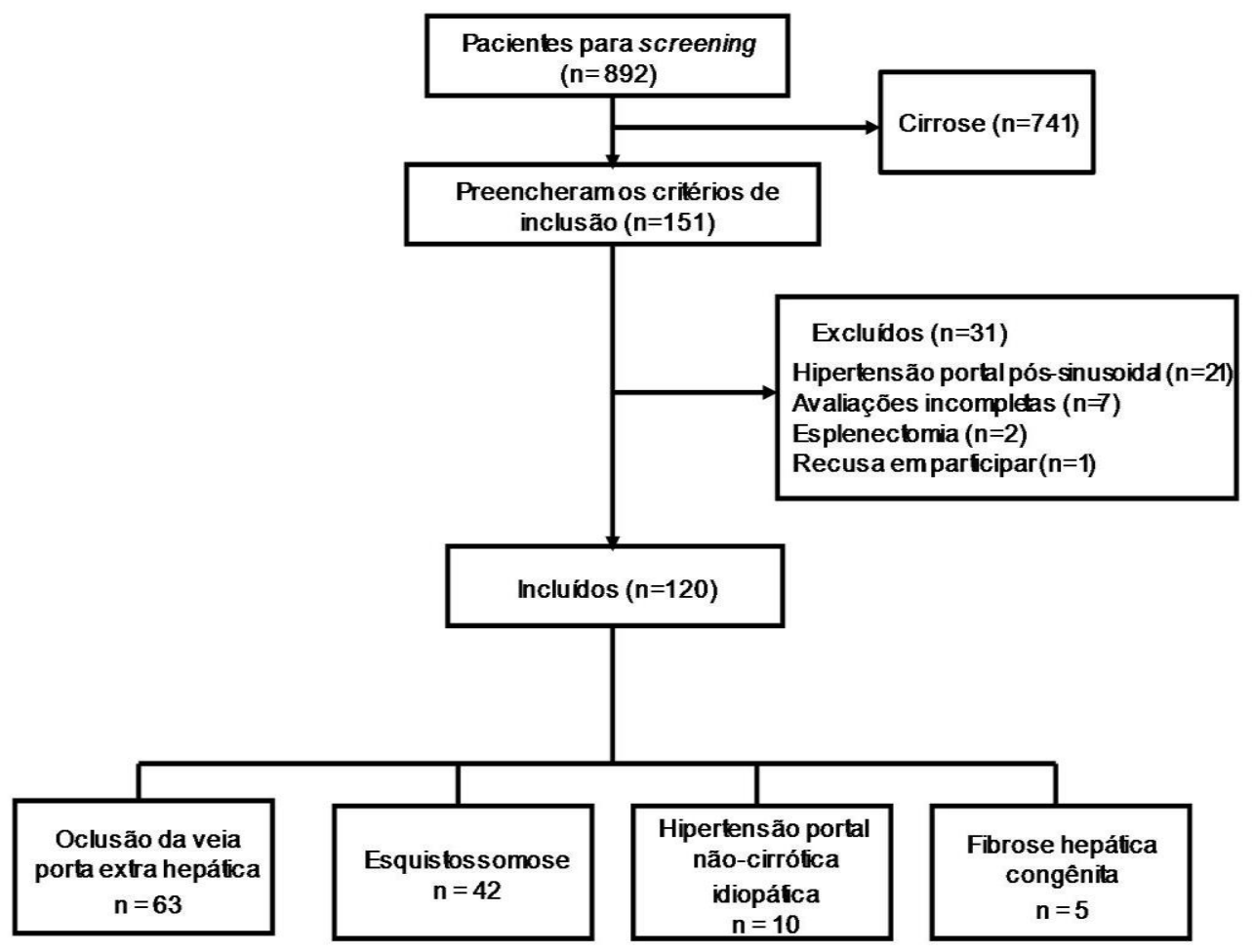


Figura 6 - Fluxograma do estudo

\subsection{Características gerais da população do estudo}

As características gerais, em relação aos parâmetros clínicos, estão apresentadas na tabela 4. Dos 120 pacientes avaliados, 95 foram adultos (79\%) e com frequência predominante do sexo masculino em $53,3 \%$ dos casos. A etiologia mais comum foi a oclusão da veia porta extra-hepática $(52,5 \%)$, seguida da esquistossomose mansônica hepatoesplênica em 35\% dos casos. Em relação a população pediátrica, foram avaliados dentre os 120 pacientes, 25 crianças (21\%), com frequência predominante do sexo masculino em $68 \%$ dos casos e com uma mediana de idade de 9,4 anos $[7,0-13,8]$. Em $96 \%$ dos casos a oclusão da veia porta extra-hepática foi a etiologia mais frequente, seguida em $4 \%$ da fibrose hepática congênita. Cinquenta e um casos apresentavam antecedente de sangramento varicoso e/ou gástrico prévios. Em relação ao uso de beta-bloqueador, 68 (56,7\%) pacientes estavam em uso, de forma contínua.

Tabela 4 - Características gerais dos pacientes

\begin{tabular}{|c|c|c|c|}
\hline \multirow[t]{2}{*}{ Parâmetros } & \multirow[t]{2}{*}{$n=120$} & \multicolumn{2}{|c|}{$\begin{array}{c}\text { Intervalo de } \\
\text { confiança de } 95 \%\end{array}$} \\
\hline & & Inferior & Superior \\
\hline \multicolumn{4}{|l|}{ Idade - anos } \\
\hline $\begin{array}{l}\text { Mediana } \\
\text { Média } \pm \text { DP }\end{array}$ & $\begin{array}{c}40,5[20,5-51,4] \\
37,6 \pm 19,3\end{array}$ & & \\
\hline Gênero masculino - no. (\%) & $64,0(53,3)$ & $44,4 \%$ & $62,1 \%$ \\
\hline \multicolumn{4}{|l|}{ Etiologia - no. (\%) } \\
\hline Oclusão da veia porta extra-hepática & $63,0(52,5)$ & $43,6 \%$ & $61,3 \%$ \\
\hline Esquistossomose & $42,0(35,0)$ & $26,9 \%$ & $43,8 \%$ \\
\hline Hipertensão portal não cirrótica idiopática & $10,0(8,3)$ & $4,4 \%$ & $14,3 \%$ \\
\hline Fibrose hepática congênita & $5,0(4,2)$ & $1,6 \%$ & $8,9 \%$ \\
\hline Sangramento digestivo prévio - no. (\%) & $51,0(42,5)$ & $33,9 \%$ & $51,4 \%$ \\
\hline Ascite - no. (\%) & $13,0(10,8)$ & $6,2 \%$ & $17,3 \%$ \\
\hline \multicolumn{4}{|l|}{ IMC $-\mathbf{k g} / \mathbf{m}^{2}$} \\
\hline Mediana & $23,8[20,6-28,0]$ & & \\
\hline Média \pm DP & $24,4 \pm 5,59$ & & \\
\hline
\end{tabular}


\begin{tabular}{llll}
\hline Uso de propranolol - no. (\%) & $68,0(56,7)$ & $47,7 \%$ & $65,3 \%$ \\
\hline
\end{tabular}

Resultados entre colchetes representam intervalo interquartil

Em relação aos parâmetros de imagem e endoscópicos, apresentados na tabela 5 , chama a atenção que $84,2 \%$ dos pacientes apresentavam varizes de esôfago, na maioria dos casos com risco de sangramento (grosso calibre).

Tabela 5 - Características dos parâmetros de imagem e endoscópicos dos pacientes

Parâmetros

$n=120$

\section{Ultrassonografia}

Diâmetro esplênico (mm)

Mediana

$150[120-175]$

Média \pm DP

$141 \pm 48$

Área do baço $\left(\mathrm{cm}^{2}\right)$

Mediana

$36[24-54]$

Média \pm DP

$41 \pm 20$

\section{Endoscopia}

Varizes - no. (\%)

$101(84,2)$

Tamanho - no. (\%)

Fino

$39(32,5)$

Grosso

$62(51,7)$

Sinais vermelhos - no. (\%)

$31(33,7)$

Resultados entre colchetes representam intervalo interquartil 
Dos 120 pacientes incluídos, setenta e quatro apresentavam trombose de porta, sendo o tipo 3 observados em $51,3 \%$ do total de casos. A classificação do tipo da trombose de porta, por etiologia, pode ser vista na tabela 6.

Tabela 6 - Classificação do tipo da trombose de veia porta por etiologia

\begin{tabular}{lcccc}
\hline $\begin{array}{l}\text { Classificação } \\
\text { da trombose } \\
\text { de porta }\end{array}$ & $\begin{array}{c}\text { Oclusão da veia } \\
\text { porta extra- } \\
\text { hepática } \\
(\mathbf{n = 6 3 )}\end{array}$ & $\begin{array}{c}\text { Esquistossomose } \\
(\mathbf{n}=42)\end{array}$ & $\begin{array}{c}\text { Hipertensão portal } \\
\text { não cirrótica } \\
\text { idiopática } \\
(\mathbf{n}=10)\end{array}$ & $\begin{array}{c}\text { Fibrose } \\
\text { hepática } \\
\text { congênita } \\
(\mathbf{n}=5)\end{array}$ \\
\hline Tipo 1 & $29(46 \%)$ & $1(10 \%)$ & $1(20 \%)$ \\
Tipo 2a & 0 & 0 & 0 & 0 \\
Tipo 2b & 0 & $2(5 \%)$ & $1(10 \%)$ & 0 \\
Tipo 3 & $34(54 \%)$ & $2(5 \%)$ & $1(10 \%)$ & $1(20 \%)$ \\
\hline Total & $63(100 \%)$ & $6(15 \%)$ & $3(30 \%)$ & $2(40 \%)$ \\
\hline
\end{tabular}

\subsection{Características da população quanto aos parâmetros laboratoriais}

A avaliação laboratorial contemplou os exames de função hepática, renal e hematológicos. Os testes bioquímicos hepáticos se mostraram dentro dos valores de normalidade, evidenciando a função hepática preservada dessa população, com uma mediana (intervalo interquartil) para o valor de albumina sérica em 4,2 g/dL $(4,0$ - 4,5) e proteínas totais séricas $6,95 \mathrm{mg} / \mathrm{dL}$ (6,55 7,40). Esses resultados podem ser observados na tabela 7. 
Tabela 7 - Resultados laboratoriais

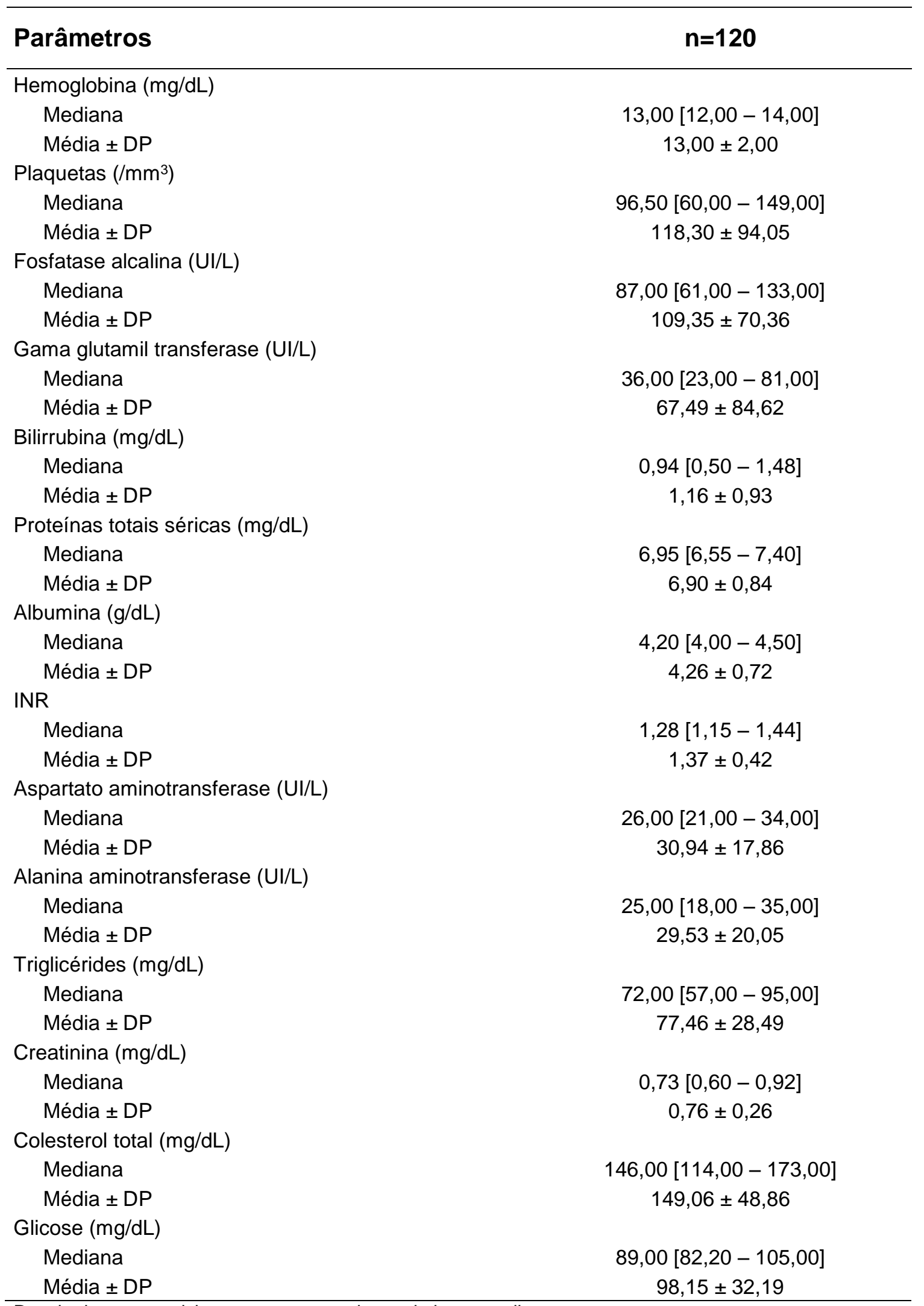

Resultados entre colchetes representam intervalo interquartil 


\subsection{Resultados globais da elastografia transitória por FibroScan}

A elastografia hepática por FibroScan apresentou valor mediano de 6,50 kPa (intervalo interquartil 5,0 - 9,3), que são compatíveis com hipertensão portal não cirrótica $(<12,5 \mathrm{KPa})$; na elastografia esplênica o valor mediano foi de $72,0 \mathrm{kPa}$ (intervalo interquartil 41,6 - 75,0).

\subsection{Resultados globais da elastografia por ARFI}

No método ARFI hepático o valor mediano foi de $1,27 \mathrm{~m} / \mathrm{s}$ (intervalo interquartil 1,13-1,42), compatível com hipertensão portal não cirrótica. No ARFI esplênico obtivemos valores medianos de $3,24 \mathrm{~m} / \mathrm{s}$ (intervalo interquartil $2,71-3,55)$.

\subsection{Resultados globais dos índices APRI, FIB-4 e razão plaqueta/baço}

Em nossa casuística obtivemos para o índice APRI o valor mediano (intervalo interquartil) de 0,75 (0,39-1,38). Para o índice FIB-4, valor mediano (intervalo interquartil) de 1,27 (0,43-2,77). Na razão plaqueta/baço, a mediana (intervalo interquartil) foi 723 (335-1194). Tomados em conjunto, esse resultados indicam valores previsivelmente compatíveis com hipertensão portal não cirrótica.

A tabela 8 sumaria os resultados globais dos índices APRI, FIB-4, razão plaqueta/baço e das elastografias transitória por FibroScan e ARFI. As figuras de 7 a 13 apresentam os gráficos desses resultados. 
Tabela 8 - Resultados globais dos métodos não invasivos para detecção de hipertensão portal

\section{Parâmetros $\quad n=120$}

Elastografia hepática - FibroScan (kPa)

Mediana

Média \pm DP

ARFI hepático $(\mathrm{m} / \mathrm{s})$

Mediana

Média \pm DP

Elastografia esplênica - FibroScan (kPa)

Mediana

Média \pm DP

ARFI esplênico $(\mathrm{m} / \mathrm{s})$

Mediana

Média \pm DP

APRI

Mediana

Média \pm DP

FIB-4

Mediana

Média \pm DP

Razão plaqueta/baço

Mediana

Média \pm DP
$6,50[5,00-9,30]$

$7,53 \pm 3,75$

$1,27[1,13-1,42]$

$1,32 \pm 0,34$

$72,0[41,6-75,0]$

$56,28 \pm 20,81$

$3,24[2,71-3,55]$

$3,16 \pm 0,61$

$0,75[0,39-1,38]$

$1,11 \pm 1,08$

$1,27[0,43-2,77]$

$2,41 \pm 3,11$

723 [335 - 1194]

$1182 \pm 1730$

Resultados entre colchetes representam intervalo interquartil 


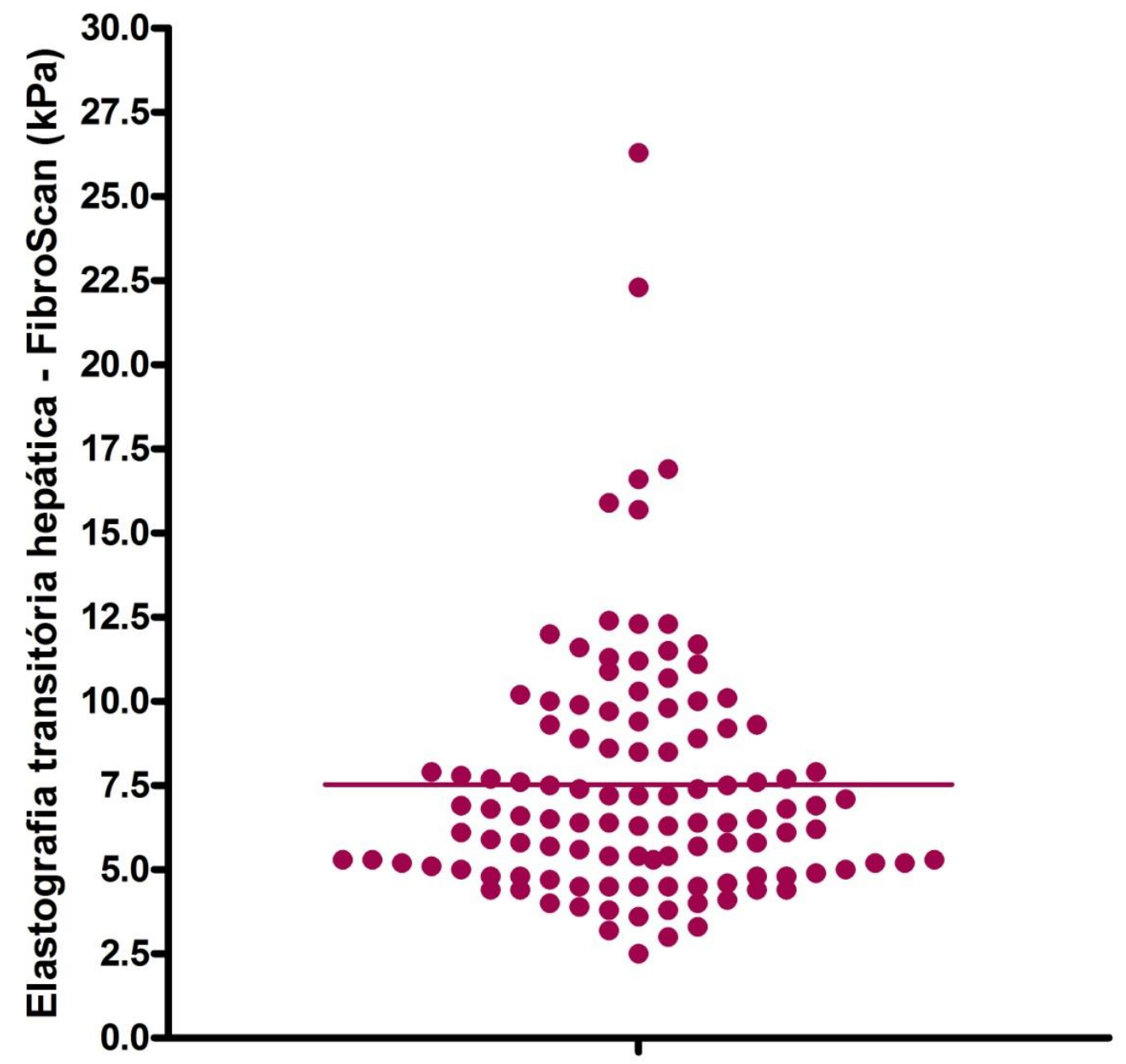

Figura 7 - Resultados globais da elastografia transitória hepática por FibroScan, nos pacientes com hipertensão portal não cirrótica 


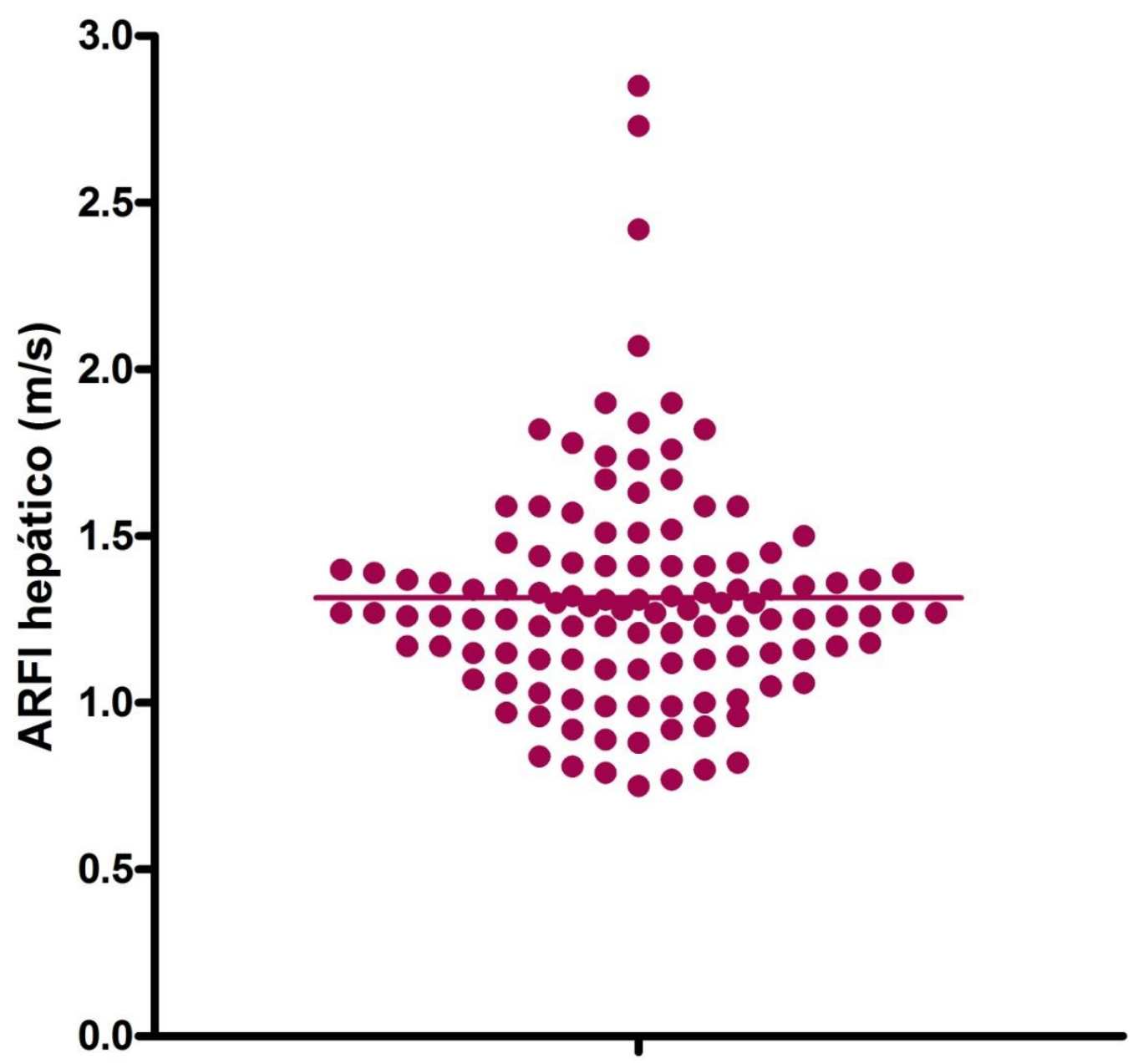

Figura 8 - Resultados globais do método ARFI hepático, nos pacientes com hipertensão portal não cirrótica 


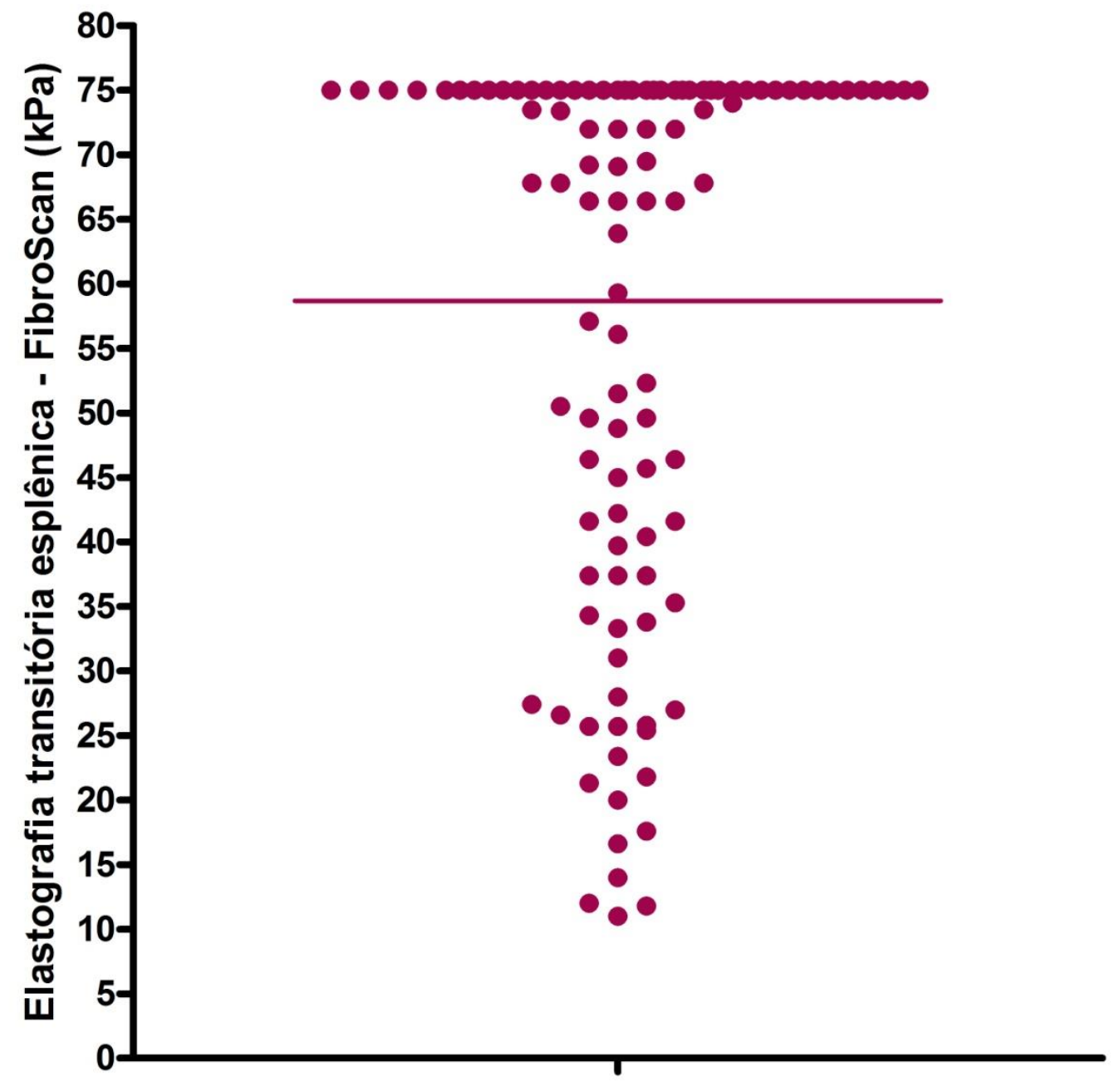

Figura 9 - Resultados globais da elastografia transitória esplênica por FibroScan, nos pacientes com hipertensão portal não cirrótica 


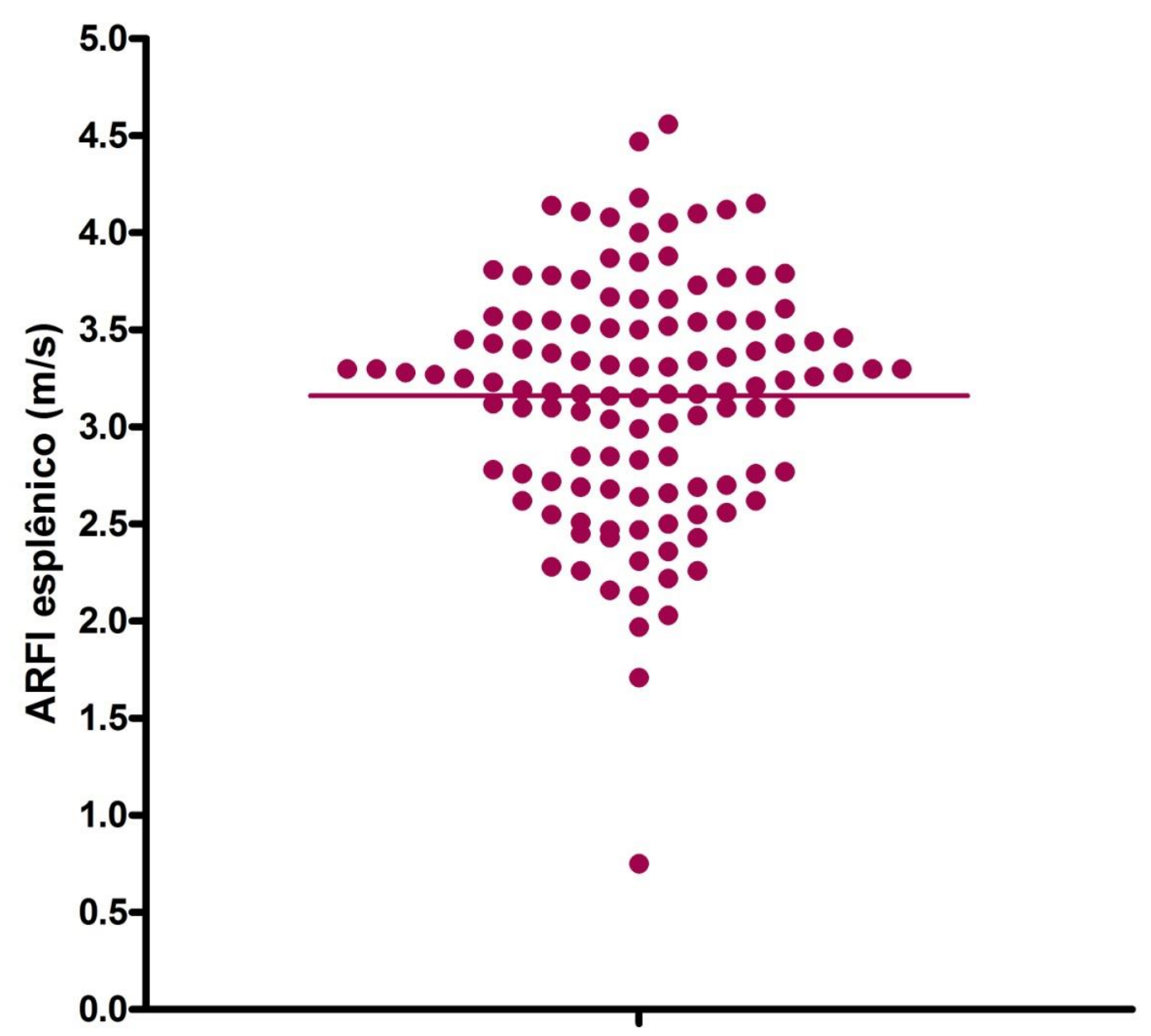

Figura 10 - Resultados globais do método ARFI esplênico, nos pacientes com hipertensão portal não cirrótica 


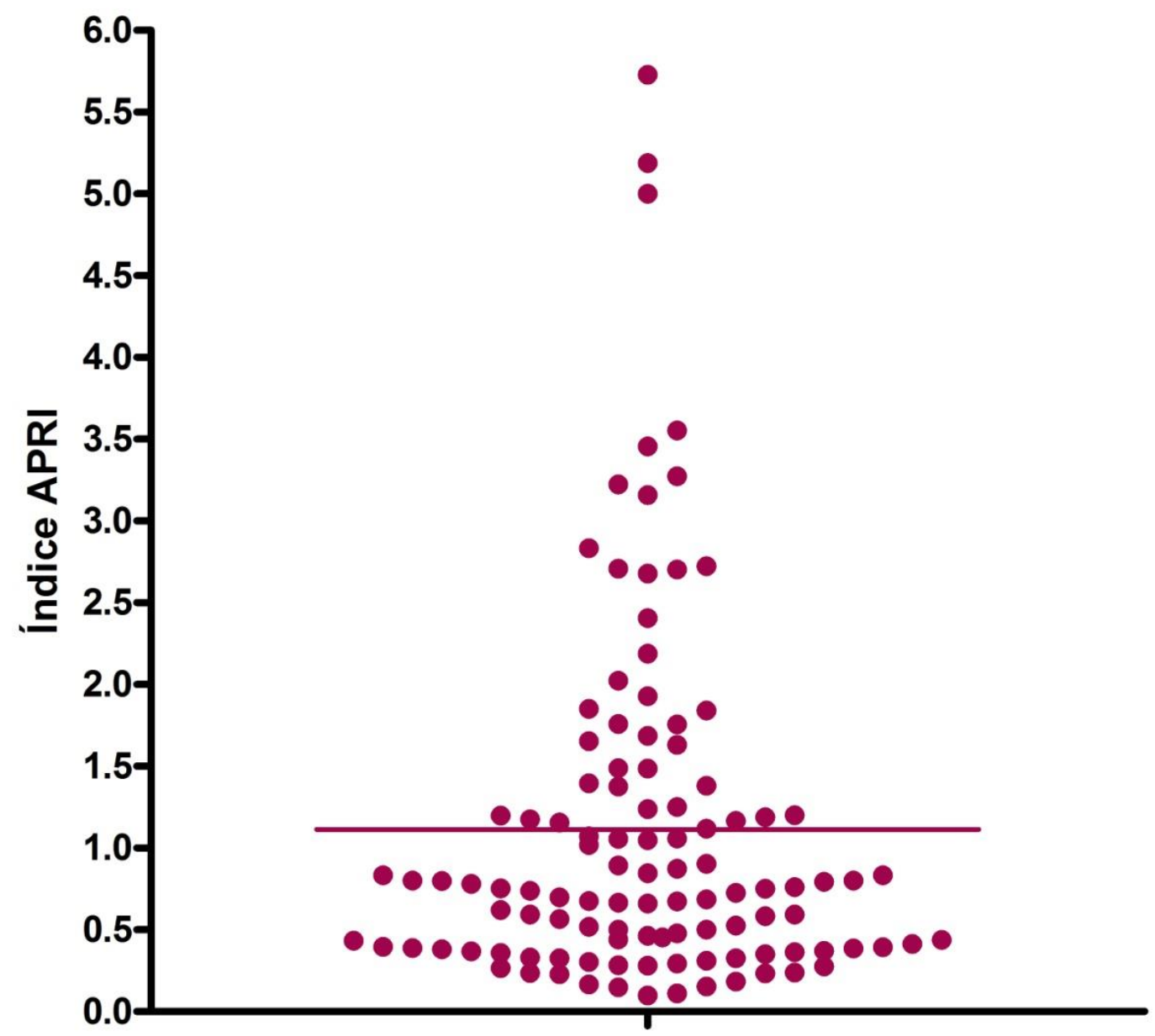

Figura 11 - Resultados globais do índice APRI, nos pacientes com hipertensão portal não cirrótica 


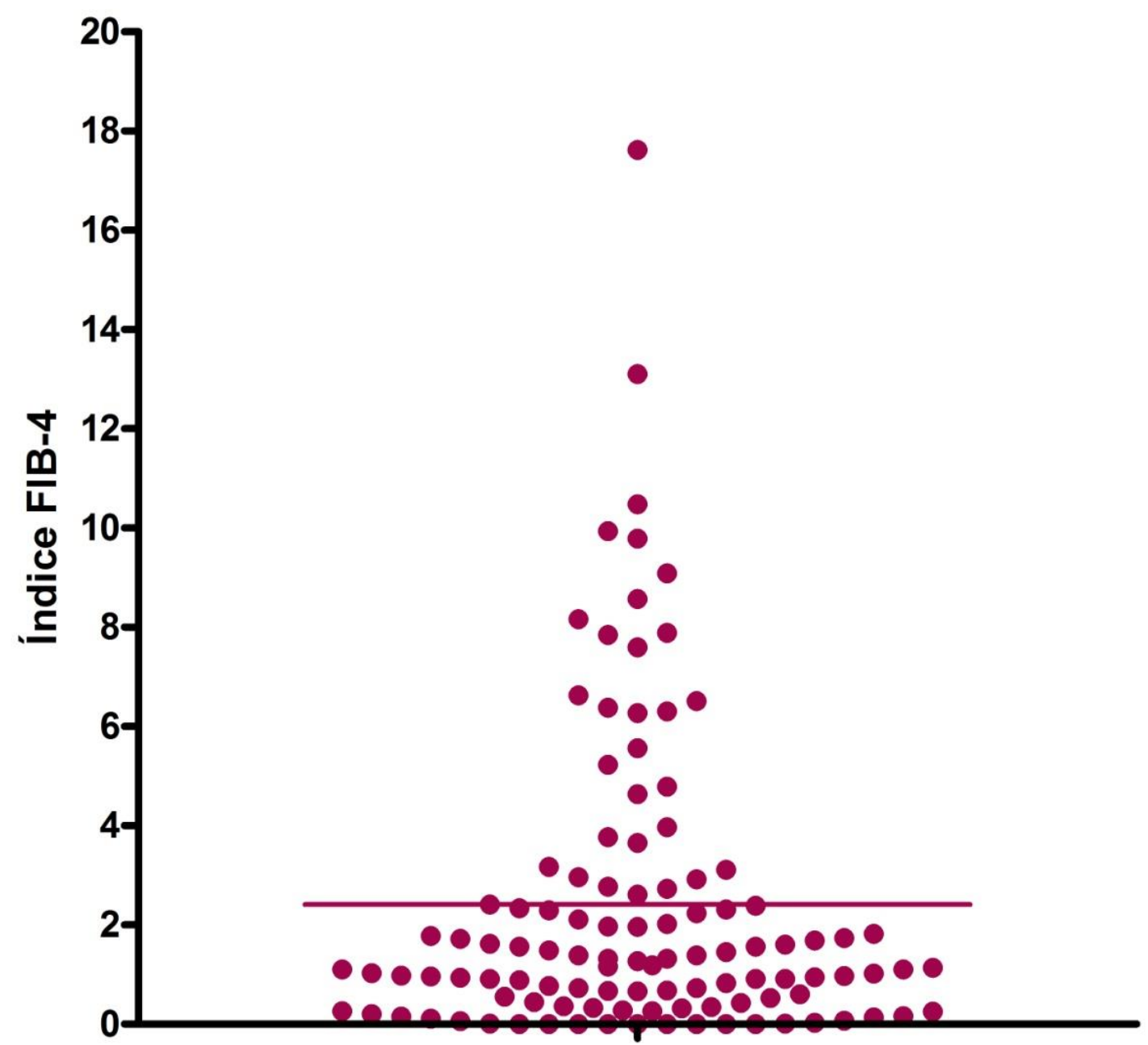

Figura 12 - Resultados globais do índice FIB-4, nos pacientes com hipertensão portal não cirrótica 


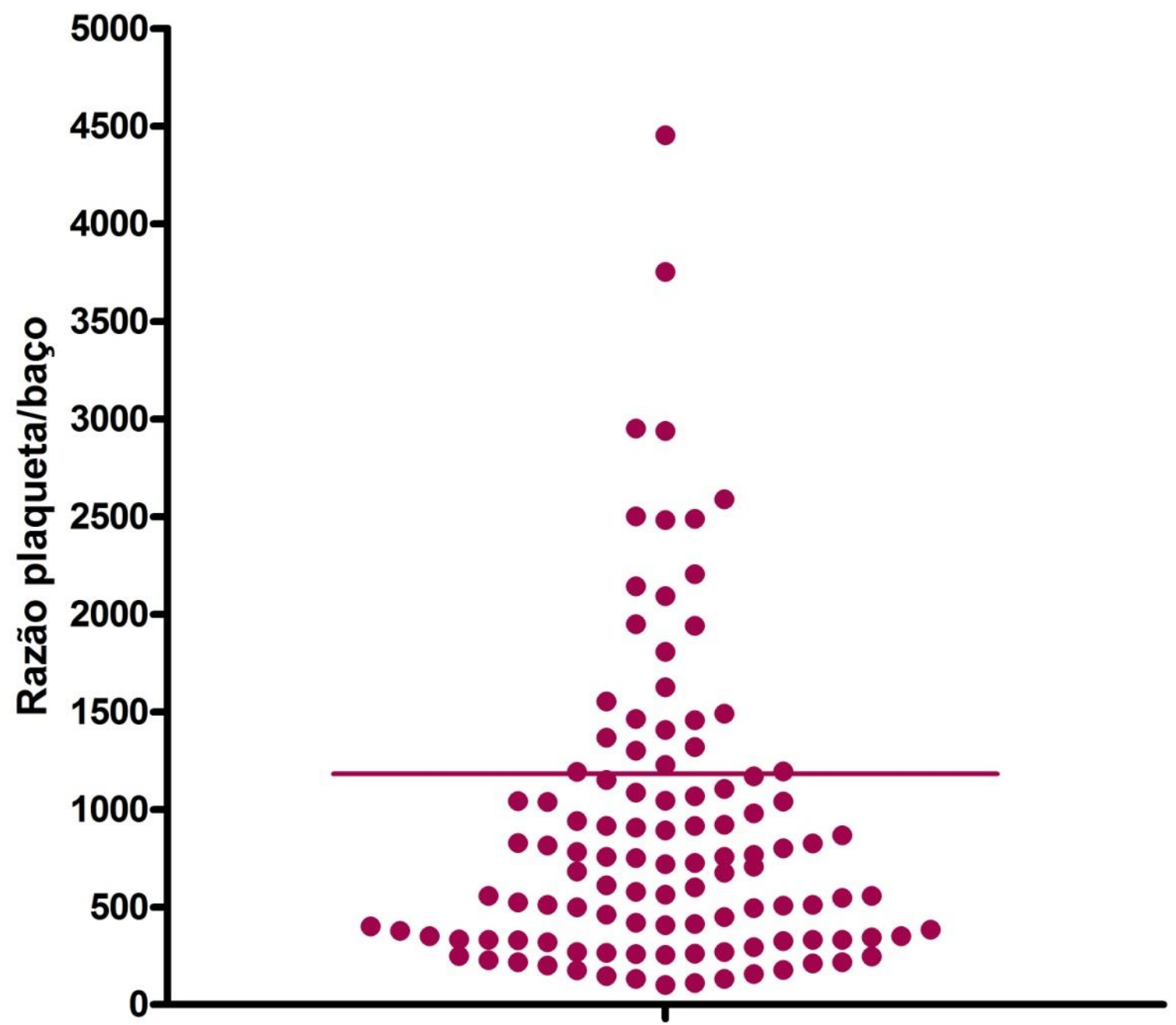

Figura 13 - Resultados globais da razão plaqueta/baço, nos pacientes com hipertensão portal não cirrótica 


\subsection{Resultados da elastografia transitória por FibroScan e ARFI e dos índices APRI, FIB-4 e razão plaqueta/baço segundo a etiologia subjacente da hipertensão portal não cirrótica}

Os valores medianos (intervalo interquartil) de elastografia hepática transitória por FibroScan foram de 5,5 kPa $(4,6$ - 6,5) na oclusão da veia porta extra-hepática; 8,7 kPa $(6,5$ - 10,1) na esquistossomose; 10,2 kPa $(7,2$ - 12,4) na hipertensão portal não cirrótica idiopática e $8,5 \mathrm{kPa}(7,2-11,7)$ na fibrose hepática congênita, enquanto os valores de ARFI foram de 1,26 m/s $(1,1-1,3)$; $1,29 \mathrm{~m} / \mathrm{s}(1,1-1,4) ; 1,36 \mathrm{~m} / \mathrm{s}(1,2-1,2) ; 1,59 \mathrm{~m} / \mathrm{s}(1,4-1,6) ;$ respectivamente.

Os valores medianos de elastografia esplênica transitória por FibroScan foram de 75,0 kPa $(45,7$ - 75,0) na oclusão da veia porta extra-hepática; 66,4 $\mathrm{kPa}(33,8$ - 75,0) na esquistossomose; 52,4 kPa $(34,3$ - 75,0) na hipertensão portal não cirrótica idiopática e $37,4 \mathrm{kPa}(27,5$ - 75,0) na fibrose hepática congênita, enquanto os valores de ARFI foram de $3,28 \mathrm{~m} / \mathrm{s}(2,85-3,55) ; 3,0$ $\mathrm{m} / \mathrm{s}(2,6-3,4) ; 2,7 \mathrm{~m} / \mathrm{s}(2,3-3,3) ; 2,76 \mathrm{~m} / \mathrm{s}(2,26-3,35) ;$ respectivamente.

A tabela 9 sumaria os resultados por etiologia das elastografias transitórias por FibroScan e ARFI e dos índices APRI, FIB-4 e razão plaqueta/baço. As figuras de 14 a 20 apresentam os gráficos desses resultados. 
Tabela 9 - Métodos não invasivos para detecção de hipertensão portal por etiologia subjacente

\begin{tabular}{|c|c|c|c|c|}
\hline Parâmetros & $\begin{array}{l}\text { Oclusão da veia } \\
\text { porta extra- } \\
\text { hepática }\end{array}$ & Esquistossomose & $\begin{array}{c}\text { HPNC } \\
\text { Idiopática }\end{array}$ & $\begin{array}{c}\text { Fibrose hepática } \\
\text { congênita }\end{array}$ \\
\hline \multicolumn{5}{|c|}{ Elastografia hepática } \\
\hline \multicolumn{5}{|l|}{ FibroScan (kPa) } \\
\hline Mediana & $5,5[4,6-6,5]$ & $8,7[6,5-10,1]$ & $10,2[7,2-12,4]$ & $8,5[7,2-11,7]$ \\
\hline Média \pm DP & $5,9 \pm 1,8$ & $8,9 \pm 3,9$ & $10,6 \pm 3,9$ & $10,3 \pm 4,1$ \\
\hline \multicolumn{5}{|c|}{ ARFI hepático $(\mathrm{m} / \mathrm{s})$} \\
\hline Mediana & $1,26[1,1-1,3]$ & $1,29[1,1-1,4]$ & $1,36[1,2-1,2]$ & $1,59[1,4-1,6]$ \\
\hline Média \pm DP & $1,27 \pm 0,23$ & $1,35 \pm 0,45$ & $1,43 \pm 0,40$ & $1,55 \pm 0,39$ \\
\hline \multicolumn{5}{|c|}{ Elastografia esplênica } \\
\hline \multicolumn{5}{|c|}{ FibroScan (kPa) } \\
\hline Mediana & $75,0[45,7-75,0]$ & $66,4[33,8-75,0]$ & $52,4[34,3-75,0]$ & $37,4[27,5-75,0]$ \\
\hline Média \pm DP & $60,82 \pm 20,56$ & $54,16 \pm 22,94$ & $52,64 \pm 21,97$ & $48,5 \pm 24,86$ \\
\hline \multicolumn{5}{|c|}{ ARFI esplênico (m/s) } \\
\hline Mediana & $3,28[2,85-3,55]$ & $3,0[2,6-3,4]$ & $2,7[2,3-3,3]$ & $2,76[2,26-3,35]$ \\
\hline Média \pm DP & $3,22 \pm 0,62$ & $3,01 \pm 0,74$ & $2,86 \pm 0,53$ & $2,8 \pm 0,55$ \\
\hline \multicolumn{5}{|l|}{ APRI } \\
\hline Mediana & $0,5[0,3-0,9]$ & $1,0[0,6-1,7]$ & $0,8[0,3-1,2]$ & $0,5[0,3-2,2]$ \\
\hline Média \pm DP & $0,77 \pm 0,65$ & $1,34 \pm 1,13$ & $1,27 \pm 1,42$ & $1,12 \pm 1,19$ \\
\hline \multicolumn{5}{|l|}{ FIB-4 } \\
\hline Mediana & $1,1[0,7-2,0]$ & $3,7[2,2-6,5]$ & $1,6[1,0-5,0]$ & $1,5[0,66-4,72]$ \\
\hline Média \pm DP & $1,63 \pm 1,73$ & $5,01 \pm 3,92$ & $3,26 \pm 3,15$ & $2,45 \pm 3,07$ \\
\hline \multicolumn{5}{|c|}{ Razão plaqueta/baço } \\
\hline Mediana & $293,3[142,9-907,1]$ & $166,7[70,37-1045]$ & $247,2[88,89-866,7]$ & $611,8[357,3-952,6]$ \\
\hline Média \pm DP & $567,7 \pm 570,3$ & $624,7 \pm 839,5$ & $585,3 \pm 830,0$ & $646,3 \pm 335,3$ \\
\hline
\end{tabular}




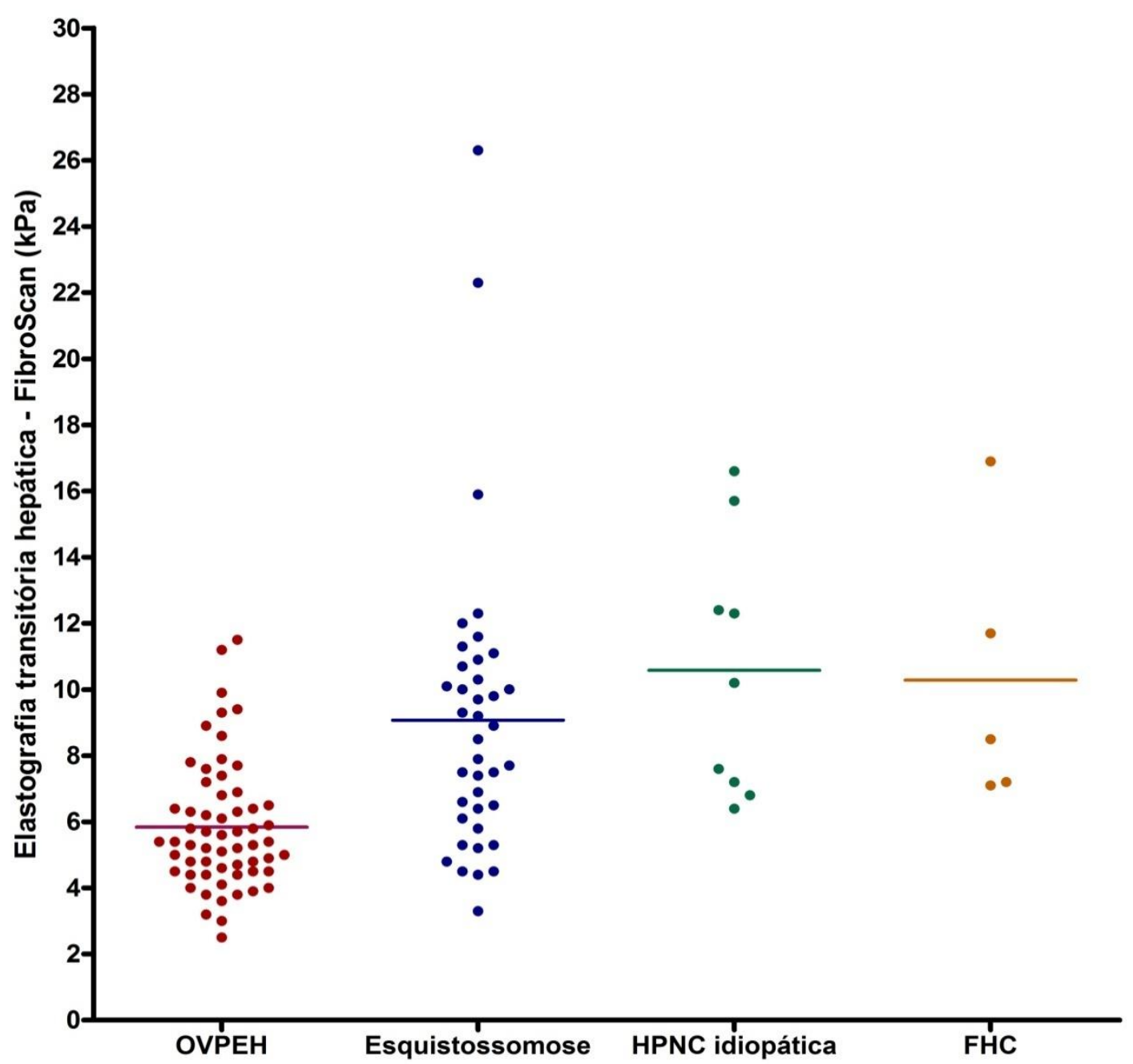

${ }^{*}$ OVPEH = Oclusão da veia porta extra-hepática; HPNC = Hipertensão portal não cirrótica; FHC = Fibrose hepática congênita

Figura 14 - Resultados por etiologia da elastografia hepática transitória por FibroScan, nos pacientes com hipertensão portal não cirrótica 


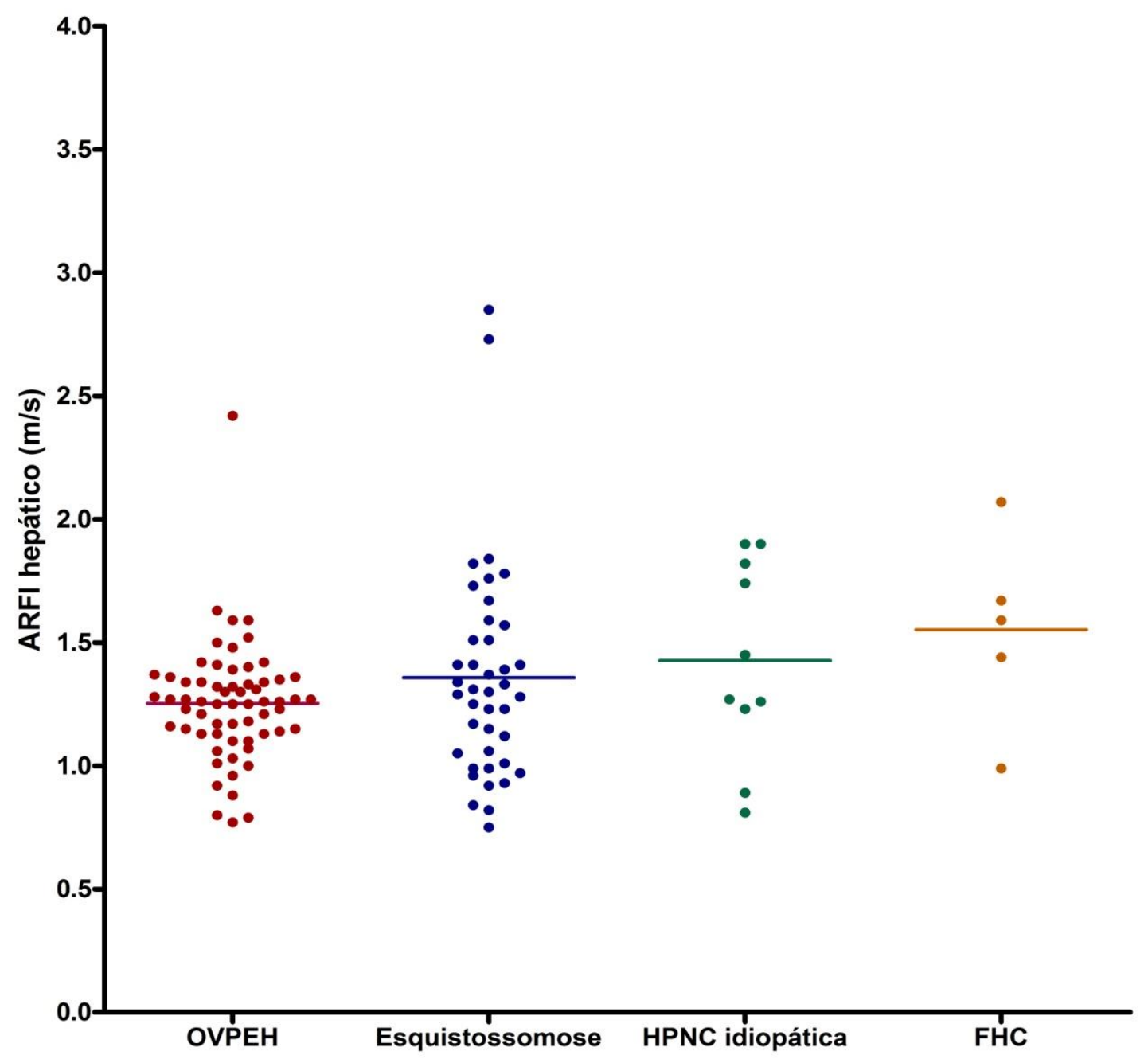

${ }^{*}$ OVPEH = Oclusão da veia porta extra-hepática; HPNC = Hipertensão portal não cirrótica; FHC = Fibrose hepática congênita

Figura 15 - Resultados por etiologia do método ARFI hepático, nos pacientes com hipertensão portal não cirrótica 


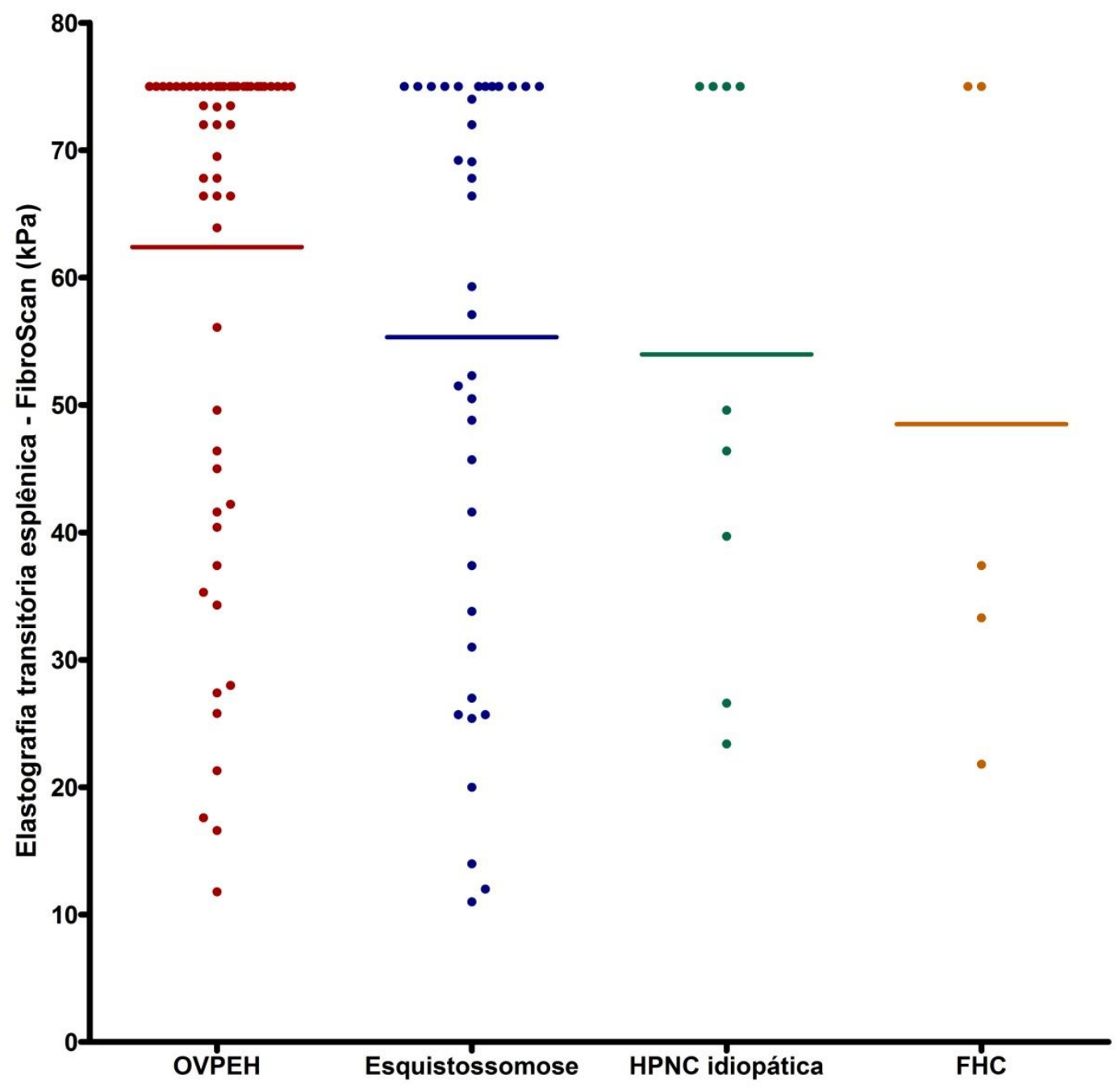

${ }^{*}$ OVPEH = Oclusão da veia porta extra-hepática; HPNC = Hipertensão portal não cirrótica; FHC = Fibrose hepática congênita

Figura 16 - Resultados por etiologia da elastografia esplênica transitória por FibroScan, nos pacientes com hipertensão portal não cirrótica 


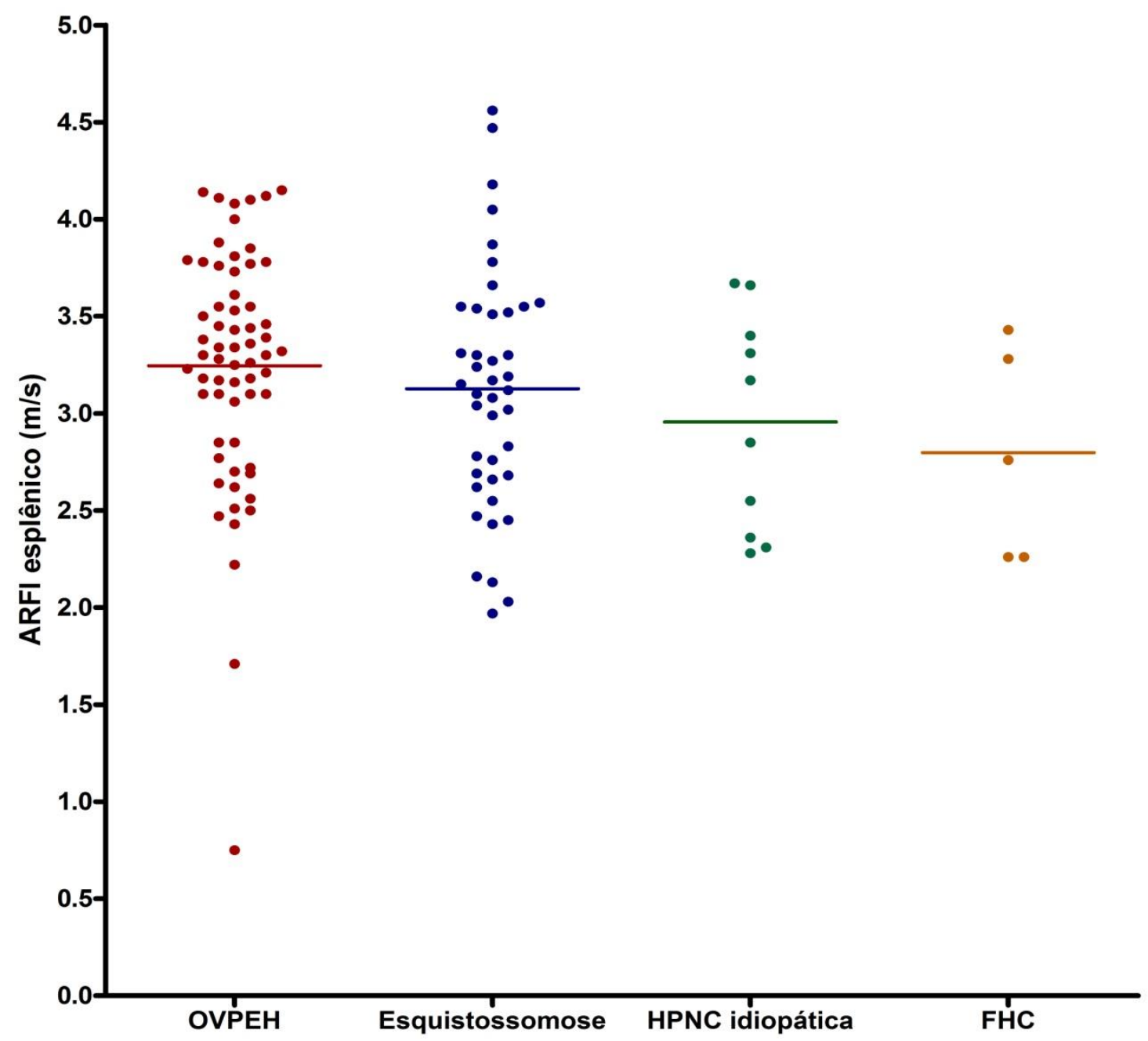

${ }^{*}$ OVPEH = Oclusão da veia porta extra-hepática; HPNC = Hipertensão portal não cirrótica; FHC = Fibrose hepática congênita

Figura 17 - Resultados por etiologia do método ARFI esplênico, nos pacientes com hipertensão portal não cirrótica 


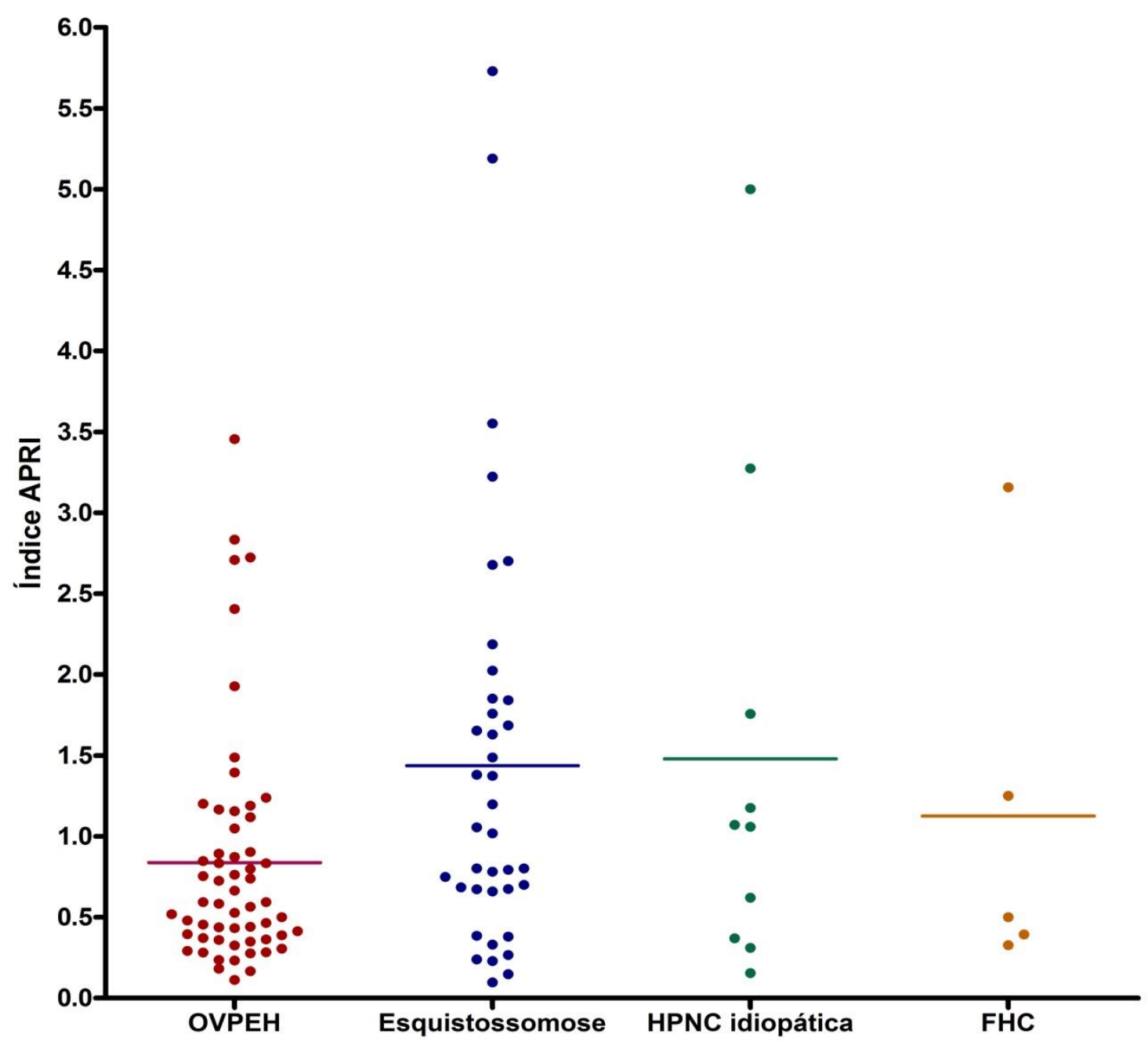

${ }^{*}$ OVPEH = Oclusão da veia porta extra-hepática; HPNC = Hipertensão portal não cirrótica; FHC = Fibrose hepática congênita

Figura 18 - Resultados por etiologia do índice APRI, nos pacientes com hipertensão portal não cirrótica 


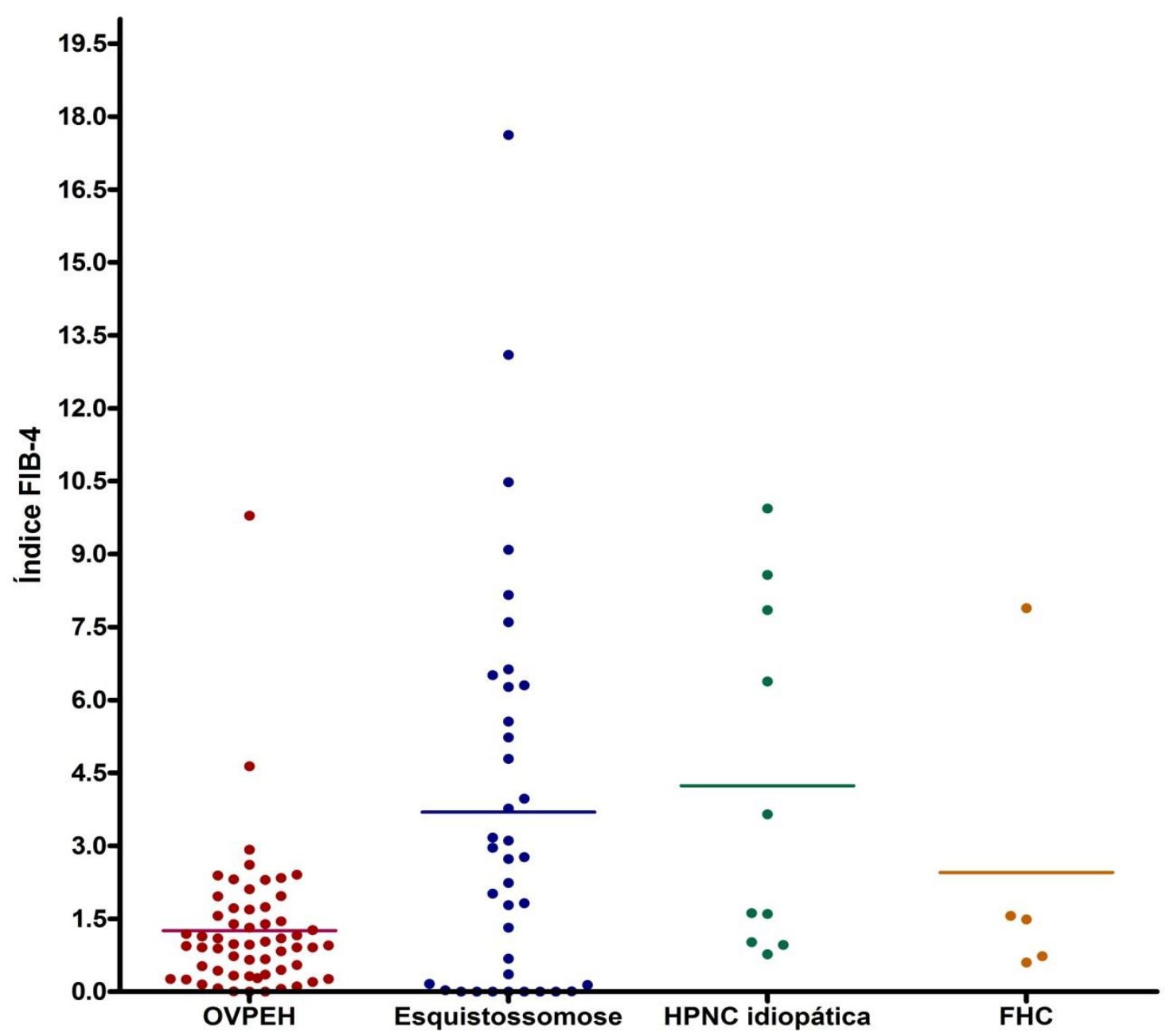

${ }^{*}$ OVPEH = Oclusão da veia porta extra-hepática; HPNC = Hipertensão portal não cirrótica; FHC = Fibrose hepática congênita

Figura 19 - Resultados por etiologia do índice FIB-4, nos pacientes com hipertensão portal não cirrótica 


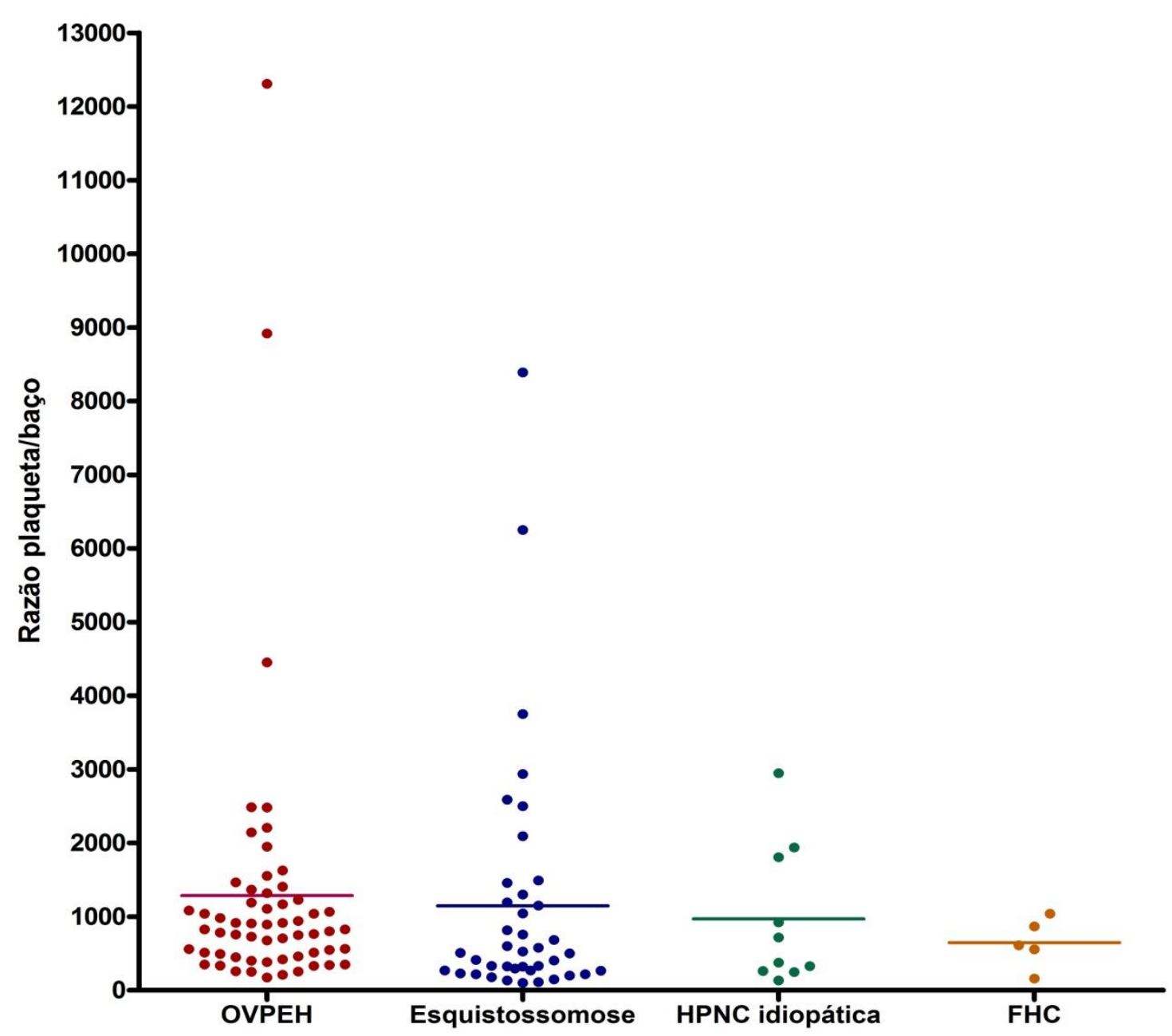

${ }^{*}$ OVPEH = Oclusão da veia porta extra-hepática; HPNC = Hipertensão portal não cirrótica; FHC = Fibrose hepática congênita

Figura 20 - Resultados por etiologia da razão plaqueta/baço, nos pacientes com hipertensão portal não cirrótica

Vale ressaltar que entre os pacientes com etiologia de hipertensão portal não cirrótica, dez pacientes apresentaram valor de elastografia transitória hepática por FibroScan igual ou maior que $12 \mathrm{kPa}$. As tabelas 10 e 11 sumariam as características basais, por imagem e anatomopatológico desses pacientes. 
Tabela 10 - Características basais dos pacientes com valor de elastografia hepática transitória por FibroScan $\geq 12 \mathrm{kPa}(\mathrm{n}=10)$

\begin{tabular}{|c|c|c|c|c|c|c|}
\hline Idade & Gênero & Etiologia & IMC & Ascite & $\begin{array}{c}\text { Tamanho } \\
\text { das varizes }\end{array}$ & $\begin{array}{c}\text { Trombose } \\
\text { portal }\end{array}$ \\
\hline 57 & Feminino & HPNC & 23,2 & Leve & Grosso & Ausente \\
\hline 41 & Masculino & Esquistossomose & 23,4 & Leve & Fino & Ausente \\
\hline 24 & Masculino & HPNC & 17,2 & Ausente & Fino & Ausente \\
\hline 20 & Feminino & $\mathrm{FHC}$ & 39,0 & Ausente & Fino & Ausente \\
\hline 43 & Feminino & HPNC & 19,3 & Ausente & Fino & Ausente \\
\hline 48 & Masculino & Esquistossomose & 20,5 & Ausente & Grosso & Ausente \\
\hline 81 & Feminino & Esquistossomose & 20,8 & Ausente & Ausente & Ausente \\
\hline 62 & Feminino & Esquistossomose & 27,83 & Ausente & Grosso & Ausente \\
\hline 50 & Masculino & Esquistossomose & 26,23 & Ausente & Grosso & Ausente \\
\hline 35 & Feminino & HPNC & 23,1 & Leve & Ausente & Ausente \\
\hline
\end{tabular}


Tabela 11 - Características dos pacientes com valor de elastografia hepática transitória por FibroScan $\geq 12 \mathrm{kPa}$, segundo os achados por imagem e relatório anatomopatológico $(n=10)$

\begin{tabular}{|c|c|c|c|c|c|}
\hline $\begin{array}{c}\text { Data da } \\
\text { inclusão }\end{array}$ & $\begin{array}{l}\text { Evolução } \\
\text { doença } \\
\text { (anos) }\end{array}$ & $\begin{array}{c}\text { FibroScan } \\
\text { hepático } \\
\text { (kPa) }\end{array}$ & $\begin{array}{c}\text { ARFI } \\
\text { hepático } \\
(\mathrm{m} / \mathrm{s})\end{array}$ & $\begin{array}{l}\text { Data da } \\
\text { biópsia }\end{array}$ & Biópsia hepática \\
\hline & & & & & Esclerose \\
\hline $18 / 12 / 2013$ & 4 & 15,7 & 1,27 & $04 / 07 / 2014$ & $\begin{array}{l}\text { hepatoportal sem } \\
\text { fibrose significativa }\end{array}$ \\
\hline 20/02/2014 & 5 & 12 & 1,57 & $25 / 11 / 2009$ & $\begin{array}{l}\text { Compatível com } \\
\text { esquistossomose }\end{array}$ \\
\hline 05/08/2014 & 12 & 12,4 & 1,74 & - & Não realizada \\
\hline $19 / 08 / 2014$ & 6 & 16,9 & 0,99 & 13/11/1998 & $\begin{array}{c}\text { Fibrose hepática } \\
\text { congênita }\end{array}$ \\
\hline & & & & & Esclerose \\
\hline $19 / 05 / 2014$ & 16 & 12,3 & 1,9 & $14 / 11 / 2013$ & $\begin{array}{c}\text { hepatoportal sem } \\
\text { fibrose significativa }\end{array}$ \\
\hline $22 / 11 / 2013$ & 27 & 26,3 & 1,73 & - & Não realizada \\
\hline 01/07/2016 & 39 & 12,3 & 2,73 & - & Não realizada \\
\hline 02/12/2016 & 40 & 22,3 & 1,84 & - & Não realizada \\
\hline 06/12/2016 & \pm 3 & 15,9 & 1,59 & - & Não realizada \\
\hline \multirow{3}{*}{$17 / 07 / 2014$} & & & & 19/12/2012 & $\begin{array}{l}\text { Esclerose } \\
\text { hepatoportal sem } \\
\text { fibrose significativa }\end{array}$ \\
\hline & 4 & 16,6 & 1,82 & & \\
\hline & & & & $04 / 05 / 2017$ & $\begin{array}{c}\text { Hepatopatia crônica } \\
\text { em transformação } \\
\text { nodular }\end{array}$ \\
\hline
\end{tabular}




\subsection{Comparação entre a população do estudo, segundo a presença de varizes esofágicas}

\subsubsection{Características basais}

Na comparação, ambos mostraram características clínicas e demográficas semelhantes, conforme exposto na Tabela 12.

Tabela 12 - Comparação entre os pacientes de acordo com a presença ou não de varizes esofágicas, segundo as características gerais $(=120)$

\section{Presença de varizes}

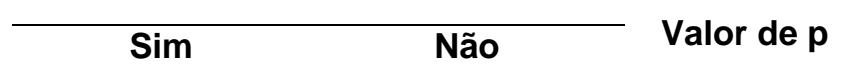

\begin{tabular}{|c|c|c|c|}
\hline \multicolumn{4}{|l|}{ Idade - anos } \\
\hline Mediana & $40,5[20,3-51,3]$ & $35,6[20,8-51,4]$ & \multirow[t]{2}{*}{0,967} \\
\hline Média \pm DP & $37,5 \pm 18,9$ & $38,5 \pm 22,3$ & \\
\hline Gênero masculino - no. (\%) & $54(52,4)$ & $10(58,8)$ & 0,794 \\
\hline \multicolumn{4}{|l|}{ Etiologia - no. (\%) } \\
\hline Oclusão da veia porta extra-hepática & $54(52,4)$ & $9(52,9)$ & \multirow{4}{*}{0,687} \\
\hline Esquistossomose & $37(35,9)$ & $5(29,4)$ & \\
\hline Hipertensão portal não cirrótica idiopática & $8(7,8)$ & $2(11,8)$ & \\
\hline Fibrose hepática congênita & $4(3,9)$ & $1(5,9)$ & \\
\hline Sangramento digestivo prévio - no. (\%) & $47(45,6)$ & $4(23,5)$ & 0,114 \\
\hline Ascite - no. (\%) & $11(10,7)$ & $2(11,8)$ & 1,000 \\
\hline \multicolumn{4}{|l|}{$\mathrm{IMC}-\mathrm{kg} / \mathrm{m}^{2}$} \\
\hline Mediana & $23,92[20,65-28,08]$ & $\begin{array}{c}22,86[19,84- \\
29,89]\end{array}$ & \multirow[t]{2}{*}{0,872} \\
\hline Média \pm DP & $24,34 \pm 5,47$ & $24,67 \pm 6,52$ & \\
\hline Uso de propranolol - no. (\%) & $62(60,2)$ & $6(35,3)$ & 0,067 \\
\hline
\end{tabular}

Resultados entre colchetes representam intervalo interquartil 
Observa-se que na população com a presença de varizes esofágicas, $45,6 \%$ dos pacientes apresentaram sangramento prévio e 10,7\% ascite. 0 intervalo médio entre a realização da endoscopia e das elastografias transitórias hepática e esplênica, pelos métodos FibroScan e ARFI foi de 5,04 meses, e não foram considerados exames com intervalo maior que 12 meses. Nesse estudo foram considerados antecedentes de sangramento tanto esofágico, quanto gástrico. Em relação à ascite, um paciente apresentava ascite moderada e os demais $(n=12)$ apresentavam ascite leve.

\subsubsection{Características dos parâmetros de imagem dos pacientes em relação a presença ou não de varizes esofágicas}

Na comparação entre os pacientes tendo como relação os parâmetros de imagem, nota-se que o diâmetro esplênico nos pacientes com varizes esofágicas foi de $150 \mathrm{~mm}$ [130-180], enquanto nos pacientes com ausência de varizes esofágicas foi de $120 \mathrm{~mm}$ [100-150], $\mathrm{p}=0,015$. Consequentemente a área do baço entre os pacientes com presença de varizes esofágicas foi maior com uma mediana de $36 \mathrm{~cm}^{2}$, enquanto os pacientes com ausência de varizes esofágicas apresentaram uma mediana de $25 \mathrm{~cm}^{2}(p=0,005)$. (tabela 13). 
Tabela 13 - Comparação entre os pacientes de acordo com a presença ou não de varizes esofágicas, segundo os parâmetros radiológicos $(n=120)$

\begin{tabular}{|c|c|c|c|}
\hline \multirow{2}{*}{ Parâmetros } & \multicolumn{2}{|c|}{ Presença de varizes } & \multirow{2}{*}{ Valor de $p$} \\
\hline & Sim & Não & \\
\hline \multicolumn{4}{|c|}{ Ultrassonografia } \\
\hline \multicolumn{4}{|c|}{ Diâmetro esplênico (mm) } \\
\hline Mediana & $150[130-180]$ & 120 [100-150] & \multirow{2}{*}{0,015} \\
\hline Média \pm DP & $144 \pm 50$ & $124 \pm 33$ & \\
\hline \multicolumn{4}{|c|}{ Área do baço $\left(\mathrm{cm}^{2}\right)$} \\
\hline Mediana & 36 [28-60] & 25 [20-32] & \multirow{2}{*}{0,005} \\
\hline Média \pm DP & $43 \pm 20$ & $29 \pm 13$ & \\
\hline
\end{tabular}

Resultados entre colchetes representam intervalo interquartil

Mesmo apresentando diferença estatística, quando os dados são analisados graficamente, observa-se que há sobreposição entre os grupos. (Figura 21 e 22). 


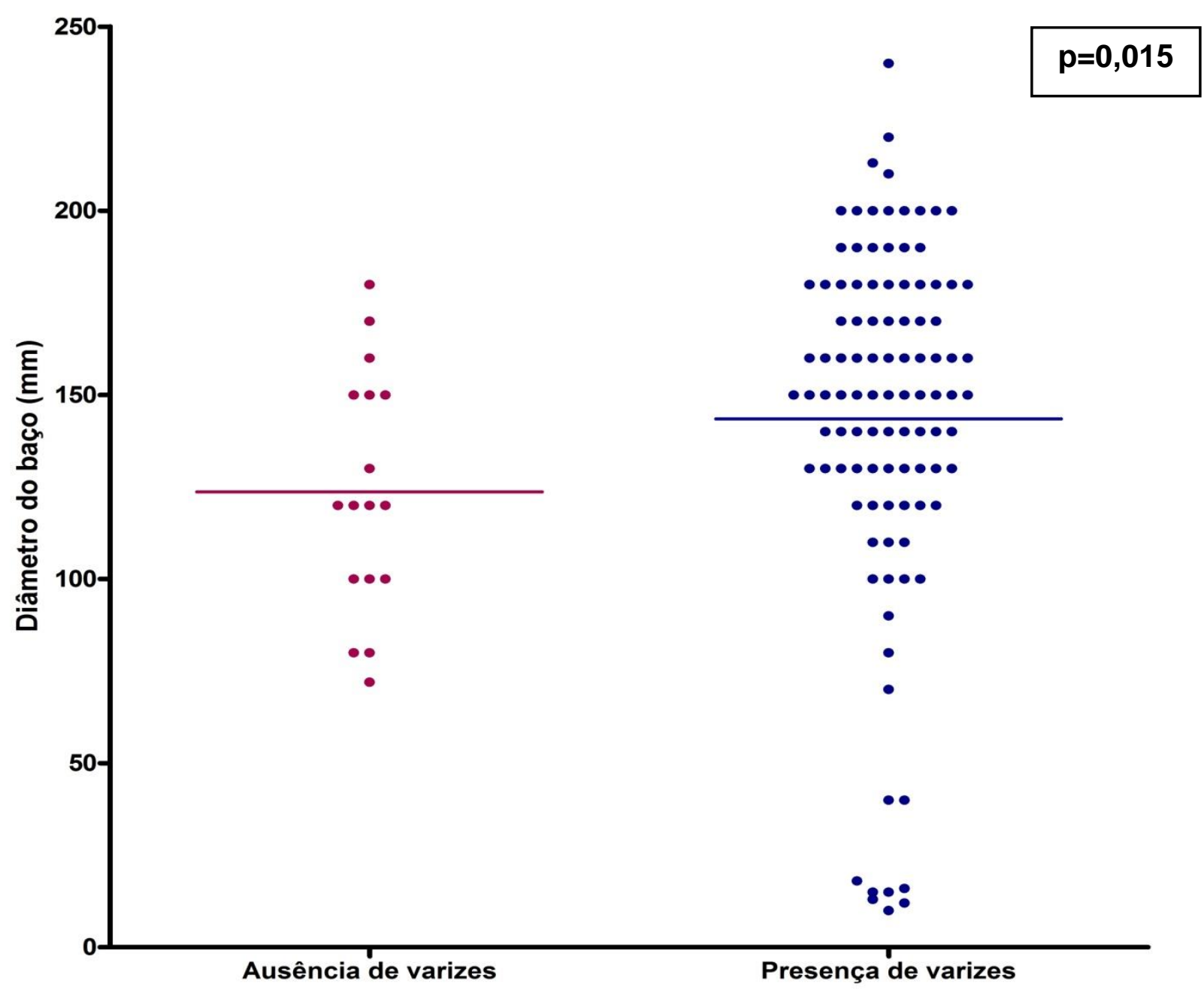

Figura 21 - Comparação entre os pacientes com a presença ou não de varizes esofágicas, de acordo com o diâmetro do baço 


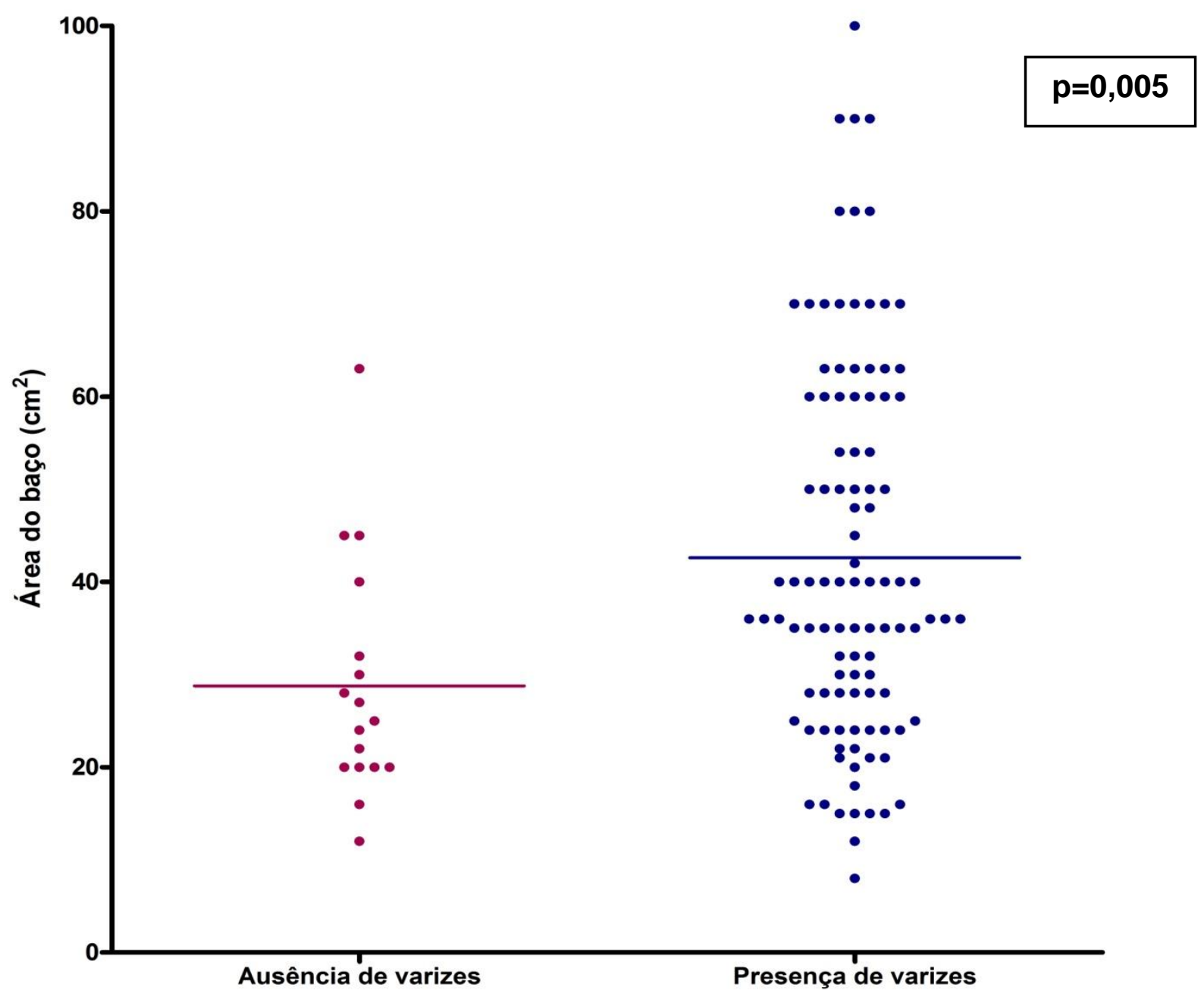

Figura 22 - Comparação entre os pacientes com a presença ou não de varizes esofágicas, de acordo com a área do baço

4.7.3 Características dos parâmetros laboratoriais dos pacientes em relação à presença ou não de varizes esofágicas

A hemoglobina, a contagem de plaquetas e os demais exames laboratoriais foram semelhantes entre os grupos. (tabela 14). 
Tabela 14 - Comparação entre os pacientes do estudo de acordo com a presença ou não de varizes esofágicas, segundo os parâmetros laboratoriais $(n=120)$

\begin{tabular}{|c|c|c|c|}
\hline \multirow{2}{*}{ Parâmetros } & \multicolumn{2}{|c|}{ Presença de varizes } & \multirow{2}{*}{ Valor de $p$} \\
\hline & Sim & Não & \\
\hline \multicolumn{4}{|c|}{ Hemoglobina (mg/dL) } \\
\hline Mediana & $13[12-14]$ & $13[12-14]$ & \multirow{2}{*}{0,927} \\
\hline Média \pm DP & $13 \pm 2$ & $13 \pm 2$ & \\
\hline \multicolumn{4}{|l|}{ Plaquetas $\left(/ \mathrm{mm}^{3}\right)$} \\
\hline Mediana & $89,5[60,0-138]$ & $117,0[71,0-201,0]$ & \multirow{2}{*}{0,348} \\
\hline Média \pm DP & $117,03 \pm 97,20$ & $125,56 \pm 74,02$ & \\
\hline \multicolumn{4}{|c|}{ Fosfatase alcalina (UI/L) } \\
\hline Mediana & 87 [61-133] & 86 [72-129] & \multirow{2}{*}{0,978} \\
\hline Média \pm DP & $109,4 \pm 69,74$ & $109 \pm 77,12$ & \\
\hline \multicolumn{4}{|c|}{ Gama glutamil transferase (UI/L) } \\
\hline Mediana & 40 [21-81] & 35 [23-95] & \multirow{2}{*}{0,782} \\
\hline Média \pm DP & $64,35 \pm 76,35$ & $87.13 \pm 126,56$ & \\
\hline \multicolumn{4}{|c|}{ Bilirrubina (mg/dL) } \\
\hline Mediana & $0,94[0,50-1,44]$ & $0,60[0,41-1,64]$ & \multirow{2}{*}{0,409} \\
\hline Média \pm DP & $1,19 \pm 0,96$ & $1,00 \pm 0,74$ & \\
\hline \multicolumn{4}{|c|}{ Proteínas totais séricas (mg/dL) } \\
\hline Mediana & $7,0[6,6-7,5]$ & $6,75[6,50-6,90]$ & \multirow{2}{*}{0,039} \\
\hline Média \pm DP & $6,94 \pm 0,86$ & $6,61 \pm 0,65$ & \\
\hline \multicolumn{4}{|l|}{ Albumina $(\mathrm{g} / \mathrm{dL})$} \\
\hline Mediana & $4,25[4,00-4,50]$ & $4,15[3,80-4,50]$ & \multirow{2}{*}{0,834} \\
\hline Média \pm DP & $4,24 \pm 0,68$ & $4,35 \pm 0,94$ & \\
\hline \multicolumn{4}{|l|}{ INR } \\
\hline Mediana & $1,27[1,17-1,43]$ & $1,28[1,08-1,49]$ & \multirow{2}{*}{0,860} \\
\hline Média \pm DP & $1,37 \pm 0,42$ & $1,41 \pm 0,43$ & \\
\hline \multicolumn{4}{|c|}{ Aspartato aminotransferase (UI/L) } \\
\hline Mediana & 26 [21-34] & $26,50[21,50-47,00]$ & \multirow{2}{*}{0,554} \\
\hline Média \pm DP & $29,76 \pm 15,21$ & $37,94 \pm 28,81$ & \\
\hline \multicolumn{4}{|c|}{ Alanina aminotransferase (UI/L) } \\
\hline Mediana & 25 [17-34] & $31[21,5-36]$ & \multirow{2}{*}{0,183} \\
\hline Média \pm DP & $28,01 \pm 14,97$ & $38,56 \pm 37,97$ & \\
\hline \multicolumn{4}{|c|}{ Triglicérides (mg/dL) } \\
\hline Mediana & $73[59,50-94,50]$ & $59,50[47,50-114,50]$ & \multirow{2}{*}{0,669} \\
\hline Média \pm DP & $77,11 \pm 25,95$ & $79,33 \pm 40,92$ & \\
\hline Creatinina $(\mathrm{mg} / \mathrm{d}$ & & & \\
\hline Mediana & $0,73[0,61-0,89]$ & $0,81[0,56-1,05]$ & \\
\hline Média \pm DP & $0,75 \pm 0,25$ & $0,84 \pm 0,35$ & 0,486 \\
\hline Colesterol total ( & & & \\
\hline Mediana & $151,00[115-173]$ & $135,50[102-154$ & \\
\hline Média \pm DP & $149,55 \pm 47,18$ & $146,25 \pm 59,93$ & 0,342 \\
\hline Glicose (mg/dL) & & & \\
\hline Mediana & 90 [82-105] & 85 [83-100] & \\
\hline Média \pm DP & $99,65 \pm 34,50$ & $89,92 \pm 11,58$ & 0,430 \\
\hline
\end{tabular}

Resultados entre colchetes representam intervalo interquartil 


\subsubsection{Características dos métodos não invasivos dos pacientes em relação à presença ou não de varizes esofágicas}

A elastografia hepática por FibroScan mostrou-se valores abaixo de $12 \mathrm{kPa}$, configurando um padrão não cirrótico, tanto nos pacientes com ou sem presença de varizes. A elastografia esplênica por FibroScan e ARFI esplênico não evidenciaram valores estatisticamente significante entre pacientes com ou sem varizes esofagianas. No entanto, somente na avaliação pelo FIB-4, houve diferença significativa com $p=0,011$, em relação aos outros métodos não invasivos não houve diferença estatística, conforme tabela 15.

Tabela 15 - Comparação entre os pacientes do estudo de acordo com a presença ou não de varizes esofágicas, segundo os métodos não invasivos para detecção de hipertensão portal $(n=120)$

\begin{tabular}{|c|c|c|c|}
\hline \multirow{2}{*}{ Parâmetros } & \multicolumn{2}{|c|}{ Presença de varizes } & \multirow{2}{*}{$\begin{array}{c}\text { Valor de } \\
\mathbf{p}\end{array}$} \\
\hline & Sim & Não & \\
\hline \multicolumn{4}{|c|}{ Elastografia hepática - FibroScan (kPa) } \\
\hline Mediana & $6,70[5,15-9,55]$ & $5,40[50-7,50]$ & \multirow{2}{*}{0,119} \\
\hline Média \pm DP & $7,70 \pm 3,80$ & $6,58 \pm 3,35$ & \\
\hline \multicolumn{4}{|c|}{ ARFI hepático (m/s) } \\
\hline Mediana & $1,28[1,14-1,42]$ & $1,23[0,96-1,41]$ & \multirow{2}{*}{0,338} \\
\hline Média \pm DP & $1,32 \pm 0,32$ & $1,29 \pm 0,48$ & \\
\hline \multicolumn{4}{|c|}{ Elastografia esplênica - FibroScan (kPa) } \\
\hline Mediana & $73,45[43,60-75,00]$ & $\begin{array}{c}49,60[23,40- \\
75,00]\end{array}$ & \multirow[t]{2}{*}{0,104} \\
\hline Média \pm DP & $60,06 \pm 20,12$ & $49,45 \pm 23,67$ & \\
\hline \multicolumn{4}{|c|}{ ARFI esplênico $(\mathrm{m} / \mathrm{s})$} \\
\hline Mediana & $3,26[2,77-3,55]$ & $3,02[2,51-3,28]$ & \multirow{2}{*}{0,065} \\
\hline Média \pm DP & $3,20 \pm 0,62$ & $2,94 \pm 0,53$ & \\
\hline \multicolumn{4}{|l|}{ APRI } \\
\hline Mediana & $0,76[0,39-1,38]$ & $0,69[0,40-2,13]$ & \multirow[b]{2}{*}{0,970} \\
\hline Média \pm DP & $1,10 \pm 1,09$ & $1,17 \pm 1,05$ & \\
\hline \multicolumn{4}{|l|}{ FIB-4 } \\
\hline Mediana & $1,49[0,66-2,96]$ & $0,57[0,11-1,15]$ & \multirow{2}{*}{0,011} \\
\hline Média \pm DP & $2,63 \pm 3,22$ & $1.14 \pm 1,96$ & \\
\hline \multicolumn{4}{|c|}{ Razão plaqueta/baço } \\
\hline Mediana & 713 [333-1170] & 883 [524-1718] & \multirow{2}{*}{0,235} \\
\hline Média \pm DP & $1189 \pm 1839$ & $1137 \pm 832$ & \\
\hline
\end{tabular}




\subsection{Comparação da população do estudo, segundo a presença de varizes esofágicas de alto risco}

\subsubsection{Características basais}

Na comparação, ambos mostraram características clínicas e demográficas semelhantes, conforme exposto na Tabela 16.

Tabela 16 - Comparação entre os pacientes de acordo com a presença de varizes esofágicas de alto risco, segundo as características gerais $(n=120)$

\begin{tabular}{|c|c|c|c|}
\hline & \multicolumn{2}{|c|}{ Varizes de alto risco } & \multirow{2}{*}{ Valor de $p$} \\
\hline & Sim & Não & \\
\hline \multicolumn{4}{|l|}{ Idade - anos } \\
\hline Mediana & $40,0[23,7-49,9]$ & $40,5[18,8-52,0]$ & \multirow{2}{*}{0,682} \\
\hline Média \pm DP & $36,9 \pm 18,2$ & $38,5 \pm 20,6$ & \\
\hline Gênero masculino - no. (\%) & $31(50,0)$ & $33(56,9)$ & 0,470 \\
\hline \multicolumn{4}{|l|}{ Etiologia - no. (\%) } \\
\hline Oclusão da veia porta extra-hepática & $38(61,3)$ & $25(43,1)$ & \multirow{4}{*}{0,101} \\
\hline Esquistossomose & $17(27,4)$ & $25(43,1)$ & \\
\hline Hipertensão portal não cirrótica idiopática & $6(9,7)$ & $4(6,9)$ & \\
\hline Fibrose hepática congênita & $1(1,6)$ & $4(6,9)$ & \\
\hline Sangramento digestivo prévio - no. (\%) & $28(45,2)$ & $02(3,4)$ & 0,000 \\
\hline Ascite - no. (\%) & $08(12,9)$ & $05(8,6)$ & 0,562 \\
\hline \multicolumn{4}{|l|}{$\mathrm{IMC}-\mathrm{kg} / \mathrm{m}^{2}$} \\
\hline Mediana & $24,37[20,65-27,05]$ & $23,75[20,77-28,60]$ & \multirow[t]{2}{*}{0,834} \\
\hline Média \pm DP & $24,14 \pm 5,29$ & $24,64 \pm 5,92$ & \\
\hline Uso de propranolol - no. (\%) & $40(64,5)$ & $28(48,3)$ & 0,097 \\
\hline
\end{tabular}

Resultados entre colchetes representam intervalo interquartil 
Nota-se que a prevalência maior de varizes esofágicas de alto risco ocorreu dentre os pacientes com oclusão da veia porta extra-hepática (61,3\%); seguidos pela hipertensão portal não cirrótica idiopática $(9,7 \%)$. Vinte e oito pacientes no grupo de varizes de alto risco apresentaram antecedente pregresso de sangramento, nesse estudo considerado, tanto gástrico quanto esofágico.

4.8.2 Características dos parâmetros de imagem dos pacientes em relação a presença de varizes esofágicas de alto risco

$\mathrm{Na}$ comparação entre as medidas do baço, acordo com a presença de varizes esofágicas de alto risco, não houve diferença significante. (tabela 17).

Tabela 17 - Comparação entre os pacientes de acordo com a presença de varizes esofágicas de alto risco, segundo os parâmetros radiológicos $(n=120)$

\begin{tabular}{|c|c|c|c|}
\hline \multirow{2}{*}{ Parâmetros } & \multicolumn{2}{|c|}{ Varizes de alto risco } & \multirow{2}{*}{ Valor de p } \\
\hline & Sim & Não & \\
\hline \multicolumn{4}{|c|}{ Diâmetro esplênico (mm) } \\
\hline Mediana & $150[120-180]$ & $150[120-170]$ & \multirow{2}{*}{0,784} \\
\hline Média \pm DP & $139 \pm 56$ & $143 \pm 39$ & \\
\hline \multicolumn{4}{|c|}{ Área do baço $\left(\mathrm{cm}^{2}\right)$} \\
\hline Mediana & $38[25-60]$ & $34[24-50]$ & \multirow{2}{*}{0,214} \\
\hline Média \pm DP & $43 \pm 20$ & $39 \pm 20$ & \\
\hline
\end{tabular}

\subsubsection{Características dos parâmetros laboratoriais dos pacientes em relação à presença de varizes esofágicas de alto risco}

A hemoglobina, a contagem de plaquetas e os demais exames laboratoriais foram semelhantes entre os grupos. (tabela 18). 
Tabela 18 - Comparação entre os pacientes do estudo de acordo com a presença ou não de varizes esofágicas, segundo os parâmetros laboratoriais $(n=120)$

\begin{tabular}{|c|c|c|c|}
\hline \multirow{2}{*}{ Parâmetros } & \multicolumn{2}{|c|}{ Varizes de alto risco } & \multirow{2}{*}{ Valor de $\mathrm{p}$} \\
\hline & Sim & Não & \\
\hline \multicolumn{4}{|c|}{ Hemoglobina $(\mathrm{mg} / \mathrm{dL})$} \\
\hline Mediana & $13[12-14]$ & $13[12-15]$ & \multirow{2}{*}{0,738} \\
\hline Média \pm DP & $13 \pm 2$ & $13 \pm 2$ & \\
\hline \multicolumn{4}{|l|}{ Plaquetas $\left(/ \mathrm{mm}^{3}\right)$} \\
\hline Mediana & $\begin{array}{c}107,0[63,0- \\
138,0]\end{array}$ & $84,0[60,0-149,0]$ & \multirow{2}{*}{0,515} \\
\hline Média \pm DP & $128,42 \pm 113,18$ & $108,04 \pm 69,32$ & \\
\hline \multicolumn{4}{|c|}{ Fosfatase alcalina (UI/L) } \\
\hline Mediana & $87,50[59-138]$ & 87 [72-132] & \multirow{2}{*}{0,990} \\
\hline Média \pm DP & $115,28 \pm 81,89$ & $103,30 \pm 56,14$ & \\
\hline \multicolumn{4}{|c|}{ Gama glutamil transferase (UI/L) } \\
\hline Mediana & 45 [24-83] & 33 [22-68] & \multirow{2}{*}{0,215} \\
\hline Média \pm DP & $73,84 \pm 89,78$ & $61,02 \pm 79,33$ & \\
\hline \multicolumn{4}{|c|}{ Bilirrubina (mg/dL) } \\
\hline Mediana & $0,94[0,50-1,44]$ & $0,92[0,49-1,56]$ & \multirow{2}{*}{0,995} \\
\hline Média \pm DP & $1,19 \pm 1,01$ & $1,14 \pm 0,86$ & \\
\hline \multicolumn{4}{|c|}{ Proteínas totais séricas (mg/dL) } \\
\hline Mediana & $7,10[6,6-7,5]$ & $6,90[6,50-7,30]$ & \multirow{2}{*}{0,174} \\
\hline Média \pm DP & $7,03 \pm 0,78$ & $6,74 \pm 0,88$ & \\
\hline \multicolumn{4}{|l|}{ Albumina (g/dL) } \\
\hline Mediana & $4,30[4,00-4,50]$ & $4,20[4,00-4,50]$ & \multirow{2}{*}{0,981} \\
\hline Média \pm DP & $4,22 \pm 0,51$ & $4,30 \pm 0,90$ & \\
\hline \multicolumn{4}{|l|}{ INR } \\
\hline Mediana & $1,25[1,17-1,45]$ & $1,29[1,15-1,44]$ & \multirow{2}{*}{0,917} \\
\hline Média \pm DP & $1,34 \pm 0,33$ & $1,40 \pm 0,50$ & \\
\hline \multicolumn{4}{|c|}{ Aspartato aminotransferase (UI/L) } \\
\hline Mediana & $25,50[21-33,50]$ & $27,00[22,00-39,00]$ & \multirow{2}{*}{0,446} \\
\hline Média \pm DP & $30,07 \pm 17,95$ & $31,82 \pm 17,90$ & \\
\hline \multicolumn{4}{|c|}{ Alanina aminotransferase (UI/L) } \\
\hline Mediana & $25,50[17,50-37]$ & 25 [18-33] & \multirow{2}{*}{0,654} \\
\hline Média \pm DP & $29,48 \pm 16,27$ & $29,58 \pm 23,43$ & \\
\hline \multicolumn{4}{|c|}{ Triglicérides (mg/dL) } \\
\hline Mediana & 74 [61-103] & $67[52-86]$ & \multirow{2}{*}{0,125} \\
\hline Média \pm DP & $82,31 \pm 28,07$ & $73,32 \pm 28,54$ & \\
\hline Creatinina $(\mathrm{mg} / \mathrm{d}$ & & & \\
\hline Mediana & $0,72[0,61-0,89]$ & $0,74[0,59-0,95]$ & \\
\hline Média \pm DP & $0,75 \pm 0,23$ & $0,78 \pm 0,30$ & 0,898 \\
\hline Colesterol total ( & & & \\
\hline Mediana & $157,00[121-182]$ & $130[111-164]$ & \\
\hline Média \pm DP & $154,77 \pm 41,55$ & $143,76 \pm 54,75$ & 0,074 \\
\hline Glicose (mg/dL) & & & \\
\hline Mediana & 90 [80-102] & $88[83-108]$ & \\
\hline Média \pm DP & $99,37 \pm 40,02$ & $97 \pm 22,90$ & 0,685 \\
\hline
\end{tabular}

Resultados entre colchetes representam intervalo interquartil 


\subsubsection{Valores dos métodos não invasivos dos pacientes em relação à presença de varizes de alto risco}

Ao analisar os pacientes segundo a presença de varizes de alto risco, não houve diferença significante em relação a nenhum dos métodos não invasivos, conforme a tabela 19.

Tabela 19 - Comparação entre os pacientes do estudo de acordo com a presença varizes esofágicas de alto risco, segundo os métodos não invasivos para detecção de hipertensão portal $(n=120)$

\begin{tabular}{|c|c|c|c|}
\hline \multirow{2}{*}{ Parâmetros } & \multicolumn{2}{|c|}{ Varizes de alto risco } & \multirow{2}{*}{ Valor de $p$} \\
\hline & Sim & Não & \\
\hline \multicolumn{4}{|c|}{ Elastografia hepática - FibroScan (kPa) } \\
\hline Mediana & $6,10[4,80-7,70]$ & $7,15[5,70-10,30]$ & \multirow{2}{*}{0,022} \\
\hline Média \pm DP & $7,12 \pm 4,20$ & $7,98 \pm 3,16$ & \\
\hline \multicolumn{4}{|c|}{ ARFI hepático (m/s) } \\
\hline Mediana & $1,26[1,10-1,39]$ & $1,29[1,13-1,48]$ & \multirow{2}{*}{0,464} \\
\hline Média \pm DP & $1,30 \pm 0,35$ & $1,33 \pm 0,34$ & \\
\hline \multicolumn{4}{|c|}{ Elastografia esplênica - FibroScan (kPa) } \\
\hline Mediana & $75[53,30-75]$ & $63,90[33,30-75]$ & \multirow{2}{*}{0,012} \\
\hline Média \pm DP & $63,71 \pm 17,46$ & $53,19 \pm 22,87$ & \\
\hline \multicolumn{4}{|c|}{ ARFI esplênico (m/s) } \\
\hline Mediana & $3,32[2,99-3,61]$ & $3,10[2,62-3,43]$ & \multirow{2}{*}{0,033} \\
\hline Média \pm DP & $3,25 \pm 0,56$ & $3,06 \pm 0,65$ & \\
\hline \multicolumn{4}{|l|}{ APRI } \\
\hline Mediana & $0,67[0,39-1,22]$ & $0,79[0,39-1,69]$ & \multirow{2}{*}{0,283} \\
\hline Média \pm DP & $1,00 \pm 0,97$ & $1,24 \pm 1,18$ & \\
\hline \multicolumn{4}{|l|}{ FIB-4 } \\
\hline Mediana & $1,33[0,35-2,40]$ & $1,19[0,55-3,17]$ & \multirow{2}{*}{0,616} \\
\hline Média \pm DP & $1,98 \pm 2,24$ & $2,85 \pm 3,77$ & \\
\hline \multicolumn{4}{|c|}{ Razão plaqueta/baço } \\
\hline Mediana & 800 [378-1170] & 558 [333-1300] & \multirow{2}{*}{0,394} \\
\hline Média \pm DP & $1372 \pm 2112$ & $993 \pm 1228$ & \\
\hline
\end{tabular}

Resultados entre colchetes representam intervalo interquartil 


\subsection{Acurácia diagnóstica da elastografia e dos índices APRI, FIB-4 e razão plaqueta/baço para predizer varizes esofágicas}

A elastografia esplênica por FibroScan com ponto de corte $65,100 \mathrm{kPa}$ apresentou acurácia de 0,624 para diagnosticar a presença de varizes, com um intervalo de confiança 95\% assintótico de [0,462-0,787; $p=0,121]$.

A elastografia esplênica por ARFI com ponto de corte de $2,67 \mathrm{~m} / \mathrm{s}$ apresentou acurácia de 0,640 para diagnosticar a presença de varizes, com um intervalo de confiança 95\% assintótico de [0,5-0,78; $p=0,065]$.

Os cálculos de acurácia, sensibilidade, especificidade, valor preditivo positivo, valor preditivo negativo, e razões de verossimilhança positiva e negativa empregando-se os pontos de corte definidos pelas curvas ROC estão mostrados na tabela 20 .

Tabela 20 - Desempenho global dos testes, de acordo com a presença de varizes esofágicas

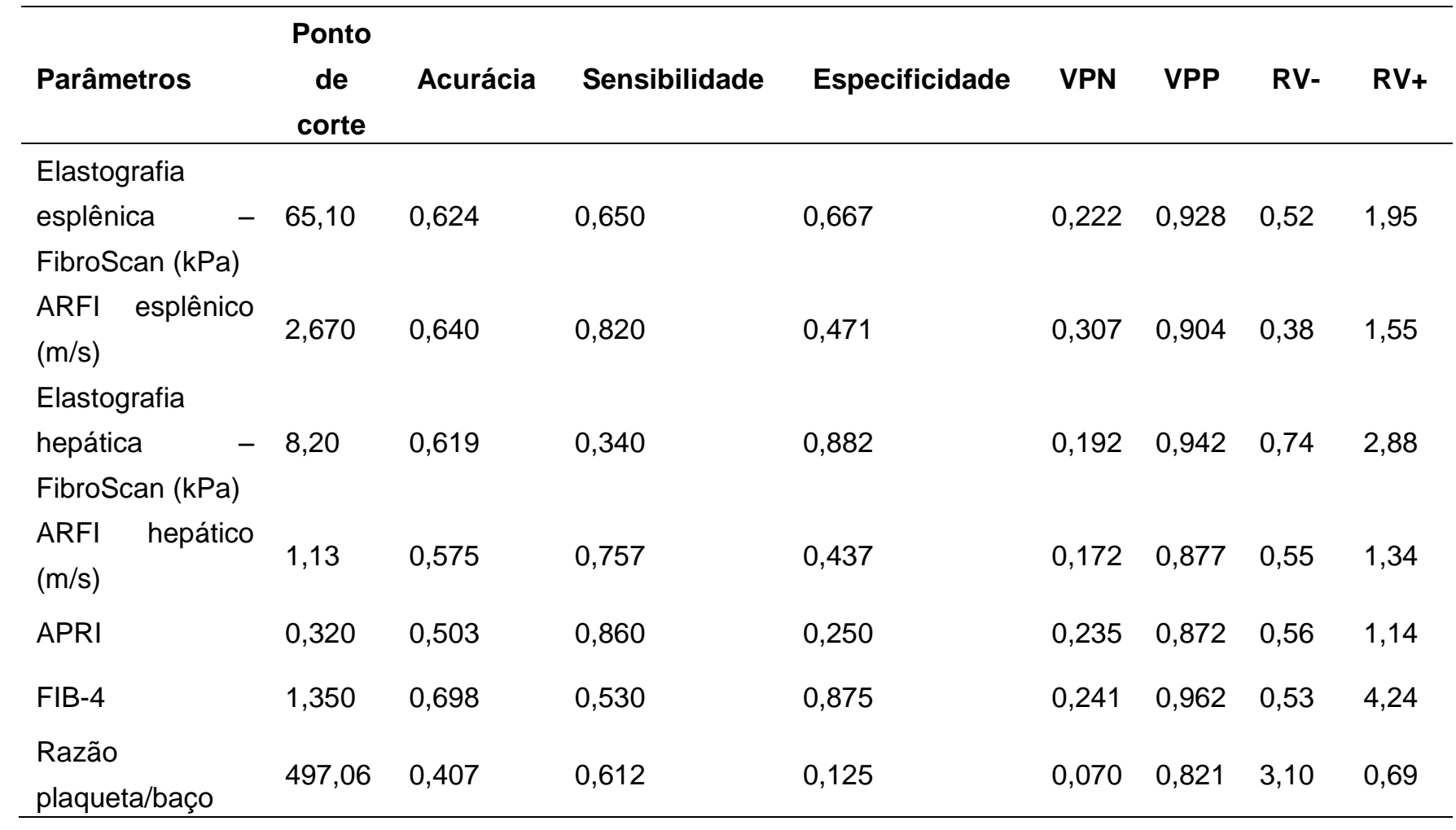

VPN= Valor preditivo negativo; VPP=Valor preditivo positivo; RV=Razão de verossimilhança; (-) Negativo e (+) Positivo 


\subsection{Acurácia diagnóstica da elastografia e dos índices APRI, FIB-4 e razão plaqueta/baço para predizer varizes esofágicas de alto risco de sangramento}

A elastografia esplênica por FibroScan com ponto de corte $41,900 \mathrm{kPa}$ apresentou acurácia de 0,630 para diagnosticar a presença de varizes, com um intervalo de confiança 95\% assintótico de [0,528-0,763; $p=0,016]$.

A elastografia esplênica por ARFI com ponto de corte de $3,17 \mathrm{~m} / \mathrm{s}$ apresentou acurácia de 0,613 para diagnosticar a presença de varizes, com um intervalo de confiança 95\% assintótico de [0,510-0,715; $p=0,033]$.

Os cálculos de acurácia, sensibilidade, especificidade, valor preditivo positivo, valor preditivo negativo, e razões de verossimilhança positiva e negativa empregando-se os pontos de corte definidos pelas curvas ROC, estão apresentados na tabela 21 .

Tabela 21 - Desempenho global dos testes, de acordo com a presença de varizes esofágicas de alto risco

\begin{tabular}{|c|c|c|c|c|c|c|c|c|}
\hline Parâmetros & $\begin{array}{l}\text { Ponto } \\
\text { de } \\
\text { corte }\end{array}$ & Acurácia & Sensibilidade & Especificidade & VPN & VPP & RV- & RV+ \\
\hline $\begin{array}{l}\text { Elastografia } \\
\text { esplênica } \\
\text { FibroScan (kPa) }\end{array}$ & 40,05 & 0,630 & 0,850 & 0,320 & 0,740 & 0,602 & 0,46 & 1,25 \\
\hline $\begin{array}{l}\text { ARFI esplênico } \\
(\mathrm{m} / \mathrm{s})\end{array}$ & 3,17 & 0,613 & 0,661 & 0,586 & 0,615 & 0,617 & 0,57 & 1,59 \\
\hline $\begin{array}{l}\text { Elastografia } \\
\text { hepática } \\
\text { FibroScan }(\mathrm{kPa})\end{array}$ & 5,65 & 0,375 & 0,525 & 0,241 & 0,317 & 0,430 & 1,97 & 0,69 \\
\hline $\begin{array}{l}\text { ARFI hepático } \\
(\mathrm{m} / \mathrm{s})\end{array}$ & 1,40 & 0,461 & 0,226 & 0,649 & 0,440 & 0,428 & 1,19 & 0,64 \\
\hline APRI & 0,66 & 0,441 & 0,500 & 0,345 & 0,413 & 0,443 & 1,44 & 0,76 \\
\hline FIB-4 & 1,60 & 0,543 & 0,446 & 0,450 & 0,515 & 0,531 & 1,23 & 0,81 \\
\hline $\begin{array}{l}\text { Razão } \\
\text { plaqueta/baço }\end{array}$ & 738,33 & 0,546 & 0,596 & 0,614 & 0,603 & 0,607 & 0,65 & 1,54 \\
\hline
\end{tabular}

VPN= Valor preditivo negativo; VPP=Valor preditivo positivo; $R V=$ Razão de verossimilhança; (-) Negativo e (+) Positivo 


\subsection{Combinação de métodos não invasivos}

As variáveis número de plaquetas e diâmetro do baço inferem indiretamente a presença de hipertensão portal (hiperesplenismo). Com base no estudo de Kim et al. ${ }^{51}$, formulamos dois modelos, o primeiro com a multiplicação da medida da elastografia transitória esplênica por FibroScan pelo valor da razão plaqueta/baço e, o segundo, com a multiplicação da medida do ARFI esplênico pelo valor da razão plaqueta/baço. Com as seguintes equações: medida da elastografia transitória esplênica por FibroScan $\mathrm{x}$ razão plaqueta/baço (denominado equação 1) e medida do ARFI esplênico x razão plaqueta/baço (denominado equação 2). Obtivemos os seguintes resultados:

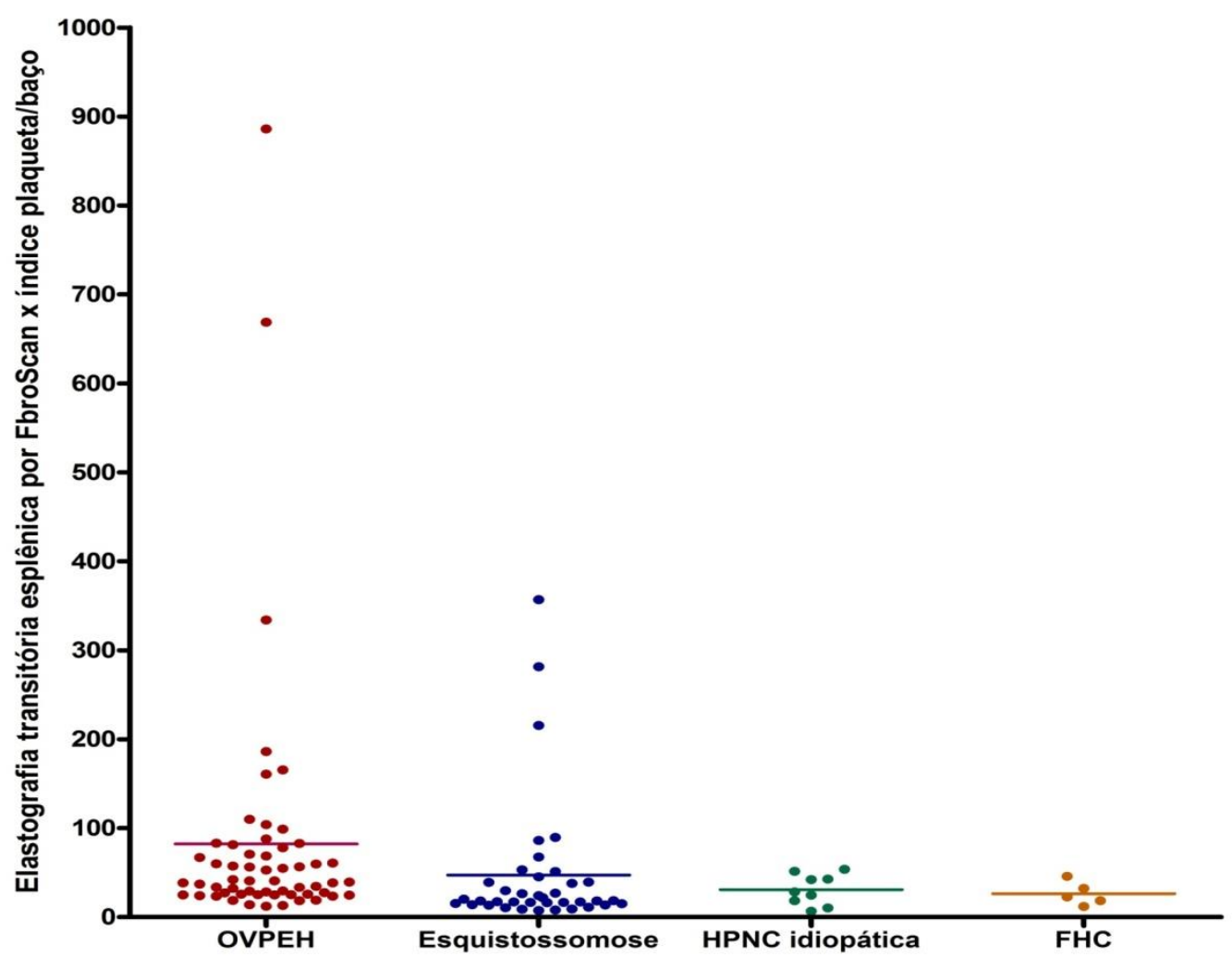

${ }^{*}$ OVPEH = Oclusão da veia porta extra-hepática; HPNC = Hipertensão portal não cirrótica; FHC = Fibrose hepática congênita 
Figura 23 - Resultados por etiologia da elastografia transitória esplênica por FibroScan $\mathrm{x}$ razão plaqueta/baço, nos pacientes com hipertensão portal não cirrótica

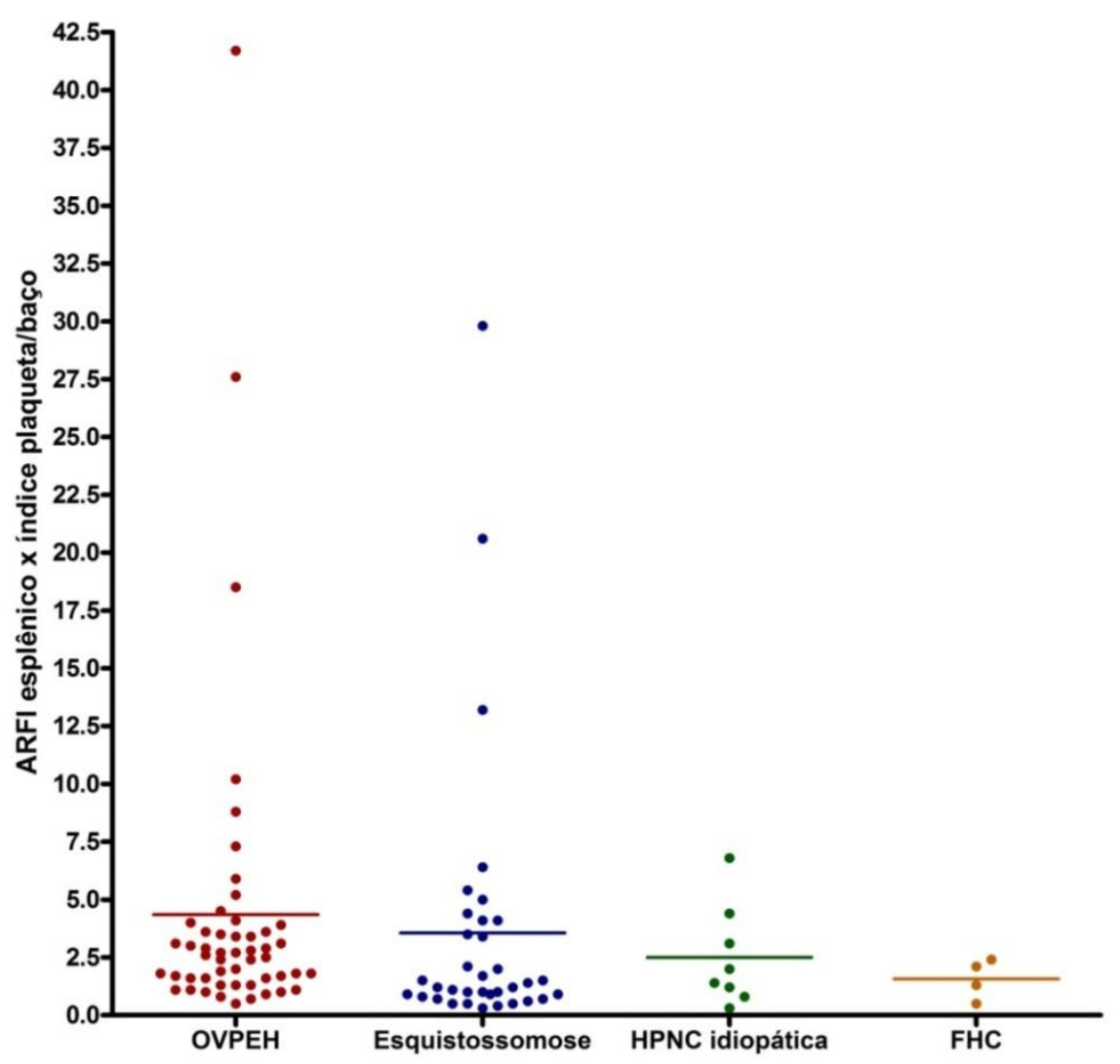

*OVPEH = Oclusão da veia porta extra-hepática; HPNC = Hipertensão portal não cirrótica; FHC = Fibrose hepática congênita

Figura 24 - Resultados por etiologia do ARFI esplênico por FibroScan x razão plaqueta/baço, nos pacientes com hipertensão portal não cirrótica

Tabela 22 - Comparação entre os pacientes do estudo de acordo com a presença de varizes esofágicas, segundo as equações 1 e 2 para detecção de hipertensão portal $(n=120)$

\begin{tabular}{lccc}
\hline Parâmetros & \multicolumn{2}{c}{ Presença de varizes } & Valor de \\
\cline { 2 - 3 } & Sim & Não & p \\
\hline Equação 1 & & \\
$\quad$ Mediana & $33,40[18,50-59,66]$ & $26,52[22,64-42,32]$ & 0,606 \\
$\quad$ Média \pm DP & $67,03 \pm 122,79$ & $37,65 \pm 29,01$ & \\
Equação 2 & & & \\
$\quad$ Mediana & $1,92[1,05-3,57]$ & $2,23[1,42-4,48]$ & 0,320 \\
$\quad$ Média \pm DP & $3,80 \pm 6,24$ & $3,17 \pm 2,25$ & \\
\hline Resultados entre colchetes representam intervalo interquartil &
\end{tabular}


Tabela 23 - Comparação entre os pacientes do estudo de acordo com a presença varizes esofágicas de alto risco, segundo as equações 1 e 2 para detecção de hipertensão portal $(n=120)$

\begin{tabular}{lccc}
\hline Parâmetros & Sim & Não & Valor de \\
\cline { 2 - 3 } & & & $\mathbf{p}$ \\
\hline Equação 1 & $40,82[23,73-81,43]$ & $25,10[17,43-39,10]$ & 0,004 \\
Mediana & $89,18 \pm 154,69$ & $36,85 \pm 36,85$ & \\
Média \pm DP & & & \\
Equação 2 & & & \\
Mediana & $2,51[1,26-4,09]$ & $1,69[1,05-3,39]$ & 0,195 \\
Média \pm DP & $4,50 \pm 7,11$ & $2,93 \pm 4,13$ & \\
\hline Resultados entre colchetes representam intervalo interquartil &
\end{tabular}

Mesmo a equação 1 apresentando um valor de $\mathrm{p}$ com diferença estatisticamente significante, quando analisado os dados graficamente, observa-se que há sobreposição entre os grupos. (Figura 25). 


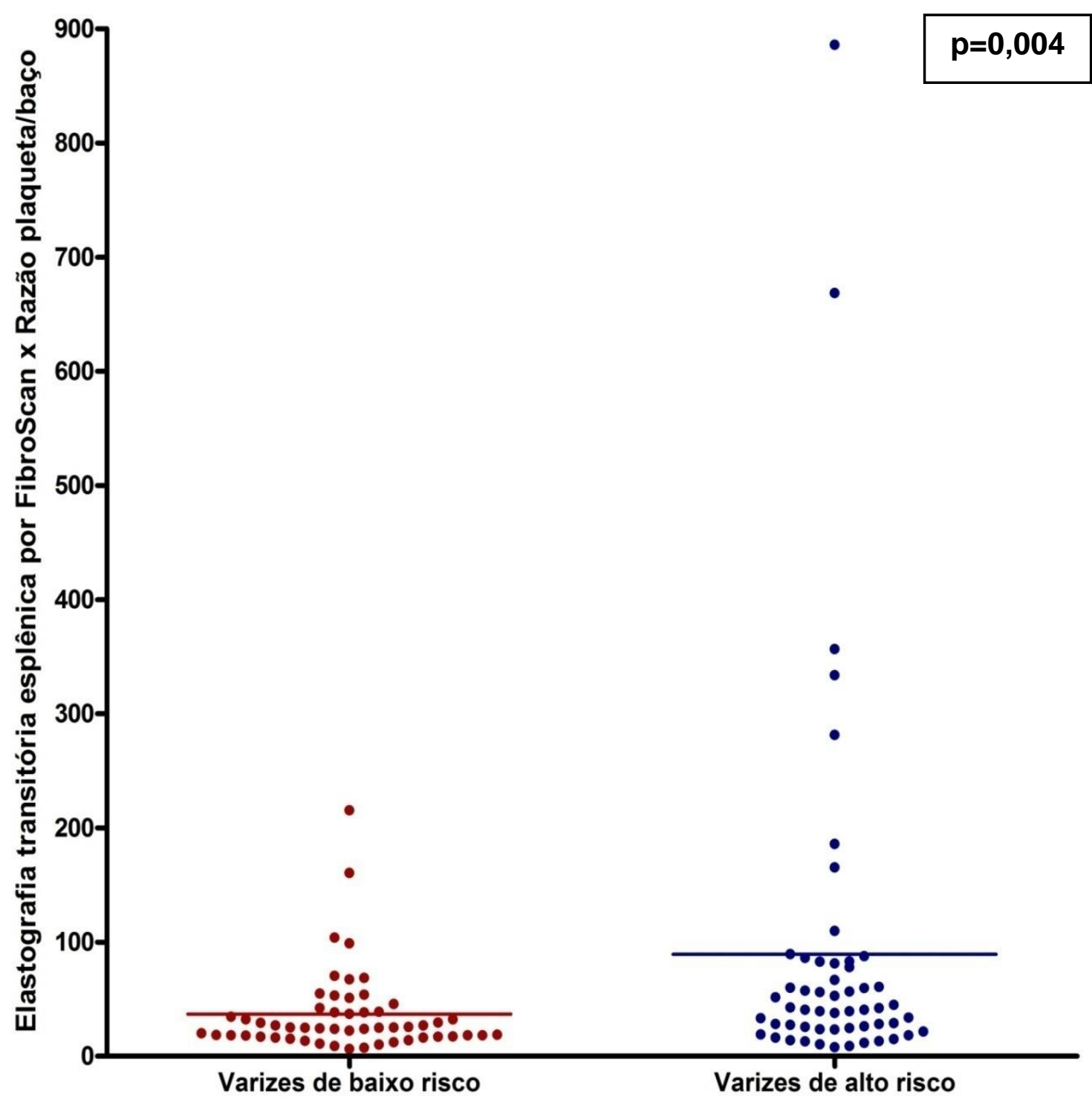

Figura 25 - Comparação entre os pacientes com a presença de varizes de baixo risco e de alto risco, de acordo com os valores obtidos pela equação 1

$\mathrm{Na}$ análise do desempenho global para predizer presença de varizes esofágicas, a equação 1 , com ponto de corte 32,39 , apresentou acurácia de 0,54 para diagnosticar a presença de varizes, com um intervalo de confiança $95 \%$ assintótico de $[0,399-0,687 ; p=0,606]$. 
A equação 2, com ponto de corte de 1,25, apresentou acurácia de 0,42 para diagnosticar a presença de varizes, com um intervalo de confiança $95 \%$ assintótico de $[0,283-0,561 ; p=0,32]$.

Os cálculos de acurácia, sensibilidade, especificidade, valor preditivo positivo, valor preditivo negativo, e razões de verossimilhança positiva e negativa empregando-se os pontos de corte definidos pelas curvas ROC estão mostrados na tabela 24 .

Tabela 24 - Desempenho global das equações, de acordo com a presença de varizes esofágicas

\begin{tabular}{lcccccccc}
\hline Parâmetros & $\begin{array}{c}\text { Ponto } \\
\text { de } \\
\text { corte }\end{array}$ & Acurácia & Sensibilidade & Especificidade & VPN & VPP & RV- & RV+ \\
\hline Equação 1 & 32,39 & 0,54 & 0,51 & 0,71 & 0,17 & 0,92 & 0,67 & 1,80 \\
Equação 2 & 1,25 & 0,42 & 0,66 & 0,12 & 0,82 & 0,06 & 2,69 & 0,75 \\
\hline
\end{tabular}

$\mathrm{VPN}=$ Valor preditivo negativo; VPP=Valor preditivo positivo; $\mathrm{RV}=$ Razão de verossimilhança; (-) Negativo e (+) Positivo

$\mathrm{Na}$ análise do desempenho global para predizer presença de varizes esofágicas de alto risco, a equação 1 , com ponto de corte 39,20 , apresentou acurácia de 0,66 para diagnosticar a presença de varizes de alto risco, com um intervalo de confiança $95 \%$ assintótico de $[0,556-0,763 ; p=0,004]$.

A equação 2, com ponto de corte de 2,35, apresentou acurácia de 0,57 para diagnosticar a presença de varizes, com um intervalo de confiança 95\% assintótico de [0,464-0,676; $p=0,195]$. 
Os cálculos de acurácia, sensibilidade, especificidade, valor preditivo positivo, valor preditivo negativo, e razões de verossimilhança positiva e negativa empregando-se os pontos de corte definidos pelas curvas ROC estão apresentados na tabela 25 .

Tabela 25 - Desempenho global das equações, de acordo com a presença de varizes esofágicas de alto risco

\begin{tabular}{ccccccccc}
\hline Parâmetros & $\begin{array}{c}\text { Ponto } \\
\text { de } \\
\text { corte }\end{array}$ & Acurácia & Sensibilidade & Especificidade & VPN & VPP & RV- & RV+ \\
\hline Equação 1 & 39,20 & 0,66 & 0,56 & 0,75 & 0,63 & 0,70 & 0,57 & 2,34 \\
Equação 2 & 2,35 & 0,57 & 0,54 & 0,64 & 0,58 & 0,59 & 0,70 & 1,54 \\
\hline
\end{tabular}

VPN= Valor preditivo negativo; VPP=Valor preditivo positivo; RV=Razão de verossimilhança; (-) Negativo e (+) Positivo 
$\circ$

$\mathrm{O}^{\circ}$

\section{Discussão}




\section{DISCUSSÃO}

\subsection{Aspectos gerais}

$\mathrm{Na}$ hipertensão portal não cirrótica, a história natural da doença ainda é incerta devido à escassez de dados publicados. Deste modo, a indicação para solicitação de endoscopia e a profilaxia primária é uma questão atual e de grande interesse entre os pesquisadores. ${ }^{18}$

Em um estudo canadense, que envolveu entrevista com médicos, observou-se que $70 \%$ das indicações de endoscopia em pacientes pediátricos com hepatopatias eram para triagem endoscópica de varizes. Em $51 \%$ dos casos, evidências ultrassonográficas de colaterais porto-sistêmicas e em $47 \%$ a presença de esplenomegalia foram o motivo de solicitação de endoscopia diagnóstica. ${ }^{60}$

Esses dados refletem as recomendações atuais de inúmeros consensos internacionais para indicar triagem endoscópica de varizes esofágicas em todos os pacientes com cirrose ou outras formas de hipertensão portal. Dada a natureza invasiva, ainda que minimamente, da endoscopia digestiva, com necessidade frequente de sedação, abre-se espaço para o estudo de métodos alternativos. Nesse cenário, métodos não invasivos, como a elastografia ultrassônica vem ganhando destaque na literatura por permitir estratificar 0 risco do paciente apresentar varizes esofagianas. Exemplo desse destaque é o reconhecimento pelo consenso de Baveno, em sua sexta edição, que a elastografia pode ajudar a selecionar subgrupos de pacientes em que a endoscopia diagnóstica pode ser adiada. ${ }^{61,62}$ 
Os métodos não invasivos, como exames de imagem mostrando colaterais porto-sistêmicas, veia umbilical recanalizada ou reversão do fluxo portal, a mensuração da rigidez do fígado, a contagem de plaquetas e o diâmetro do baço podem ajudar a identificar pacientes com alto risco de hipertensão portal clinicamente significante. Igualmente podem identificar pacientes com baixa probabilidade de apresentarem varizes de alto risco. No entanto a maioria dos dados vem de estudo de pacientes com cirrose, geralmente secundária à hepatite crônica C. ${ }^{63}$ No que se refere à hipertensão portal não cirrótica, os estudos não são numerosos, de forma que não se sabe qual papel desempenhariam na identificação das varizes e na estratificação do seu risco de ruputura.

Dessa maneira, a utilização de métodos não invasivos, como as técnicas de elastografia hepatoesplênica (transitória por FibroScan e ARFI), na hipertensão portal não cirrótica, pode ser uma alternativa útil na seleção de candidatos à endoscopia, sobretudo na população pediátrica. Essa premissa impulsionou esse estudo para avaliar a acurácia diagnóstica dessas técnicas, tanto para predizer a presença de varizes esofagianas como para predizer as de alto risco nessa população.

O presente estudo apresenta alguns aspectos que o tornam singular. Foram incluídos 120 pacientes com hipertensão portal não cirrótica, uma casuística expressiva, considerando-se a raridade da condição. Além disso, estudamos pacientes pediátricos, subgrupo de grande interesse, pela clara lacuna na literatura em relação a métodos não invasivos para evitar endoscopia e consequentemente anestesia e intubação em crianças. 
No sentido de termos uma casuística menos enviesada, adotamos algumas restrições na inclusão de pacientes para evitar a contaminação por condições que, apesar de classificadas como não cirróticas, apresenta mecanismo fisiopatológico distinto para a hipertensão portal. Excluindo os casos de hipertensão portal intra-hepática pós-sinusoidal, constituímos um grupo mais homogêneo, formado por doenças que caracteristicamente produzem hipertensão não cirrótica pré-sinusoidal. Importante ainda é o desenho prospectivo do estudo, com estrita aderência à metodologia STARD para estudos de acurácia diagnóstica.

$\mathrm{Na}$ nossa casuística, 74 pacientes apresentaram trombose de porta, representando $61 \%$ do total de pacientes, sendo a maioria do sexo masculino $(n=41)$. Resultado semelhante foi encontrado no estudo de Khalid Al Hashmi et al. ${ }^{64} \mathrm{em}$ que um total de 39 pacientes com trombose de veia porta foram incluídos; $24(61,5 \%)$ foram classificados como não cirróticos. De forma semelhante ao que observamos, a trombose de veia porta foi mais comum em homens do que mulheres $(25(64,1 \%)$ versus $14(35,8 \%)$, respectivamente, $\mathrm{p}=0,020)$.

A incidência de ascite na hipertensão portal não cirrótica tem sido relatada como rara, ao redor de $2 \%$, no estudo de Sarin \& Kapoor. ${ }^{65} \mathrm{Em}$ outro estudo é relatado que entre 10 a 34\% dos pacientes com hipertensão portal não cirrótica desenvolvem ascite geralmente após o primeiro episódio de sangramento, associado à hipoalbuminemia e tempo de evolução da doença. ${ }^{12}$

No nosso estudo, treze pacientes apresentavam ascite, representando aproximadamente $10 \%$ da nossa casuística, sendo doze com ascite leve e um com ascite moderada. Desses pacientes, cinco tinham o diagnóstico de 
hipertensão portal não cirrótica idiopática; quatro com esquistossomose e quatro com oclusão da veia porta extra-hepática.

Todos pacientes no presente estudo tinham esplenomegalia, com uma média de área do baço em 47,3 $\mathrm{cm}^{2}$. O aumento do diâmetro do baço em pacientes com doença hepática crônica quase sempre reflete o aumento da pressão portal. ${ }^{60}$ No estudo de Fagundes et al. ${ }^{66}$ foram avaliadas crianças com hipertensão portal, as crianças cirróticas com esplenomegalia tiveram 14,6 vezes mais chances de ter varizes esofágicas em comparação com crianças cirróticas sem esplenomegalia. Em nosso estudo das 25 crianças e adolescentes avaliados com hipertensão portal não cirrótica, um adolescente apresentou diâmetro do baço igual a 100 mm, dentro do valor de normalidade e, as demais crianças apresentaram esplenomegalia, valores avaliados segundo a idade ${ }^{67}$, a presença de varizes esofágicas nessa população foi de $84 \%$, sendo que quatro crianças não tinham varizes esofagianas e apresentaram esplenomegalia.

Embora a esplenomegalia seja um achado comum na história natural de pacientes com hipertensão portal, ${ }^{50,68,69}$ o mecanismo patogenético que leva ao aumento do baço ainda é pouco compreendido, embora seja claro que a esplenomegalia não seja simplesmente devida à congestão do baço, mas também à hiperplasia tecidual caracterizada por uma combinação de angiogênese, fibrogênese, ampliação e hiperativação do linfóide esplênico. Ao todo, essas mudanças provavelmente resultam no aumento da rigidez do tecido esplênico..$^{50}$

O número de plaquetas como fator independente da presença de varizes perde confiabilidade devido à multicausalidade de fatores; no entanto, em 
pacientes com trombose de veia porta, a trombocitopenia está diretamente relacionada à hipertensão portal, bem como ao desenvolvimento de varizes. ${ }^{17}$ Em nosso estudo os pacientes apresentaram plaquetopenia leve, com valores medianos e intervalo interquatil de número de plaquetas $\left(\mathrm{mm}^{3}\right)$ de 107 [63-138].

A identificação de pacientes com maiores chances de apresentar varizes esofágicas, por meio de métodos não invasivos ou minimamente invasivos, é tema de interesse atual. Muitos estudos foram realizados na população cirrótica adulta, poucos na população cirrótica pediátrica e não há estudos na população com hipertensão portal não cirrótica com população pediátrica e adulta.

\subsection{Métodos não invasivos para predizer presença de varizes esofágicas}

No consenso de Baveno $\mathrm{VI}^{62}$ há uma atualização na recomendação para solicitação de endoscopia para pacientes com cirrose compensada. Caso apresentem valor da mensuração da rigidez hepática por FibroScan <20 kPa e valor do número de plaquetas $>150.000 \mathrm{~mm}^{3}$, sugere-se que a endoscopia poderia ser então evitada. Em nosso estudo os pacientes com hipertensão portal não cirrótica, considerando um valor de corte de 8,20 kPa de elastografia hepática para predizer varizes esofágicas, apresentou uma modesta acurácia de 0,619; com valores altos de especificidade igual a 0,882 e de VPP igual 0,942. Em nossa casuística dos 120 pacientes avaliados, $32(26 \%)$ pacientes apresentaram valor de elastografia transitória hepática <20 kPa e número de plaquetas $>150,000 \mathrm{~mm}^{3}$; dentre esses casos, 14 (43\%) pacientes apresentaram varizes de alto risco de sangramento. Esse dados sinalizam que

a medida da elastografia transitória hepática por FibroScan, por medir o grau 
de rigidez (indiretamente, fibrose), não é suficientemente acurada para refletir as alterações hemodinâmicas decorrentes da hipertensão portal que levam à formação de varizes..$^{70,71}$

Em pacientes com cirrose, estudos em relação à elastografia transitória esplênica por FibroScan, obtiveram os seguintes resultados. Colecchia et al.50 definiram um ponto de corte $\geq 55,0 \mathrm{kPa}$, com uma acurácia de 0,899; RV+ de 16,85 para predizer presença de varizes esofagianas em pacientes com cirrose. Stefanescu et al..$^{72}$ consideraram um ponto de corte $>28 \mathrm{kPa}$ com uma acurácia de 0,$749 ; R V+$ de 2,08 e VPN de $31 \%$. Em nosso estudo, encontramos um ponto de corte de $\geq 65,1 \mathrm{kPa}$, com acurácia de 0,654 ; intervalo de confiança $95 \%, 0,46-0,78 ; \mathrm{RV}+$ de 1,$95 ; \mathrm{VPN}$ de $52 \% ; \mathrm{p}=0,121$ para predizer varizes esofagianas em pacientes com hipertensão portal não cirrótica.

Vale ressaltar que há uma questão técnica adicional no que diz respeito ao limite de detecção superior para a mensuração da rigidez do órgão pelo aparelho FibroScan, que está regulado com um limite de $75 \mathrm{kPa}$ (efeito "teto"). Em nosso estudo a mediana da elastografia esplênica por FibroScan foi de 72 $\mathrm{kPa}$, e em comparação com os outros estudos observa-se que o valor de corte para predizer varizes esofágicas na hipertensão portal não cirrótica foi maior daqueles calculados para a população cirrótica. Dos 120 pacientes avaliados em nosso estudo, 52 (43\%) obtiveram uma valor de FibroScan esplênico igual a $75 \mathrm{kPa}$; desses apenas quatro pacientes não tinha varizes de esôfago, o que pode sugerir que um limite superior de detecção de $75 \mathrm{kPa}$, estabelecido pelo equipamento, pode ser muito restritivo para uma avaliação satisfatória da rigidez esplênica nesses pacientes. 
No estudo de Attia et al. ${ }^{73}$ o ARFI hepático apresentou alta sensibilidade e especificidade, na detecção de presença de varizes esofagianas em pacientes cirróticos. Na literatura a acurácia entre os estudos para predizer varizes esofágicas na cirrose variou de 0,60 a $0,87^{74,75}$. No estudo de Park et al. ${ }^{76} \mathrm{o}$ ARFI hepático foi insatisfatório para predizer varizes esofágicas na cirrose, obtendo uma acurácia de 0,769. Em nosso estudo, obtivemos acurácia ainda mais abaixa, de 0,575 , para predizer varizes. Tomados em conjunto esses resultados indicam um desempenho fraco a mediado da elastografia hepática para predizer varizes.

Em estudo desenvolvido no Japão, com pacientes com cirrose, os valores de rigidez esplênica por ARFI foram maiores entre os pacientes com presença de varizes esofágicas do que em controles nesse estudo $(n=132)$, sendo a mediana dos valores da rigidez esplênica por ARFI, em pacientes cirróticos de $3,36 \mathrm{~m} / \mathrm{s}$; e nos individuos saudáveis foi de $2,16 \mathrm{~m} / \mathrm{s}^{3}$

Em nosso estudo a mediana dos valores do ARFI esplênico na hipertensão portal não cirrótica foi de $3,24 \mathrm{~m} / \mathrm{s}$. O nosso resultado demonstrou que o valor do ARFI esplênico para a hipertensão portal não cirrótica está em valores intermediários entre os população saudável e aqules de pacientes com cirrose.

No estudo de Takuma et al. ${ }^{3}$ o desempenho diagnóstico do ARFI esplênico para predizer presença de varizes, considerando um ponto de corte de 3,18 m/s na população cirrótica, teve uma acurácia de 0,75; sensibilidade de 0,985; VPN de 0,084; RV- de 0,025. No estudo de Bota et al. ${ }^{77}$ o ARFI, considerando um ponto de corte de $2,51 \mathrm{~m} / \mathrm{s}$, obteve uma acurácia de 0,91; sensibilidade de 0,917 e VPN de 0,871; conseguiu predizer a presença de cirrose em comparação a indivíduos saudáveis, no entanto o método não foi capaz de 
predizer a presença de varizes. Em nosso estudo, com um ponto de corte de $2,67 \mathrm{~m} / \mathrm{s}$ na população com hipertensão portal não cirrótica encontramos valores moderados de acurácia de 0,64; intervalo de confiança 95\%, 0,50-0,78; sensibilidade de 0,650; VPN de 0,307; RV- de 0,38; $p=0,065$. Essa diferença de resultados pode estar associada à diferença na prevalência de varizes esofágicas nos estudos de Takuma $^{3}$, Bota ${ }^{77}$ e no presente, que foram de, respectivamente, $38,8 \%, 74,1 \%$ vs $84,2 \%$ e pela diferença intrínseca entre as condições (cirrose versus não cirrose).

Estudos de Chen et al..$^{78} \mathrm{e}$ Schwarzenberger et al..$^{79}$ concluíram que a razão plaqueta/baço com um valor de corte de 909 não foi suficientemente precisa para predizer varizes esofágicas em pacientes com cirrose. Os nossos achados são semelhantes a esses estudos; mesmo estabelecendo um ponto de corte de 497,06 para os pacientes com hipertensão não cirrótica, esse método não teve um bom desempenho diagnóstico para essa avaliação.

No estudo de Li et al. ${ }^{80} \mathrm{e}$ em uma recente metanálise ${ }^{81}$ com pacientes com vírus $B$, a acurpacia do índice APRI foi de $0,72(0,61-0,88)$, demonstrando um modesto desempenho na identificação de fibrose. Em nosso estudo com pacientes com hipertensão portal não cirrótica, esse método não teve um bom desempenho para predizer varizes esofágicas. Com o ponto de corte de 0,320 , a acurácia foi $0,50(0,33-0,66)$.

O índice FIB-4 permitiu a identificação dos graus de fibrose na população cirrótica. Um escore de $<1,45$ e $>3,25$ permite a identificação correta de pacientes com fibrose moderada ou significativa, respectivamente ${ }^{82}$. Em nosso estudo com pacientes com hipertensão portal não cirrótica, os pacientes apresentaram uma mediana de 1,27 para o índice FIB-4. Como se trata de um 
marcador de fibrose, esse resultado corrobora que os pacientes não tinham cirrose. Dessa maneira o desempenho desse método para predizer varizes esofágicas em pacientes com hipertensão não cirrótica apresentou uma acurácia de 0,698; VPP 96,2\%; RV+ 4,24. Em nosso estudo, os individuos apresentaram função hepática preservada e como esse índice determina o grau de fibrose, em nossa população, mesmo com uma acurácia modesta, apresentou uma valor preditivo positivo alto para predizer varizes esofágicas.

Os resultados do presente estudo fornecem modesta acurácia diagnóstica para os métodos não invasivos: elastografias esplênicas (FibroScan e ARFI) e o índice FIB-4, para predizer varizes esofagianas na população com hipertensão portal. Os demais métodos apresentaram baixo desempenho.

\subsection{Métodos não invasivos para predizer presença de varizes esofágicas de alto risco}

A disponibilidade de métodos não invasivos para avaliar a fibrose hepática permite o diagnóstico de cirrose no estágio inicial, nos pacientes compensados e assintomáticos. No entanto, esses pacientes correm risco de descompensação e requerem rastreamento endoscópico periódico para detecção de varizes de esôfago e, se necessário tratamento profilático para varizes de alto risco de sangramento. ${ }^{76} \mathrm{O}$ mesmo raciocínio acontece quando pensamos na população com hipertensão portal não cirrótica. Se um método não invasivo for capaz de conseguir restringir a endoscopia para pacientes considerados de alto risco, muitos pacientes com varizes de baixo risco poderiam evitar ou retardar a realização da endoscopia. 
$\mathrm{Na}$ literatura, a elastografia transitória hepática por FibroScan, tem apresentado resultados promissores para a detecção de varizes de alto risco em pacientes com cirrose, com uma sensibilidade variando de 0,77 a 1,00; com uma especificidade de 0,60 a 0,87; com RV+ de 1,65 a 5,79 e VPN de 0,00 a 0,48 . No entanto, os pontos de corte que foram utilizados, apresentaram ema variabilidade considerável, entre 16,6 e 38,2 kPa ${ }^{83,84}$. Na hipertensão portal não cirrótica, nosso resultado demonstrou, para a elastografia hepática por fibroscan, sensibilidade de 0,52; especificidade de 0,54; RV+ de 0,69; RV- de 1,97 e VPN de 0,31. Esse desempenho foi obtido com o ponto de corte de 5,65 $\mathrm{kPa}$.

No presente estudo, utilizando a elastografia transitória esplênica por FibroScan, o grupo com a presença de varizes de alto risco apresentou valores medianos de $75 \mathrm{kPa}[53,30-75,00]$ enquanto o grupo com varizes de baixo risco apresentou valores de $63,90 \mathrm{kPa}[33,30-75,00]$. Embora essa diferença tenha sido estatisticamente significante, houve considerável superposição de valores entre os dois grupos, o que limita a aplicabilidade da elastografia como ferramenta para reconhecer o risco das varizes e indicar ou não endoscopia.

Diferentemente do nosso estudo, Colecchia et al. ${ }^{50}$ estudando pacientes com cirrose e empregando a elastografia transitória esplênica por FibroScan, não observou diferença estatística quando comparados os grupos pelo calibre da variz esofágica, os valores medianos para o grupo com varizes de fino foi de $54 \mathrm{kPa}$ e para o grupo com varizes de grosso calibre foi de $60 \mathrm{kPa}$.

No estudo de Calvaruso et al..$^{85}$ em uma população com cirrose pelo vírus da hepatite C, observou-se, com um ponto de corte de $54 \mathrm{kPa}$ na elastografia 
transitória esplênica por FibroScan, acurácia de 0,82; sensibilidade de 0,80 e VPN de 0,90, para detecção de varizes de alto risco para sangramento.

O desempenho diagnóstico da elastografia hepática por ARFI em nosso estudo para predizer varizes de alto risco de sangramento foi insatisfatório com uma acurácia de 0,46; resultado semelhante aos estudos na literatura com a população com pacientes cirróticos, que apresentaram uma acurácia de $0,77^{76}$; $0,71^{3}$ e $0,58^{74}$ para predizer varizes de alto risco de sangramento, reforçando que isoladamente a elastografia hepática por ARFI não apresenta bom desempenho para predizer varizes ae alto risco.

A detecção de varizes de esôfago de alto risco pela elastografia esplênica por ARFI foi estudada por Takuma et al. ${ }^{3}$, relatando-se um alto desempenho diagnóstico na detecção de varizes de alto risco em pacientes com cirrose, com uma acurácia de 0,930. Ao contrário desses achados, Vermehren et al..$^{74}$ relataram que o desempenho diagnóstico da elastografia esplênica por ARFI para prever varizes de alto risco foi significativamente baixo com uma acurácia de 0,58. Em nosso estudo, obtivemos uma acurácia modesta de 0,63 para predizer varizes de alto risco em pacientes com hipertensão portal não cirrótica. Essa diferença pode ter acontecido pela prevalência de varizes esofágicas de alto risco nos estudos, respectivamente $\left(25,6 \%{ }^{3} ; 36 \%^{74}\right.$ vs $\left.51,7 \%\right)$ e pela diferença intrínseca entre as condições (cirrose versus não cirrose).

A razão plaqueta/baço foi um índice proposto por Giannini et al. ${ }^{35}$ para identificar presença de varizes. Em nosso estudo o desempenho do método para detecção de varizes de esôfago de alto risco demonstrou fraca acurácia de 0,54 , sensibilidade de 0,59 e VPP de 0,60 , considerando um valor de corte 
de 738,33. Não há estudos na literatura que avaliaram esse método na hipertensão portal não cirrótica para compararmos com nossos resultados.

O índice APRI no estudo de Park et al. ${ }^{76}$, em pacientes com cirrose, para predizer varizes de alto risco de sangramento apresentou uma acurácia de 0,76; sensibilidade de 0,95; especificidade de 0,74; VPN de 0,98, considerando um ponto de corte de 0,96. Em nosso estudo o desempenho do método foi baixo demonstramos uma acurácia de 0,41; sensibilidade de 0,50; especificidade de 0,34 e VPN de 0,41. O nosso ponto de corte foi de 0,66. Em ambos estudos, o índice APRI foi adotado para ser um método de associação, no entanto seu desempenho foi inferior, nos dois casos.

Em uma recente metanálise ${ }^{86}$ avaliou a acurácia diagnóstica de métodos não invasivos para detectar presença de varizes de esôfago em pacientes com cirrose. Entre os métodos, avaliou-se o desempenho do FIB-4, na detecção de varizes de alto risco. Como conclusão dessa análise, foi demonstrado que o desempenho global foi de uma acurácia de 0,70 ; sensibilidade de 0,62; especificidade de 0,$64 ; \mathrm{RV}+2,02 ; \mathrm{RV}-0,56$; concluindo um moderado desempenho. Na hipertensão portal não cirrótica, conforme demonstrado pelo presente estudo, o desempenho foi muito mais modesto. O FIB-4 apresentou uma acurácia de 0,54; sensibilidade de 0,44; especificidade de 0,45; $R V+0,81$; RV- 1,23. O FIB-4 é um método indicado para determinar presença e gravidade de fibrose hepática. O valor mediano dos nossos pacientes foi de 1,33, portanto considerados com metavir F0-F1 de fibrose, o que justificaria o baixo desempenho do método para essa população, sem fibrose significativa no fígado. 
O estudo de Abraldes et al. ${ }^{63}$ avaliou os métodos não invasivos para avaliar a hipertensão portal e detectar varizes de esôfago em pacientes com cirrose compensada. $\mathrm{O}$ estudo demonstrou que quando há associação de métodos não invasivos há uma alta capacidade de reconhecer hipertensão portal; no entanto na detecção de varizes de alto risco não houve bom desempenho com uma acurácia de 0,73 . Igualmente, em nosso estudo, quando associamos o valor da elastografia transitória esplênica por FibroScan e a razão plaqueta/baço, para predizer varizes de alto risco em pacientes com hipertensão portal não cirrótica, considerando um ponto de corte de 39,20 obtivemos uma acurácia de 0,66; com especificidade de 0,75 e VPP de 0,70; com valor de $p$ igual a 0,004

Os resultados do presente estudo indicam modesta acurácia diagnóstica para os métodos de elastografias hepatoesplênicas (FibroScan e ARFI) e baixa pra os demais métodos. Apesar da associação do FibroScan com a razão plaqueta/baço melhorar levemente o desempenho para predizer varizes esofagianas de alto risco de sangramento, os resultados foram considerados com baixa aplicabilidade clínica. Isto se deveu à grande superposição de valores de elastografia, tanto hepático quando esplênica, entre os grupos com e sem varizes e entre os grupos com varizes de alto e baixo risco de sangramento.

\subsection{Limitações e perspectivas}

A triagem endoscópica para diagnóstico de varizes esofágicas e sua indicação para a profilaxia e tratamento de varizes de esôfago de alto risco de 
sangramento é atualmente recomendada para todos os pacientes com hipertensão portal; no entanto a maioria dos indivíduos não tem varizes ou que não requerem terapia profilática. Por esse motivo, métodos não invasivos são altamente desejáveis.

As limitações deste estudo incluem o fato de ser um estudo unicêntrico sem validação externa. Devemos mencionar a limitação da aplicabilidade das elastografia por motivos técnicas: pacientes com ascite volumosa, alterações hepáticas sistêmicas, como congestão, além de espaços intercostais estreitos são fatores confundidores, principalmente pela técnica FibroScan.

Se um teste simples e não invasivo estiver disponível, muitos pacientes podem evitar com segurança a endoscopia. A medida das elastografias transitórias (FibroScan e ARFI), embora potencialmente útil na triagem não invasiva para varizes esofágicas, ainda requer métodos complementares usando outros parâmetros, para maior confiabilidade.

A maioria dos critérios adotados na prática clínica para os pacientes com hipertensão portal não cirrótica são baseados nas informações obtidas de pacientes com cirrose. No entanto, a história evolutiva da hipertensão portal não cirrótica deve ser mais bem compreendida, para futuro desenvolvimento de recomendações específicas para essa população. Ainda há poucos estudos na população com hipertensão portal não cirrótica, e menor ainda, na população pediátrica. Esse estudo foi o pioneiro em avaliar métodos não invasivos para predizer varizes esofágicas em pacientes com hipertensão portal não cirrótica. Há espaço para estudos futuros com a elastografia por ressonância magnética e para desenvolvimento de novos métodos para medir a pressão no sistema portal de forma menos invasiva que o HVPG. Desta forma, poderemos predizer 
melhor o risco de desenvolvimento e ruptura de varizes neste heterogêneo grupo de doenças que é a hipertensão portal não cirrótica. 
$\circ$

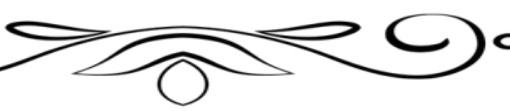

Conclusões 


\section{CONCLUSÕES}

Na hipertensão portal não cirrótica:

1) Observamos valores próximos à normalidade nos resultados da elastografia hepática pelas técnicas FibroScan e ARFI. Em pacientes com varizes de esôfago, valores normais podem ser úteis para identificar pacientes com hipertensão portal não cirrótica.

2) Os métodos de elastografia transitória esplênica apresentaram uma acurácia moderada e alto valor preditivo positivo para diagnosticar presença de varizes.

3) A medida da elastografia transitória esplênica por FibroScan quando associada à razão plaqueta/baço, tem uma acurácia moderada com uma alta especificidade, para varizes de alto risco de sangramento.

4) O FIB-4 apresentou melhor desempenho com uma acurácia moderada e alto valor preditivo positivo para predizer varizes esofágicas. O desempenho dos outros índices tanto para predizer varizes e se elas eram de alto risco foi baixo.

5) Foi observada considerável superposição de valores entre pacientes com e sem varizes esofagianas e aqueles com varizes de baixo e alto risco de sangramento, o que limita a aplicação a utilidade clínica dos métodos de elastografia nesse cenário. 
(5)

\section{Referências}




\section{REFERÊNCIAS}

1. de Franchis R, Faculty BV. Revising consensus in portal hypertension: report of the Baveno $\mathrm{V}$ consensus workshop on methodology of diagnosis and therapy in portal hypertension. J Hepatol. 2010;53(4):762-8.

2. Garcia-Tsao G. Portal hypertension. Curr Opin Gastroenterol. 2002;18(3):351-9.

3. Takuma Y, Nouso K, Morimoto Y, Tomokuni J, Sahara A, Toshikuni N, et al. Measurement of spleen stiffness by acoustic radiation force impulse imaging identifies cirrhotic patients with esophageal varices. Gastroenterology. 2013;144(1):92-101.e2.

4. Seijo S, Reverter E, Miquel R, Berzigotti A, Abraldes JG, Bosch J, et al. Role of hepatic vein catheterisation and transient elastography in the diagnosis of idiopathic portal hypertension. Dig Liver Dis. 2012;44(10):855-60.

5. Ogren $M$, Bergqvist D, Björck $M$, Acosta $S$, Eriksson $H$, Sternby $\mathrm{NH}$. Portal vein thrombosis: prevalence, patient characteristics and lifetime risk: a population study based on 23,796 consecutive autopsies. World J Gastroenterol. 2006;12(13):2115-9.

6. Toda KS, Kikuchi L, Chagas AL, Tanigawa RY, Paranaguá-Vezozzo DC, Pfiffer $\mathrm{T}$, et al. Hepatocellular Carcinoma Related to Schistosoma mansoni Infection: Case Series and Literature Review. J Clin Transl Hepatol. 2015;3(4):260-4.

7. Vezozzo DC, Farias AQ, Cerri GG, Da Silva LC, Carrilho FJ. Assessment of portal hemodynamics by Doppler ultrasound and of liver morphology in the hepatosplenic and hepatointestinal forms of schistosomiasis mansoni. Dig Dis Sci. 2006;51(8):1413-9. 
8. Ponziani FR, Zocco MA, Campanale C, Rinninella E, Tortora A, Di Maurizio L, et al. Portal vein thrombosis: insight into physiopathology, diagnosis, and treatment. World J Gastroenterol. 2010;16(2):143-55.

9. Aoki $\mathrm{H}$, Hasumi A, Yoshida K. A questionnaire study on treatment of idiopathic portal hypertension and extrahepatic portal obstruction. In: H K, editor. Annual report on portal portal hemodynamics abnormalities (in Japanese). Tokio: Japan Ministry of Health and Welfare; 1988. p. 179-89.

10. Schouten JN, Garcia-Pagan JC, Valla DC, Janssen HL. Idiopathic noncirrhotic portal hypertension. Hepatology. 2011;54(3):1071-81.

11. Sarin SK, Kumar A, Chawla YK, Baijal SS, Dhiman RK, Jafri W, et al. Noncirrhotic portal fibrosis/idiopathic portal hypertension: APASL recommendations for diagnosis and treatment. Hepatol Int. 2007;1(3):398-413.

12. Khanna R, Sarin SK. Non-cirrhotic portal hypertension - diagnosis and management. J Hepatol. 2014;60(2):421-41.

13. Hillaire S, Bonte E, Denninger MH, Casadevall N, Cadranel JF, Lebrec D, et al. Idiopathic non-cirrhotic intrahepatic portal hypertension in the West: a reevaluation in 28 patients. Gut. 2002;51(2):275-80.

14. Sorensen TI. Definition of death in relation to variceal bleeding. In: Burroughs AK, editor. Methodology and reviews of clinical trials in portal hypertension. Amsterdam: Excerpta Medica; 1987. p. 31-5.

15. Pande C, Kumar A, Sarin SK. Non-cirrhotic portal fibrosis: a clinical profile of 366 patients [abstract]. Am J Gastroenterol. 2006;101:S191.

16. Graham DY, Smith JL. The course of patients after variceal hemorrhage. Gastroenterology. 1981;80(4):800-9. 
17. Shneider BL. Portal Hypertension. In: Suchy FJ, Sokal RJ, Balistreri WF, editors. eds. Liver Disease in Children. 3th ed. Philadelphia: Lippincott Williams \& Wilkins; 2007. pp. 138-162

18. Ling SC, Walters T, McKiernan PJ, Schwarz KB, Garcia-Tsao G, Shneider BL. Primary prophylaxis of variceal hemorrhage in children with portal hypertension: a framework for future research. J Pediatr Gastroenterol Nutr. 2011;52(3):254-61.

19. Ferri PM, Ferreira AR, Fagundes ED, Liu SM, Roquete ML, Penna FJ. Portal vein thrombosis in children and adolescents: 20 years experience of a pediatric hepatology reference center. Arq Gastroenterol. 2012;49(1):69-76.

20. Sarin SK, Lahoti D, Saxena SP, Murthy NS, Makwana UK. Prevalence, classification and natural history of gastric varices: a long-term follow-up study in 568 portal hypertension patients. Hepatology. 1992;16(6):1343-9.

21. Sarin SK, Sollano JD, Chawla YK, Amarapurkar D, Hamid S, Hashizume $\mathrm{M}$, et al. Consensus on extra-hepatic portal vein obstruction. Liver Int. 2006;26(5):512-9.

22. Sarin SK, Valla D, Barosi G, et al. Portal hypertension V. Procedings of the fifth Baveno international consensus workshop on methodology of diagnosis and treatment. de Franchis R, editor. Oxford: Blackwell publishing. 161-4 p.

23. Bittencourt PL, Farias $A Q$, Strauss $E$, Mattos AA, Pannel of the 1st Brazilian Consensus of Variceal Bleeding $\mathrm{BaSoH}$. Variceal bleeding: consensus meeting report from the Brazilian Society of Hepatology. Arq Gastroenterol. 2010;47(2):202-16.

24. Calès P, Zabotto B, Meskens $C$, Caucanas JP, Vinel JP, Desmorat H, et al. Gastroesophageal endoscopic features in cirrhosis. Observer variability, 
interassociations, and relationship to hepatic dysfunction. Gastroenterology. 1990;98(1):156-62.

25. Chen CY, Sheu MZ, Su SY. Prophylactic endoscopic variceal ligation (EVL) with multiple band ligator for esophageal varices. Gastroenterology. 1998;114:A1224.

26. de Franchis R, Eisen GM, Laine L, Fernandez-Urien I, Herrerias JM, Brown RD, et al. Esophageal capsule endoscopy for screening and surveillance of esophageal varices in patients with portal hypertension. Hepatology. 2008;47(5):1595-603.

27. Sherlock S. Aspiration liver biopsy, technique and diagnostic application. Lancet. 1945:397-401.

28. de Franchis R. Evolving consensus in portal hypertension. Report of the Baveno IV consensus workshop on methodology of diagnosis and therapy in portal hypertension. J Hepatol. 2005;43(1):167-76.

29. Garcia-Tsao G, Sanyal AJ, Grace ND, Carey W. Practice Guidelines Committee of the American Association for the Study of Liver Diseases. Prevention and management of gastroesophageal varices and variceal hemorrhage in cirrhosis. Hepatology. 2007;46(3):922-38.

30. North Italian Endoscopic Club for the Study and Treatment od Esophageal Varices. Prediction of the first variceal hemorrhage in patients with cirrhosis of the liver and esophageal varices. A prospective multicenter study. $\mathrm{N}$ Engl J Med. 1988;319(15):983-9.

31. Sass DA, Chopra KB. Portal hypertension and variceal hemorrhage. Med Clin North Am. 2009;93(4):837-53, vii-viii. 
32. Armonis A, Patch D, Burroughs A. Hepatic venous pressure measurement: an old test as a new prognostic marker in cirrhosis? Hepatology. 1997;25(1):245-8.

33. Casado M, Bosch J, García-Pagán JC, Bru C, Bañares R, Bandi JC, et al. Clinical events after transjugular intrahepatic portosystemic shunt: correlation with hemodynamic findings. Gastroenterology. 1998;114(6):1296-303.

34. Glatard AS, Hillaire S, d'Assignies G, Cazals-Hatem D, Plessier A, Valla $D C$, et al. Obliterative portal venopathy: findings at $C T$ imaging. Radiology. 2012;263(3):741-50.

35. Giannini EG, Botta F, Borro P, Dulbecco P, Testa E, Mansi C, et al. Application of the platelet count/spleen diameter ratio to rule out the presence of oesophageal varices in patients with cirrhosis: a validation study based on follow-up. Dig Liver Dis. 2005;37(10):779-85.

36. Giannini EG, Zaman A, Kreil A, Floreani A, Dulbecco P, Testa E, et al. Platelet count/spleen diameter ratio for the noninvasive diagnosis of esophageal varices: results of a multicenter, prospective, validation study. Am $\mathrm{J}$ Gastroenterol. 2006;101(11):2511-9.

37. Zimbwa TA, Blanshard C, Subramaniam A. Platelet count/spleen diameter ratio as a predictor of oesophageal varices in alcoholic cirrhosis. Gut. 2004;53(7):1055.

38. Justice AC, Covinsky KE, Berlin JA. Assessing the generalizability of prognostic information. Ann Intern Med. 1999;130(6):515-24.

39. Wai CT, Greenson JK, Fontana RJ, Kalbfleisch JD, Marrero JA, Conjeevaram HS, et al. A simple noninvasive index can predict both significant fibrosis and cirrhosis in patients with chronic hepatitis C. Hepatology. 2003;38(2):518-26. 
40. Sterling RK, Lissen E, Clumeck N, Sola R, Correa MC, Montaner J, et al. Development of a simple noninvasive index to predict significant fibrosis in patients with HIV/HCV coinfection. Hepatology. 2006;43(6):1317-25.

41. Chin JL, Pavlides M, Moolla A, Ryan JD. Non-invasive Markers of Liver Fibrosis: Adjuncts or Alternatives to Liver Biopsy? Front Pharmacol. 2016;7:159.

42. Eisen GM, Eliakim R, Zaman A, Schwartz J, Faigel D, Rondonotti E, et al. The accuracy of PillCam ESO capsule endoscopy versus conventional upper endoscopy for the diagnosis of esophageal varices: a prospective three-center pilot study. Endoscopy. 2006;38(1):31-5.

43. Ebinuma H, Saito H, Komuta M, Ojiro K, Wakabayashi K, Usui S, et al. Evaluation of liver fibrosis by transient elastography using acoustic radiation force impulse: comparison with Fibroscan(®). J Gastroenterol. $2011 ; 46(10): 1238-48$.

44. Sandrin L, Fourquet B, Hasquenoph JM, Yon S, Fournier C, Mal F, et al. Transient elastography: a new noninvasive method for assessment of hepatic fibrosis. Ultrasound Med Biol. 2003;29(12):1705-13.

45. Saito H, Tada S, Nakamoto N, Kitamura K, Horikawa H, Kurita S, et al. Efficacy of non-invasive elastometry on staging of hepatic fibrosis. Hepatol Res. 2004;29(2):97-103.

46. Fahey BJ, Nightingale KR, Nelson RC, Palmeri ML, Trahey GE. Acoustic radiation force impulse imaging of the abdomen: demonstration of feasibility and utility. Ultrasound Med Biol. 2005;31(9):1185-98.

47. Talwalkar JA, Yin M, Venkatesh S, Rossman PJ, Grimm RC, Manduca A, et al. Feasibility of in vivo MR elastographic splenic stiffness measurements in the assessment of portal hypertension. AJR Am $J$ Roentgenol. 2009;193(1):122-7. 
48. Friedrich-Rust M, Ong MF, Martens S, Sarrazin C, Bojunga J, Zeuzem S, et al. Performance of transient elastography for the staging of liver fibrosis: a meta-analysis. Gastroenterology. 2008;134(4):960-74.

49. Grgurevic I, Cikara I, Horvat J, Lukic IK, Heinzl R, Banic M, et al. Noninvasive assessment of liver fibrosis with acoustic radiation force impulse imaging: increased liver and splenic stiffness in patients with liver fibrosis and cirrhosis. Ultraschall Med. 2011;32(2):160-6.

50. Colecchia A, Montrone L, Scaioli E, Bacchi-Reggiani ML, Colli A, Casazza G, et al. Measurement of spleen stiffness to evaluate portal hypertension and the presence of esophageal varices in patients with HCVrelated cirrhosis. Gastroenterology. 2012;143(3):646-54.

51. Kim BK, Han KH, Park JY, Ahn SH, Kim JK, Paik YH, et al. A liver stiffness measurement-based, noninvasive prediction model for high-risk esophageal varices in B-viral liver cirrhosis. Am $J$ Gastroenterol. 2010;105(6):1382-90.

52. Committee WE. Prevention and control of schistosomiasis and soiltransmitted helminthiasis. World Health Organ Tech Rep Ser. 2002;912:i-vi, 157 , back cover.

53. Sarin SK, Aggarwal SR. Idiopathic portal hypertension. Digestion. $1998 ; 59(4): 420-3$.

54. Ling SC. Congenital cholestatic syndromes: what happens when children grow up? Can J Gastroenterol. 2007;21(11):743-51.

55. Bossuyt PM, Reitsma JB, Bruns DE, Gatsonis CA, Glasziou PP, Irwig LM, et al. The STARD statement for reporting studies of diagnostic accuracy: explanation and elaboration. Ann Intern Med. 2003;138(1):W1-12. 
56. de Lédinghen $\mathrm{V}$, Vergniol J. Transient elastography for the diagnosis of liver fibrosis. Expert Rev Med Devices. 2010;7(6):811-23.

57. Bedossa $P$, Poynard $T$. An algorithm for the grading of activity in chronic hepatitis C. The METAVIR Cooperative Study Group. Hepatology. 1996;24(2):289-93.

58. Friedrich-Rust M, Nierhoff J, Lupsor M, Sporea I, Fierbinteanu-Braticevici C, Strobel D, et al. Performance of Acoustic Radiation Force Impulse imaging for the staging of liver fibrosis: a pooled meta-analysis. J Viral Hepat. 2012;19(2):e212-9.

59. Buderer NM. Statistical methodology: I. Incorporating the prevalence of disease into the sample size calculation for sensitivity and specificity. Acad Emerg Med. 1996;3(9):895-900.

60. Gana JC, Valentino PL, Morinville V, O'Connor C, Ling SC. Variation in care for children with esophageal varices: a study of physicians', patients', and families' approaches and attitudes. J Pediatr Gastroenterol Nutr. 2011;52(6):751-5.

61. Jakab SS, Garcia-Tsao G. Screening and Surveillance of Varices in Patients with Cirrhosis. Clin Gastroenterol Hepatol. 2018.

62. Abraldes JG, Bureau C, Stefanescu H, Augustin S, Ney M, Blasco H, et al. Noninvasive tools and risk of clinically significant portal hypertension and varices in compensated cirrhosis: The "Anticipate" study. Hepatology. 2016;64(6):2173-84.

63. Al Hashmi K, Al Aamri L, Al Lamki S, Pathare A. Portal Vein Thrombosis in Adult Omani Patients: A Retrospective Cohort Study. Oman Med J. 2017;32(6):522-7. 
64. Sarin SK, Kapoor D. Non-cirrhotic portal fibrosis: current concepts and management. J Gastroenterol Hepatol. 2002;17(5):526-34.

65. Fagundes ED, Ferreira AR, Roquete ML, Penna FJ, Goulart EM, Figueiredo Filho PP, et al. Clinical and laboratory predictors of esophageal varices in children and adolescents with portal hypertension syndrome. J Pediatr Gastroenterol Nutr. 2008;46(2):178-83.

66. Megremis SD, Vlachonikolis IG, Tsilimigaki AM. Spleen length in childhood with US: normal values based on age, sex, and somatometric parameters. Radiology. 2004;231(1):129-34.

67. Berzigotti A, Zappoli P, Magalotti D, Tiani C, Rossi V, Zoli M. Spleen enlargement on follow-up evaluation: a noninvasive predictor of complications of portal hypertension in cirrhosis. Clin Gastroenterol Hepatol. 2008;6(10):112934.

68. Bolognesi M, Merkel C, Sacerdoti D, Nava V, Gatta A. Role of spleen enlargement in cirrhosis with portal hypertension. Dig Liver Dis. 2002;34(2):14450.

69. de Franchis R, Faculty BV. Expanding consensus in portal hypertension: Report of the Baveno VI Consensus Workshop: Stratifying risk and individualizing care for portal hypertension. J Hepatol. 2015;63(3):743-52.

70. Lim JK, Groszmann RJ. Transient elastography for diagnosis of portal hypertension in liver cirrhosis: is there still a role for hepatic venous pressure gradient measurement? Hepatology. 2007;45(5):1087-90.

71. Bosch J, Navasa M, Garcia-Pagán JC, DeLacy AM, Rodés J. Portal hypertension. Med Clin North Am. 1989;73(4):931-53.

72. Stefanescu H, Grigorescu M, Lupsor M, Procopet B, Maniu A, Badea R. Spleen stiffness measurement using Fibroscan for the noninvasive assessment 
of esophageal varices in liver cirrhosis patients. J Gastroenterol Hepatol. $2011 ; 26(1): 164-70$.

73. Attia D, Schoenemeier B, Rodt T, Negm AA, Lenzen H, Lankisch TO, et al. Evaluation of Liver and Spleen Stiffness with Acoustic Radiation Force Impulse Quantification Elastography for Diagnosing Clinically Significant Portal Hypertension. Ultraschall Med. 2015;36(6):603-10.

74. Vermehren J, Polta A, Zimmermann O, Herrmann E, Poynard T, Hofmann WP, et al. Comparison of acoustic radiation force impulse imaging with transient elastography for the detection of complications in patients with cirrhosis. Liver Int. 2012;32(5):852-8.

75. Morishita N, Hiramatsu N, Oze T, Harada N, Yamada R, Miyazaki M, et al. Liver stiffness measurement by acoustic radiation force impulse is useful in predicting the presence of esophageal varices or high-risk esophageal varices among patients with HCV-related cirrhosis. J Gastroenterol. 2014;49(7):1175-82.

76. Park Y, Kim SU, Park SY, Kim BK, Park JY, Kim DY, et al. A novel model to predict esophageal varices in patients with compensated cirrhosis using acoustic radiation force impulse elastography. PLoS One. 2015;10(3):e0121009.

77. Bota S, Sporea I, Sirli R, Popescu A, Dănilă M, Sendroiu M, et al. Spleen assessment by Acoustic Radiation Force Impulse Elastography (ARFI) for prediction of liver cirrhosis and portal hypertension. Med Ultrason. 2010;12(3):213-7.

78. Chen YP, Zhang Q, Dai L, Liang XE, Peng J, Hou JL. Is transient elastography valuable for high-risk esophageal varices prediction in patients with hepatitis-B-related cirrhosis? J Gastroenterol Hepatol. 2012;27(3):533-9.

79. Schwarzenberger E, Meyer T, Golla V, Sahdala NP, Min AD. Utilization of platelet count spleen diameter ratio in predicting the presence of esophageal varices in patients with cirrhosis. J Clin Gastroenterol. 2010;44(2):146-50. 
80. Li J, Mao RC, Li XL, Zheng JW, Qi X, Yuan Q, et al. A novel noninvasive index for the prediction of moderate to severe fibrosis in chronic hepatitis $B$ patients. Dig Liver Dis. 2018;50(5):482-9.

81. Xiao G, Yang J, Yan L. Comparison of diagnostic accuracy of aspartate aminotransferase to platelet ratio index and fibrosis-4 index for detecting liver fibrosis in adult patients with chronic hepatitis B virus infection: a systemic review and meta-analysis. Hepatology. 2015;61(1):292-302.

82. Vallet-Pichard A, Mallet V, Nalpas B, Verkarre V, Nalpas A, DhalluinVenier V, et al. FIB-4: an inexpensive and accurate marker of fibrosis in HCV infection. comparison with liver biopsy and fibrotest. Hepatology. 2007;46(1):326.

83. Li T, Qu Y, Yang B, Xue Y, Wang L. Evaluation of large esophageal varices in cirrhotic patients by transient elastography: a meta-analysis. Rev Esp Enferm Dig. 2016;108(8):464-72.

84. Qu Y, Li T, Ye Q, Zhang L, Wang L. A Beginning or the End? A Metaanalysis to Assess the Diagnostic Accuracy of Transient Elastography for the Prediction of Esophageal Varices. Saudi J Gastroenterol. 2016;22(5):345-52.

85. Calvaruso V, Bronte F, Conte E, Simone F, Craxì A, Di Marco V. Modified spleen stiffness measurement by transient elastography is associated with presence of large oesophageal varices in patients with compensated hepatitis C virus cirrhosis. J Viral Hepat. 2013;20(12):867-74.

86. Deng H, Qi X, Guo X. Diagnostic Accuracy of APRI, AAR, FIB-4, FI, King, Lok, Forns, and Fibrolndex Scores in Predicting the Presence of Esophageal Varices in Liver Cirrhosis: A Systematic Review and Meta-Analysis. Medicine (Baltimore). 2015;94(42):e1795. 